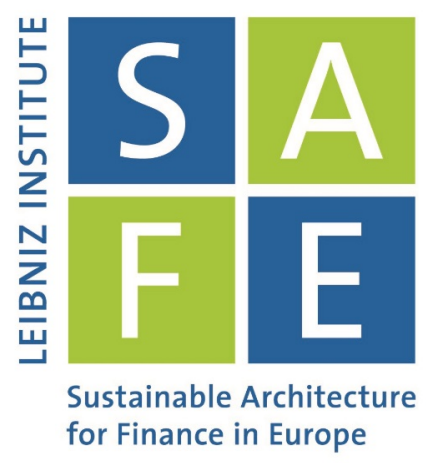

Pietro Dindo | Andrea Modena | Loriana Pelizzon

\title{
Risk Pooling, Leverage, and the Business Cycle
}

SAFE Working Paper No. 271

\section{Leibniz Institute for Financial Research SAFE} Sustainable Architecture for Finance in Europe 


\title{
Risk Pooling, Leverage, and the Business Cycle*
}

\section{Pietro Dindo, Andrea Modena, and Loriana Pelizzon ${ }^{\dagger}$}

\author{
This version: 25th February 2020
}

\begin{abstract}
This paper studies the impact of financial sector size and leverage on business cycles and risk-free rates dynamics. We model a general equilibrium productive economy where financial intermediaries provide costly risk mitigation to households by pooling the idiosyncratic risks of their investment activities. We find that leverage amplifies variations of intermediaries' relative size, but may also mitigate the business cycle. Moreover, it makes risk-free rates pro-cyclical. Households benefit the most when the financial sector is neither too small, thus avoiding high consumption fluctuations and costly mitigation, nor too big, so that fewer resources are lost after intermediation costs. (JEL: E13, E32, E69, G12)
\end{abstract}

Keywords: Business Cycle, Frictions, Leverage, Mitigation, Risk Pooling.

${ }^{*}$ We would like to thank Alberto Bisin, Harjoat Bhamra, Nina Boyarchenko, Matthijs Breugem, Markus Brunnermeier, Giuliano Curatola, Michael Donadelli, Ester Faia, Daniel Grosshans (discussant), Tony He, Arvind Krishnamurthy, Deborah Lucas, Elisa Luciano, Alexander Ludwig, Marcella Lucchetta, Francesco Menoncin, Aaron Pancost, Jean-Charles Rochet, Paolo Siconolf, Marco Tolotti, and Grigory Vilkov as well as the participants in seminars at the 24th CEF conference, the University of Venice, the 42nd Meeting of the AMASES (Naples), the Goethe University Frankfurt, the 6th Workshop in Macro Banking \& Finance (Alghero), the Midwest Macro Meeting 2018 (Nashville), the ASSET conference 2018 (Florence), the SAFE annual conference 2018, the University of Brescia, the VERA Macro-Finance workshop 2019 (Venice), the 2019 CESifo area Conference on Macro, Money \& International Finance (Munich), and the $26^{\text {th }}$ DFG meeting (Essen) for the helpful discussions and comments. We gratefully acknowledge research support from the Leibniz Institute for Financial Research SAFE.

${ }^{\dagger}$ Dindo: Dept. of Economics, Ca’ Foscari University of Venice (email: pietro.dindo@unive.it); Modena: Dept. of Economics, Ca' Foscari University of Venice \& Goethe University Frankfurt (email: andrea.modena@unive.it); Pelizzon: Dept. of Economics, Ca' Foscari University of Venice \& SAFE, Goethe University Frankfurt (email: pelizzon@safe.uni-frankfurt.de). Corresponding author: Andrea Modena 


\section{Introduction}

There is widespread agreement that financial intermediation is not only a veil between savers and borrowers. On the contrary, it plays a fundamental role to properly characterize business and financial cycles altogether (Adrian and Shin, 2010; Borio, 2014; Brunnermeier and Sannikov, 2014, 2016; He et al., 2017; He and Krishnamurthy, 2011, 2013, 2019).

The focus of many recent studies that embody a financial sector in a general equilibrium setting is on the negative externalities that come after intermediaries' activity. Endogenous risk - amplification of exogenous shocks - is generated by the interaction of heterogeneous agents in presence of financial frictions. Much less has been done to develop theoretical models showing that also positive externalities associate to financial sector's deeds.

Broadly speaking, one could think of various channels through which the financial sector may affect positively the real economy: its supply of payment services, its fundamental role at pricing and allocating risks, its capacity of converting illiquid assets into cash without undue loss of value, and many others. In this paper, we exclusively focus on two specific and related functions of the financial sector: risk pooling and mitigation.

In a nutshell, the main contribution of our paper is to work out a dynamic general equilibrium model of a productive economy where financial intermediaries, on the asset side, pool idiosyncratic risky stakes in firms, pay the associated intermediation cost, and bear only their systematic risk component. On the liability side, by issuing short-term risk-free debt (i.e. via leverage), they provide households with risk-mitigation instruments. In equilibrium, this mechanism originates a structural mismatch between the risk of intermediaries' assets and liabilities, whose magnitude fundamentally determines the width of business cycle fluctuations jointly with the dynamics of risk-free interest rates. In particular, we show that the extent of intermediaries' risk mismatch associates to their risk-pooling capacity and therefore generates: i) State-dependent mitigation of aggregate output and consumption fluctuations and ii) Pro-cyclical risk-free interest rates that can become negative during economic downturns, due to high demand of safe assets. Moreover, we show that iii) Households are better off when the financial sector is neither too small, thus avoiding wide consumption fluctuations and costly risk mitigation, nor too big, so that fewer resources are lost after intermediation 
costs.

We model our economy in continuous-time, and solve for the equilibrium joint dynamics of capital prices and size of the financial sector. We assume that capital is either held by equally risk averse heterogeneous households or by an aggregate financial sector. Financial frictions are introduced by assuming restricted market participation and, in the spirit of Diamond (1984), the financial sector has a cost advantage at pooling idiosyncratic risks.

Due to restricted market participation, each household has free access to its own specific firm only, sustaining both systematic and idiosyncratic risks. Therefore, households are not able to diversify idiosyncratic risks among themselves and, in order to reduce the risk of their portfolio, they purchase a risk-free bond issued by the financial sector. The bond acts as an instrument of risk mitigation and allows households to smooth consumption. ${ }^{1}$

The choice of risk mitigation through risk-free bonds implies that the financial sector leverage is counter-cyclical. After a negative shock, the (relative) size of the financial sector decreases, while its leverage increases further to keep up with households' higher demand for risk-free bonds. Risk-free rates may even become negative when the financial sector becomes too small and highly leveraged. ${ }^{2}$ The opposite holds as a response to positive shocks: the financial sector increases its size, and so does its supply of risk-free bonds, even if its leverage reduces. This mechanism is consistent with recent empirical findings suggesting counter-cyclical financial leverage (see He et al., 2017). ${ }^{3}$

From the macroeconomic perspective, the sensitivity of aggregate output and consumption to exogenous systematic shocks also depends on financial sector size and leverage, due to a pecuniary externality generated by the intermediation cost. On the one hand, the pecu-

\footnotetext{
${ }^{1}$ We silence both channels of firms and households leverage on purpose because our focus is on the effect that financial sector risk pooling has on the business cycle, without the indirect effects of non-financial firms' and households' leverage (differently from Brunnermeier and Sannikov, 2014; Korinek and Simsek, 2016, among others).

${ }^{2}$ This result is in line with Gourinchas and Rey (2017) who show that a weakened financial sector may lead to persistently low, or even negative, short-term interest rates for an extended period of time.

${ }^{3}$ This stylized fact stays in stark contrast with previous evidence in Adrian et al. (2014) where leverage is pro-cyclical. This is due to our choice of considering financial intermediaries focusing on their activity as central dealers of idiosyncratic risky claims, and relates to the marginal value of the financial sector's aggregate wealth. Pro-cyclical leverage empirical evidence also features in Adrian and Shin (2010, 2013) and has a theoretical foundation in Adrian and Boyarchenko (2012). In this stream of the literature, pro-cyclical leverage is a consequence of pro-cyclical VaR leverage constraints. The problem of leverage cyclicality is also discussed in Adrian et al. (2016), where they consider the difference between market and book leverage.
} 
niary externality produces a negative relationship between financial sector size and output growth rate: the larger the financial sector, the more risky stakes it holds, the lower the aggregate productivity of capital (due to high intermediation cost per unit of capital), the lower its price, the lower the investment in new capital. ${ }^{4}$

On the other hand, the same externality positively affects the business cycle by mitigating aggregate output fluctuations. When a negative (positive) systematic shock to capital hits the economy, it decreases (increases) intermediaries' relative size, it increases (decreases) capital equilibrium prices, increasing (decreasing) investments and thus dampening the fluctuations of capital and output. Aggregate and households' consumption dynamics also benefit from the mitigation offered by the financial sector through the risk-free bond, but experience low growth when leverage is too high because risk mitigation becomes increasingly costly.

In our model, there exists a tight relationship between financial leverage and Sharpe ratios. On this point, we are in line with the previous intermediary asset pricing literature (He and Krishnamurthy, 2011, 2013). However, differently from previous studies, the link between asset prices, risk-free rates, and leverage is due to the risk pooling capacity of the financial sector. In this regard, we show that the magnitude of the idiosyncratic risk fundamentally contributes to risk premiums, despite the fact that they can be pooled. This effect is tied up to the assumption of households restricted market participation as it mirrors their demand of risk-free bonds, and does not require a crisis situation to take place (as instead it is in He and Krishnamurthy, 2013).

In the last part of the paper, we study agents' welfare as related to the size of the financial sector. Overall, we find that households benefit the most when the financial sector is neither too small (offering too little - and costly - risk mitigation) nor too big (so that households have a lower capitalization).

Motivated by this finding, we investigate whether static leverage constraints and redistributive taxation policies could improve households' welfare. According to our model: i) A tax that redistributes wealth from the financial sector to the households prevents the former

\footnotetext{
${ }^{4}$ This result squares nicely with the empirical evidence in Philippon and Reshef (2012) claiming that the size of financial intermediaries relates to the remuneration of their executives; in fact, they show that the size distribution of financial firms explains about one fifth of the premium for their executives. This is relevant because financial services account for up to $25 \%$ of the overall increase in wage inequality since 1980 . In particular, they argue that financiers may be overpaid from a social point of view.
} 
from growing too large, and so to waste too many resources after intermediation costs; ii) Leverage constraints prevent the financial sector from collecting too much capital, and so from paying the associated intermediation costs. In turn, this fosters additional growth as capital is allocated to the - more productive - households. However, it may negatively affect the mitigation of output and consumption fluctuations.

All in all, our theoretical results suggest that leverage constraints and redistributive taxation policies may be designed such that the size of the financial sector remains within an "optimal" range to improve households' welfare.

The paper proceeds as follows: Section 1.1 frames our results as related to the incumbent literature. Then, Section 2 outlines the model micro-foundation (2.1) and agents' optimization problems (2.2). Section 3 derives the competitive equilibrium (3.1) and characterizes it (3.2). Section 4 focuses on the link between financial sector leverage, risk-free interest rates (4.1), and the macroeconomic dynamics (4.2). Finally, Section 5 investigates the role of leverage constraints and redistributive taxation policies at increasing the households' welfare. Section 6 concludes.

\section{$1.1 \quad$ Related Literature}

This paper belongs to the body of literature describing the relationship between financial intermediation, the macroeconomic dynamics, and its welfare implications. Also, it relates to the literature featuring models of intermediary asset pricing.

Methodologically, we are close to the seminal work of He and Krishnamurthy $(2011,2013)$ and Brunnermeier and Sannikov (2014, 2016). However, we substantially diverge in several dimensions. He and Krishnamurthy $(2011,2013)$ consider general equilibrium endowment economies and study the dynamics of asset prices as it relates to financial intermediaries capitalization and financial crises. On the contrary, we develop a productive economy to investigate financial intermediaries risk pooling activities as connected to real business cycle and risk-free rates dynamics.

Brunnermeier and Sannikov (2014) build a model where more productive agents (experts) leverage their balance sheet. On the contrary, our most productive agents, households, do not leverage; conversely, it is the financial sector that leverages up, and sells to households 
risk-free bonds in exchange of a fraction of their firms' risky capital (equity). What follows is that, in our model, more productive agents have extra risk exposure, and therefore demand for mitigation instruments. Another important difference concerns the financial friction: whereas in Brunnermeier and Sannikov (2014) experts' consumption is always positive and households' may be negative, in our case the friction comes out of restricted market participation. These differences lead to substantially opposite equilibrium dynamics and a stationary wealth-share distribution. In these terms, our model is complementary to theirs.

We also connect to Brunnermeier and Sannikov (2016), whose core contribution is to study the value of money when offered by financial intermediaries as a risk-mitigation tool to insure idiosyncratic risks faced by households. In both papers intermediaries are short in risk mitigation instruments and long in firms' risky stakes; however, the consequences of the associated risk-mismatch mechanism are rather different. ${ }^{5}$ As in Brunnermeier and Sannikov (2016) mitigation is provided via money: a negative aggregate shock that affects intermediaries' balance sheet decreases the provision of risk mitigation - generates higher demand for money - and increases its price. The resulting deflation further depreciates intermediaries' liability, and fosters additional decrease in the provision of risk mitigation (deflationary spiral). Monetary policy is the instrument to break the spiral. In our model instead, risk mitigation is provided via short-term risk-free bonds. When a negative shock hits, the financial sector becomes smaller, the demand for short-term risk-free bonds increases, and interest rates decline. The latter positively affect the provision of idiosyncratic risk-mitigation, leading to an increase of leverage. No spiral occurs and the natural policy instrument is a leverage constraint, whose effect is primarily to decrease both the growth rate drift and volatility of financial intermediaries' wealth share (leading to a higher welfare for households).

More specifically, we can structure our contribution along the following dimensions: the role of exogenous (systematic and) idiosyncratic risks in a dynamic model with frictions $(I R)$; the role of financial sector leverage $(L V)$ and size in amplifying (but also mitigating)

\footnotetext{
${ }^{5}$ The source of the risk-mismatch in Brunnermeier and Sannikov (2016) is as follows: it is assumed that there are two types of capital (both necessary to produce the consumption good) and while the equilibrium value of money captures risks associated to the production of both types, the financial intermediary can invest only in one type of risky firms.
} 
the propagation of exogenous shocks $(A M)$, as well as their effect over the business cycle, consumption, and their fluctuations $(B C)$; how the allocation of risk and restricted market participation relates to asset pricing $(A P)$; the welfare implications of leverage and size of the financial sector $(W)$.

An early approach connecting the allocation of risk to portfolio choices $(I R)$ in a general equilibrium set-up can be found in Heaton and Lucas (2004). Their analysis builds on the observation that idiosyncratic risk is priced by the market, since agents are risk averse and unable to diversify idiosyncratic shocks by themselves. Nevertheless, they do not consider any financial sector.

By introducing restricted market participation, our model also relates to the body of literature that studies incomplete markets and the role of aggregate uninsurable shocks in equilibrium dynamics. Seminal papers in this field are Aiyagari and Gertler (1991), Huggett (1993), as well as Aiyagari and Rao (1994).

In our paper, endogenous risk takes place as an amplification/mitigation $(A M)$ of exogenous systematic shocks. As in Brunnermeier and Sannikov (2014), our model features the so called volatility paradox (see also Adrian and Brunnermeier, 2016), i.e. lower exogenous risk may lead to higher endogenous volatility, especially when financial capitalisation is low. However, our model differs in several substantial ways: first, we account for both systematic and idiosyncratic risks as determinants of aggregate fluctuations. This feature squares with empirical evidence suggesting a relationship between macroeconomic dynamics and the state of the financial system (Adrian et al., 2019). Second, in our model the effect of increasing idiosyncratic risk leads to further leverage. This is because, after restricted market participation, households increase their demand for risk-free bonds. Another relevant element of our model is that equilibrium risk-free interest rates fluctuate over time (and may take negative values) instead of being constant.

As for $L V$, our paper moves along the seminal stream accounting for financial frictions in general equilibrium (for a general discussion see Brunnermeier et al., 2012; Moritz and Taylor, 2012) and, more specifically, to those known as post-crisis macro models (see Haven et al., 2016). An important feature we share with the post-crisis literature is the connection 
between financial leverage and the magnitude of economic fluctuations. ${ }^{6}$

Still concerning $L V$, the core difference between the aforementioned stream of literature and our paper consists of both the source of frictions, restricted market participation in place of an agency problem as well as of their externalities: in our model intermediaries leverage endogenously generates a mitigation effect that may overtake the amplification of business cycle fluctuations. ${ }^{7}$

From the asset pricing perspective $(A P)$, our contribution has common characteristics with the literature of general equilibrium models where financial cycles and constraints determine asset prices, as for example in He and Krishnamurthy $(2011,2013)$.

The core difference is that our model does not need the constraints to be binding in order to generate those effects. Moreover, we explicitly micro-found the demand for risk-free assets and show that in certain states of the world real risk-free interest rates could be negative.

In light of the role of financial leverage and size as related to the business cycle $(B C)$ and risk-free interest rates during crises (see He et al., 2010), our results relate to those papers at the intersection between finance and macroeconomics treating systemic risk, as for example Nuno and Rey (2017). ${ }^{8}$

Finally, we investigate the relationship between the size of the financial sector, leverage, and welfare $(W)$. On this side, we are related to the work of Philippon (2010) studying the interaction between financial and non-financial sectors and investigating whether it is optimal to subsidize or tax the former. However, our model is largely different, and so it is the role played by the financial sector. We also partially relate to the literature that investigates optimal financial leverage constraints, in particular to Phelan (2016) and Pancost and Robatto (2019).

A common element between this work and Phelan (2016) is the relationship linking financial leverage constraints and welfare. His paper suggests that a policy of recapitalizing banks, that mechanically decreases leverage to the optimal level, is welfare-improving. This

\footnotetext{
${ }^{6}$ The idea of the financial cycle being determinant of the business cycle is introduced in Carlstrom and Fuerst (1997). A similar setting with adjustment costs on capital investment can be found in Kiyotaki and Moore (1997), and it is developed in a New Keynesian setting by Bernanke et al. (1999).

${ }^{7}$ The idea that uninsurable risk associates to structural financial leverage is introduced in a theoretical setting by Krishnamurthy (2003).

${ }^{8}$ With Nuno and Rey (2017) we share the trade-off between economic growth and stability, although our mechanism of amplification is deeply different.
} 
relates to the concept of welfare maximizing size of the financial sector suggested by our model. Nevertheless, we strongly differ with respect to several aspects: first, we introduce restricted market participation as a friction that allows us to model the demand for risk-free assets. Second, our model displays a smooth dynamics rather then a step-wise process of aggregate consumption. This allows us to relate financial leverage to the economic macrodynamics.

Similar to our setting, Pancost and Robatto (2019) consider the role of banks in providing risk pooling services as well as their role of supplying risk mitigation instruments through deposits (for a similar argument, see also DeAngelo and Stulz, 2015). Although we reach similar conclusion concerning the welfare improvement that may come to households after imposing leverage constraints, the mechanism and focus of our papers differ substantially. Pancost and Robatto (2019) argue for an optimal capital requirement to be imposed on a risk neutral financial intermediary as dependent on the trade-off between good and badrisk taking. Conversely, this paper focuses on the relationship between financial sector risk pooling and the macro-financial dynamics in a model where, due to restricted market participation, the relative size of households and intermediaries matters.

In summary, the strength of our model (and of its theoretical predictions) is its ability to jointly consider several different dimensions: the role of systematic and idiosyncratic risks; how their allocation channels mitigation of exogenous systematic shocks; the role of leverage constraints as related to the dynamics of the financial sector size; their effect on the macroeconomic dynamics and, in turn, households' welfare. The combination of all these characteristics in a relatively manageable general equilibrium framework poses this paper to be complementary with respect to the previous literature.

\section{The Model}

In this section, we first introduce the overall economic environment. Then, we discuss agents' optimization problems and describe the features of the return on risky assets. We start with a narrative description of the model.

We consider a continuous-time infinite-horizon production economy with two goods: 
physical capital (such as a tree) and output (perishable good, such as apples). Each good is produced by a specific type of firms, the perishable good acts as numéraire.

There are two types of assets: risky claims and risk-free bonds. Risky claims are written on the profits of capital-producing firms. The risk to which they are exposed is both systematic (economy-wide) and idiosyncratic (firm-specific). Risk-free bonds have value as risk-mitigation instruments and are in zero-net supply.

The economy is populated by two classes of agents: financial intermediaries and households. Intermediaries are allowed to invest in all firms; accordingly, they pool idiosyncratic risks and are exposed to systematic shocks only. The expected return on their (risky) assets is reduced by a cost of intermediation paid for each unit of capital. Conversely, due to restricted market participation, each household is allowed to invest in one capital producing firm only. Since households do not pay the intermediation cost, they earn higher expected returns. However, their over-exposure to idiosyncratic risk generates positive demand for risk-mitigation instruments. As we shall see, in equilibrium, this demand will be satisfied by the financial sector through its short position in risk-free bonds. ${ }^{9}$

The share of risky claims that is left un-pooled, i.e. that remains in the hands of households', determines the idiosyncratic risk allocation in the economy and with it consumption, output, risky assets, and equilibrium prices.

\subsection{Technologies and Risky Claims}

We consider two types of firms: Type I has the inter-temporal role of generating new physical capital (trees) through a concave technology $\Phi(\cdot)$ that uses the perishable good (apples) as input. Let $[0,1]$ be a continuum of type I firms and let $d W_{t} \perp d \tilde{W}_{t}^{i} \perp d \tilde{W}_{t}^{j}$ $\forall i \neq j,\{i, j\} \in[0,1]$ be independent standard Brownian motions defined on the filtered probability space $(\Omega, \mathcal{H}, \mathbb{P})$, where $\left\{\mathcal{H}_{t}, t>0\right\}$ is the natural filtration over the measurable space $(\Omega, \mathcal{H})$. The capital stock $k_{t}^{i} \in \mathbb{R}$ managed by firm $i \in[0,1]$ follows a bi-variate Itô

\footnotetext{
${ }^{9}$ From the households' perspective, the restricted access to financial markets is an exceedingly relevant topic. For instance, Davydiuka et al. (2018) provide a theoretical model that motivates the substantial decline of small firms going public in the last 20 years (as documented in Gao et al., 2013) by the presence of increasing financial frictions, such as IPO and regulatory-disclosure related costs.
} 
diffusion

$$
T_{t}^{i}: \quad \frac{d k_{t}^{i}}{k_{t}^{i}}=\left[\Phi\left(\iota_{t}^{i}\right)-\delta\right] d t+\sigma d W_{t}+\tilde{\sigma} d \tilde{W}_{t}^{i}, \text { with } \Phi(\iota)=\frac{1}{\theta} \log (1+\theta \iota)
$$

where $\delta$ is the depreciation rate, $\iota_{t}^{i}$ is the reinvestment rate as dependent on the concavity parameter $\theta, \sigma$ and $\tilde{\sigma}$ are constant systematic and idiosyncratic diffusion terms, respectively.

Capital producing firms live one period. At each instant $t$, they are constituted by transfers of physical capital executed by either households or intermediaries, and liquidated at $s=t+d t$. Accordingly, type I firms finance their own constitution by issuing risky claims with stochastic pay-off $d R_{t}^{i}$ over $[t, s]$ written on their profits. The total return on firms' risky claims is endogenous and determined in equilibrium. Firms of type I earn revenues by renting capital to firms of type II at the instantaneous rate $p_{t}$, and choose the re-investment rate of capital $\iota$ to maximise the expected return on their risky claims issuances. Note that the zero profit condition of capital producing firms' must be consistent with the equilibrium return on the risky claim $d R_{t}^{i}$. This is equivalent to a non-arbitrage condition, i.e. the return on firms' risky issuance (their equity) is such that the present discounted value of their revenues under the risk-neutral measure equals the current value of physical capital stock supplied by the agents. If such condition holds, each firm breaks even for each $k_{t}^{i}$, its size is indeterminate, and it is willing to supply each market demand. ${ }^{10}$

Firms of type II, also a continuum, do not have an inter-temporal dimension, and produce perishable good $y_{t}^{i}$ through a linear production function that has capital as input:

$$
y_{t}^{i}=A k_{t}^{i}
$$

The profit of each firm of type II at time $t$ is thus simply $\left(A-p_{t}\right) k_{t}^{i}$. Therefore, in equilibrium, they always break even and their size is indeterminate.

\footnotetext{
${ }^{10}$ Type $I$ firms' technology is non-linear in $\iota$; however, linearity in $k$ is maintained through the identification of $c=\iota k$ as expense for the perishable consumption. Details are in Appendix A.
} 


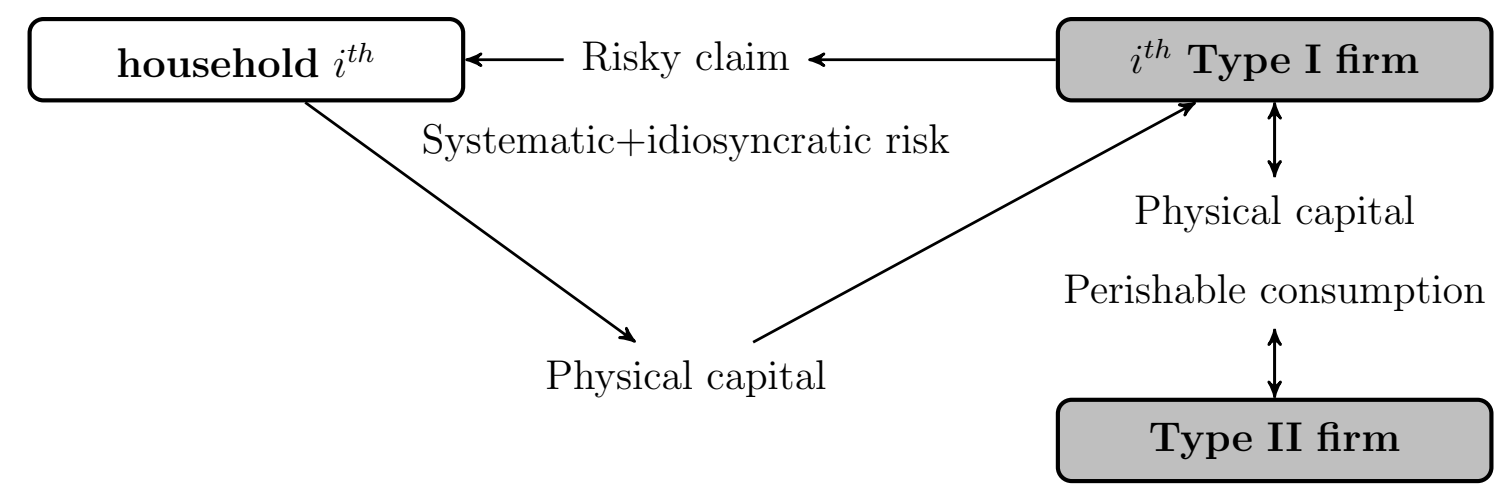

Figure 1: Micro-structure of production and risky claims for the households

\subsection{Financial Sector and Households}

The economy is populated by households and financial intermediaries. Households consist of a heterogeneous continuum of unit mass $\mathbb{H}:=[0,1]$ indexed $h \in \mathbb{H}$. Similarly, intermediaries belong to $\mathbb{F}:=(1,2]$ and are indexed $f \in \mathbb{F}$. Since the latter are homogeneous, they can be accounted for as a representative financial sector.

Intermediaries and households trade physical capital in a perfectly competitive market at the endogenous price $q_{t}$. Each agent has an initial endowment $e_{0}^{i} \neq 0$ and, over each time interval $[t, t+d t)$, she consumes at a rate $\frac{c_{t}^{i}}{e_{t}^{i}}$. Moreover, she allocates a fraction $\omega_{t}^{i}$ of what is left to risky claims, and a fraction $\left(1-\omega_{t}^{i}\right)$ to risk-free bonds.

All agents have log utility and discount the future at a common rate $\rho$; they are infinitely lived and chose $c_{t}^{i}$ and $\omega_{t}^{i}$ to maximize their objective function

$$
V_{0}^{i}:=\max _{\left\{c_{t}^{i}, \omega_{t}^{i}\right\} \in B^{i}} \mathbb{E}_{0}\left[\int_{0}^{\infty} e^{-\rho t} \ln c_{t}^{i} d t\right], \quad i \in\{h, f\}
$$

subject to

$$
B_{t}^{i}: \quad \frac{d e_{t}^{i}}{e_{t}^{i}}=\omega_{t}^{i} d R_{t}^{i}+\left(1-\omega_{t}^{i}\right) r_{t} d t-\frac{c_{t}^{i}}{e_{t}^{i}} d t
$$

where $r_{t}$ is the risk-free interest rate, and the $i^{\text {th }}$ agent has access to a different risky portfolio with return $d R_{t}^{i}{ }^{11}$

\footnotetext{
${ }^{11}$ The derivation of the solution is in Appendix D.1. With a slight abuse of notation we use $d R_{t}^{i}$ to denote the return to the agent $i$ of firm $i=h$, and $d R_{t}^{f}$ to denote the return of the aggregate portfolio that pools risky claims issued by all firms $i \in[0,1]$.
} 
The financial sector can invest the stock of physical capital at its disposal across all type I firms, against the payment of an intermediation cost $\eta$ per unit of capital. The intermediation cost can be thought as a reduced form that represents the administrative costs that the intermediaries bear for screening and monitoring each firm, which the household instead observes, as well as for operational purposes. ${ }^{12}$

Conversely, due to restricted market participation, households cannot diversify among firms, so that her investment opportunity set is restricted to the $i^{\text {th }}$ firm only. Therefore, firms are financed by both households and intermediaries that, in our framework, provide venture capital services. Thus, the return on agent $i$ risky assets holdings, $d R_{t}^{i}$, has the following structure:

$$
d R_{t}^{i}=\underbrace{\mu_{t}^{i} d t}_{\text {Expected return }}-\underbrace{\left[\mathbb{1}_{i=f}\right] \frac{\eta}{q_{t}} d t}_{\text {Intermediation cost }}+\underbrace{\sigma_{t} d W_{t}}_{\text {Systematic risk }}+\underbrace{\left[\mathbb{1}_{i=h}\right] \tilde{\sigma} d \tilde{W}_{t}^{i}}_{\text {Idiosyncratic risk }}
$$

where $\mathbb{1}_{i}$ is the indicator function, and both expected return $\mu_{t}^{i}$ and systematic risk $\sigma_{t}$ are endogenous and determined in equilibrium as dependent on firms' optimizing behaviour. Note that the expected return on risky assets of households is higher than for the financial sector, and therefore it is the associated risk.

The relationship between household $i$ and her firm is synthetically depicted in Figure 1. Similarly, Figure 2 displays the mechanism by which the financial sector may purchase a fraction of the households' physical capital versus the issuance of short-term liabilities risk-free bonds.

It is relevant to highlight that restricted market participation, which we have assumed to be an exogenous financial friction, may emerge in equilibrium when households face transaction costs. In the Online Appendix we show that, even if households and financial intermediaries have full access to risk-free bonds and both, pooled and un-pooled, risky assets,

\footnotetext{
${ }^{12} \mathrm{~A}$ seminal paper that develops a theoretical framework where financial intermediation costs associate to a net advantage due to diversification is Diamond (1984). In an economy where all the agents are risk averse, the paper shows that financial intermediaries must have lower delegation costs than an entrepreneur to viably provide intermediation services. This intermediaries centralized monitoring structure will mean that there are no active markets for their pooled assets. This relates to the concept of restricted market participation, being the aggregate financial sector the only one supplying risk-mitigation instruments. From an empirical perspective, the side effect of risk pooling at financial institutions is treated, among the others, in Wolf (2010) and van Oordt (2014).
} 


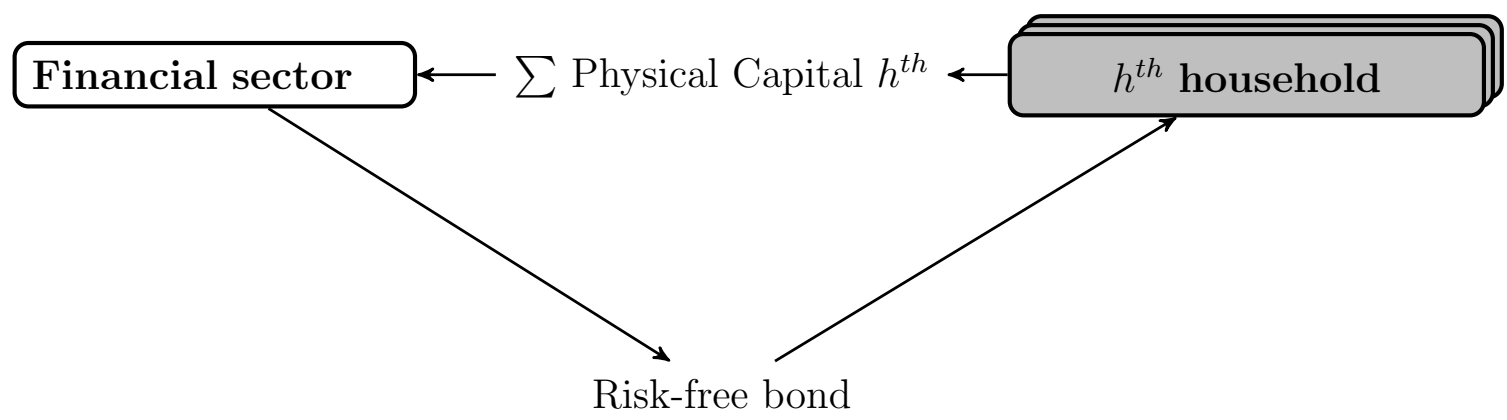

Figure 2: The financial sector and its purchase of a fraction of the households' physical capital versus the issuance of risk-free bonds.

restricted market participation does exist as long as intermediaries are more efficient at pooling claims than households, and the transaction cost is not too large. In this sense, the presence of capital markets is not self-sufficient to solve the monitoring problem, as long as the transaction cost is higher for the households than for the financial sector (see Diamond, 1984).

\section{The Equilibrium Dynamics}

Section 3.1 derives the competitive equilibrium of this economy. Then, Section 3.2 outlines the associated return on risky assets and characterizes the unique state variable: the relative capitalization of the financial sector. Henceforth, we denote all the aggregate variables with a capital letter.

\subsection{Competitive Equilibrium}

Informally, the equilibrium consists of maps from histories of systematic shocks to prices (capital prices, returns on risky claims, risk-free interest rates), production choices and consumption choices, as well as asset allocations, such that firms maximize their profits, agents maximize their expected utility, and markets clear. The formal definition is given in Appendix C.

An equilibrium snapshot of agents' balance sheets at any instant of time $t$ is in Figure 3. The dark grey boxes depict the asset allocation of each class of agents while the light grey boxes represent their liabilities. 


\section{Financial Sector}

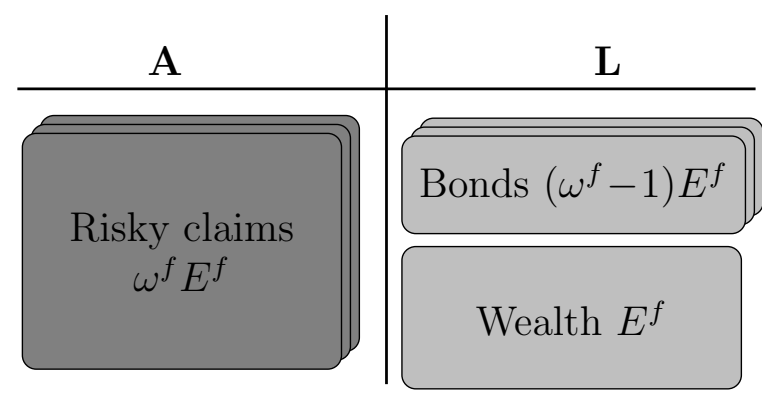

$h^{\text {th }}$ household

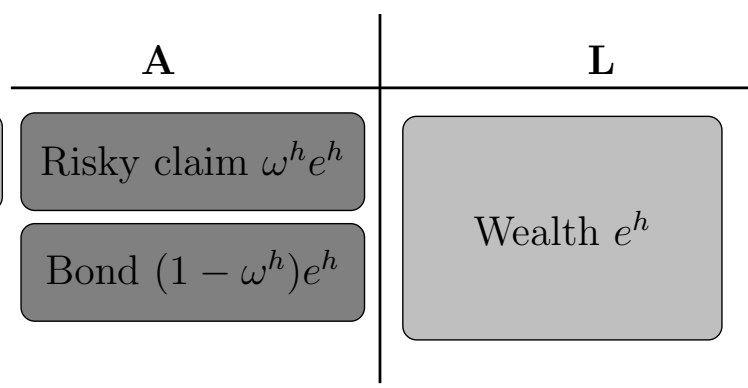

Figure 3: Synthetic agents' balance sheets at time $t$

The financial sector holds a long (leveraged) position in the aggregate portfolio of risky claims that is financed by both its own capital endowment $\int_{\mathbb{F}} e^{f} d f=E^{f}$ plus a short position in risk-free bonds $\left(\omega^{f}-1\right) E^{f}$. Conversely, each household allocates its wealth between a single risky asset and risk-free bonds. Market clearing conditions imply that the risk-free bond is in zero net supply, while financial sector capital and households' wealth sum up to the aggregate (value of) capital within the economy $K_{t} q_{t}$. Accordingly, the stock of wealth that belongs to the aggregate of households is $\int_{\mathbb{H}} e^{h} d h=E^{h}$.

Figure 4 shows the balance sheet of the $j^{\text {th }}$ capital producing firm at any time $t$. As in Figure 3, the dark grey box represents the value of the firm's assets, whereas the light grey ones depict its liabilities. Each capital producing firm is jointly financed by households' plus financial intermediaries' capital stock, that is, they bear a fraction of the risk of firms' assets. Therefore, firms neither do leverage nor default.

In summary, each firm collects physical capital from both households' and intermediaries' (straight arrows) versus the issuance of risky claims written on its profits (dashed arrows). In particular, the $j$ firm gathers capital $\omega^{h} e^{h, j}$ from the $j^{\text {th }}$ household as well as from the financial sector, that evenly finances the continuum of firms, so that $\int_{\mathbb{F}} \omega^{f} e^{f, j} d f=\int_{\mathbb{J}} \omega^{f} e^{f, j} d j=\omega^{f} E^{f}$.

\subsection{Competitive Equilibrium: Characterization}

In order to derive the equilibrium, we express optimal portfolios, drift, and diffusion of the stochastic process in (6) as functions of financial sector relative capitalization $\psi_{t}$, the state variable of our economy, defined as follows: 


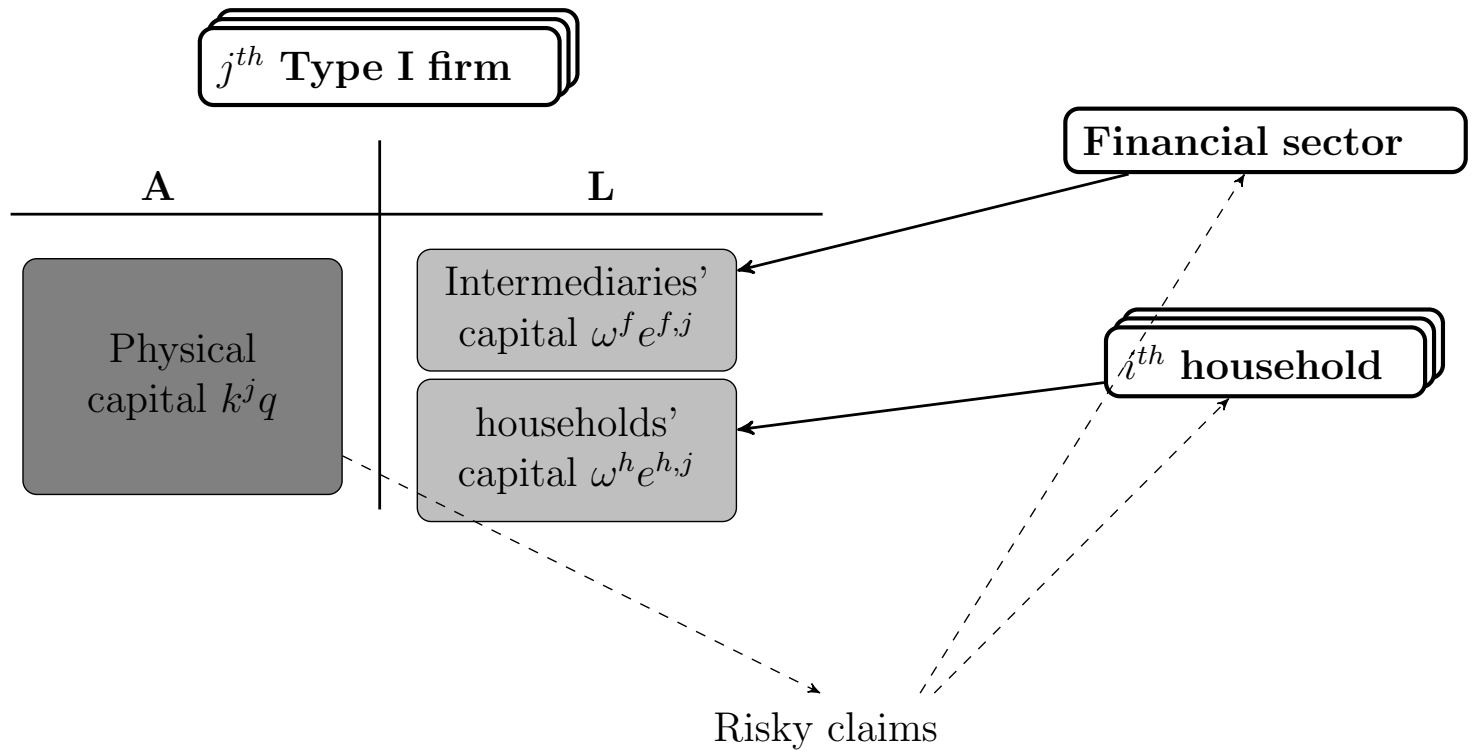

Figure 4: Synthetic balance sheet of the $j^{\text {th }}$ capital producing firm at time $t$

Definition 1. Relative Financial Capitalization Let $\psi_{t}$ be the financial sector's share of total capital value. Conversely, $\left(1-\psi_{t}\right)$ represents the households' share of aggregate capital value:

$$
\psi_{t}:=\frac{E_{t}^{f}}{K_{t} q_{t}}, \quad 1-\psi_{t}:=\frac{E_{t}^{h}}{K_{t} q_{t}} .
$$

As we shall see, all relevant equilibrium quantities can be written as a function of $\psi_{t}$ (see Appendix E).

Next, we restrict our search to the class of dynamically simple equilibria in the state variable $\psi \cdot{ }^{13}$ Moreover, we look for equilibria where the stochastic process that drives the price of physical capital $q$ is an Itô diffusion.

\section{Assumption 1. Price of Physical Capital Dynamics}

The price of physical capital evolves as an Itô diffusion:

$$
d q_{t}:=q_{t} \mu_{t}^{q} d t-q_{t} \sigma_{t}^{q} d W_{t}
$$

\footnotetext{
${ }^{13}$ The equilibrium is dynamically simple, i.e. it is time homogeneous and Markov in the state variable and it is such that there exists an associated stationary distribution. For a formal definition see Duffie et al. (1994)
} 
where $\mu_{t}^{q}$ and $\sigma_{t}^{q}$ are $\mathcal{H}_{t}$-adapted processes.

According to Assumption 1, the dynamics of capital price is not affected by idiosyncratic shocks. Moreover, the minus sign to the diffusion term implies that positive shocks to capital stock affect negatively the price of unit of capital in consumption good. ${ }^{14}$

It can be shown that (see Appendix A) the total return on the $i^{\text {th }}$ claim follows the dynamics in equation (5) with

$$
\mu_{t}^{i}=\mu_{t}:=\underbrace{\frac{A-\iota_{t}}{q_{t}}}_{\text {Dividend Yield }}+\underbrace{\Phi\left(\iota_{t}\right)-\delta+\mu_{t}^{q}-\sigma \sigma_{t}^{q}}_{\text {Capital Gain }},
$$

and

$$
\sigma_{t}:=\sigma-\sigma_{t}^{q}
$$

We now have all the ingredients to derive the dynamics of the state $\psi$ in a competitive equilibrium. Theorem 1 outlines the features of the equilibrium dynamics jointly with the conditions such that: both classes of agents survive in the long-run and a stationary density of the financial sector relative capitalization exists.

\section{Theorem 1. Relative Capitalization Dynamics}

Given the law of motion of $q$ in (6), there exists a unique (Markov) competitive equilibrium and it is characterized by the following:

1. The relative capitalization dynamics follows the diffusion process

$$
d \psi_{t}=\underbrace{\psi_{t} \sigma_{t}^{2}\left[\left(\omega_{t}^{f}-1\right)^{2}-\frac{\omega_{t}^{f} \psi_{t}}{\sigma_{t}^{2}} \frac{\eta}{q_{t}}\right]}_{\psi_{t} \mu^{\psi}\left(\psi_{t}, q\left(\psi_{t}\right)\right)} d t+\underbrace{\psi_{t} \sigma_{t}\left(\omega_{t}^{f}-1\right)}_{\psi_{t} \sigma^{\psi}\left(\psi_{t}, q\left(\psi_{t}\right)\right)} d W_{t}
$$

and

$$
\left\{\begin{array}{l}
\sigma^{q}\left(\psi_{t}, q\left(\psi_{t}\right)\right)=-\epsilon_{q, \psi} \sigma^{\psi}\left(\psi_{t}\right) \\
\mu^{q}\left(\psi_{t}, q\left(\psi_{t}\right)\right)=\mathcal{A} q\left(\psi_{t}\right)
\end{array}\right.
$$

\footnotetext{
${ }^{14}$ This choice is fundamental, as we shall see in the proof of Theorem 1 there does not exist an equilibrium with $\operatorname{Cov}_{t}\left[d k_{t}^{i}, d q_{t}\right]>0$.
} 
where $\epsilon_{q, \psi}$ is the physical capital price elasticity to financial sector relative wealth share and $\mathcal{A}$ is the characteristic operator.

2. As long as the intermediation cost $\eta$ is positive and not too high, the left-hand side and right hand side boundaries, $\psi=0$ and $\psi=1$, are never attainable,

$$
\eta \in\left(0, \tilde{\sigma}^{2} \frac{1+\theta A}{1+\theta \rho+\theta \tilde{\sigma}^{2}}\right) \Rightarrow \psi_{t} \in(0,1) \forall t \in(0, \infty), \mathbb{P}-\text { a.s. }
$$

and there exists a unique (non trivial) stationary density $\pi(\psi)$.

3. When the intermediation cost $\eta$ lays outside the interval in (10), the economy drifts either to the right-hand or to the left-hand side boundary, respectively. In particular:

(a) Full-risk-pooling economy:

$$
\eta=0 \Rightarrow \mu^{\psi}\left(\psi_{t}\right)>0 \Rightarrow \lim _{t \rightarrow \infty} \psi_{t}=1 \mathbb{P}-\text { a.s. }
$$

(b) No-risk-pooling economy:

$$
\eta>\tilde{\sigma}^{2} \frac{1+\theta A}{1+\theta \rho+\theta \tilde{\sigma}^{2}} \Rightarrow \mu^{\psi}\left(\psi_{t}\right)<0 \Rightarrow \lim _{t \rightarrow \infty} \psi_{t}=0 \mathbb{P}-\text { a.s. }
$$

Proof. The proofs of Point 1 and 2 are provided in Appendix D.2. The characteristic operator $\mathcal{A}$ is defined in Øksendal (2003). Point 3 (a) is proved by setting $\eta=0$ in the consumption market clearing condition (48). It follows that $\mu_{t}^{q}=\sigma_{t}^{q}=0$. By point $1, \mu_{t}^{\psi}>0$ and thus, $\psi_{t} \rightarrow 1$ when $t \rightarrow \infty$. Point 3 (b) is proved similarly.

The core result of Theorem 1 is to characterize the joint processes describing the dynamics of intermediaries' relative capitalization $\psi$ and physical capital price $q$ according to the conjecture in Assumption 1. Given this relationship, we can solve the model by finding drift and diffusion for their law of motion numerically (details are in the Online Appendix).

Another important result is that, provided intermediation costs are neither too low nor too high, the relative capitalization keeps floating around its long-run average where both 
classes of agents have positive relative capitalization (point 3). In this sense, heterogeneity is persistent. ${ }^{15}$

Instead, when intermediation costs are either null or too high (depending on the size of idiosyncratic volatility), the economy collapses in one of two "extreme" cases: the fullrisk-pooling economy and the no-risk-pooling economy (see point 3 and Appendix E for the characterization of prices and allocations in these benchmark cases).

In the intermediate case where both classes of agents coexist, henceforth an economy with partial risk pooling, it is interesting to outline the way exogenous systematic shocks affect equilibrium prices and relative wealth share dynamics altogether.

To illustrate this relationship, Figure 5 plots drift (left) and diffusion (right) for the law of motion of financial relative capitalization $\psi$ (top) and capital price $q(\psi)$ (bottom) as a function of the state $\psi \in(0,1)$. Moreover, Figure 6 (left) reports the price level as a function of the state. In red, we depict the benchmark cases of full (solid) and no-risk-pooling (dashed). ${ }^{16}$

Concerning the capital price level, the larger the relative size of the financial sector $\psi$, the lower $q(\psi)$. This negative relation is due to the higher incidence of intermediation costs on the average productivity of capital when the financial sector is large. For example, in the extreme case where the financial sector manages all the capital, the intermediation cost is paid on all units of capital.

In general, positive exogenous systematic shocks shift the size $\psi$ (and thus $q$ ) to the right towards one, because in equilibrium, due to leverage and risk pooling, the total return on financial sector assets is higher than the return on the households' portfolio. The opposite occurs for negative shocks. Importantly, the response of the relative size and capital price dynamics to exogenous shocks is state dependent: when the financial sector capitalization

\footnotetext{
${ }^{15}$ Note that the long-run dynamics of $\psi_{t}$ does not necessarily coincide with the associated deterministic steady state where the drift is null. A discussion upon the relationship between steady-state and long-term average of the stochastic process describing the equilibrium is in Klimenko et al. (2017).

${ }^{16}$ We solve the model numerically - details are in the Online Appendix - by assuming the following parameters: $A=0.5, \delta=0.05, \tilde{\sigma}=0.55, \sigma=0.2, \eta=0.05, \theta=2$, and $\rho=0.05$. According to Ang et al. (2006) and Fangjian (2009), reasonable values for the annualized systematic and idiosyncratic volatilities are approximately $20 \%$ and $55 \%$, respectively. The remaining parametric specification is close to the one in Brunnermeier and Sannikov (2016). To verify the model robustness, the Online Appendix discusses the changes of equilibrium dynamics with respect to the key parameters in the model, namely the size of systematic and idiosyncratic risk as well as intermediation costs.
} 

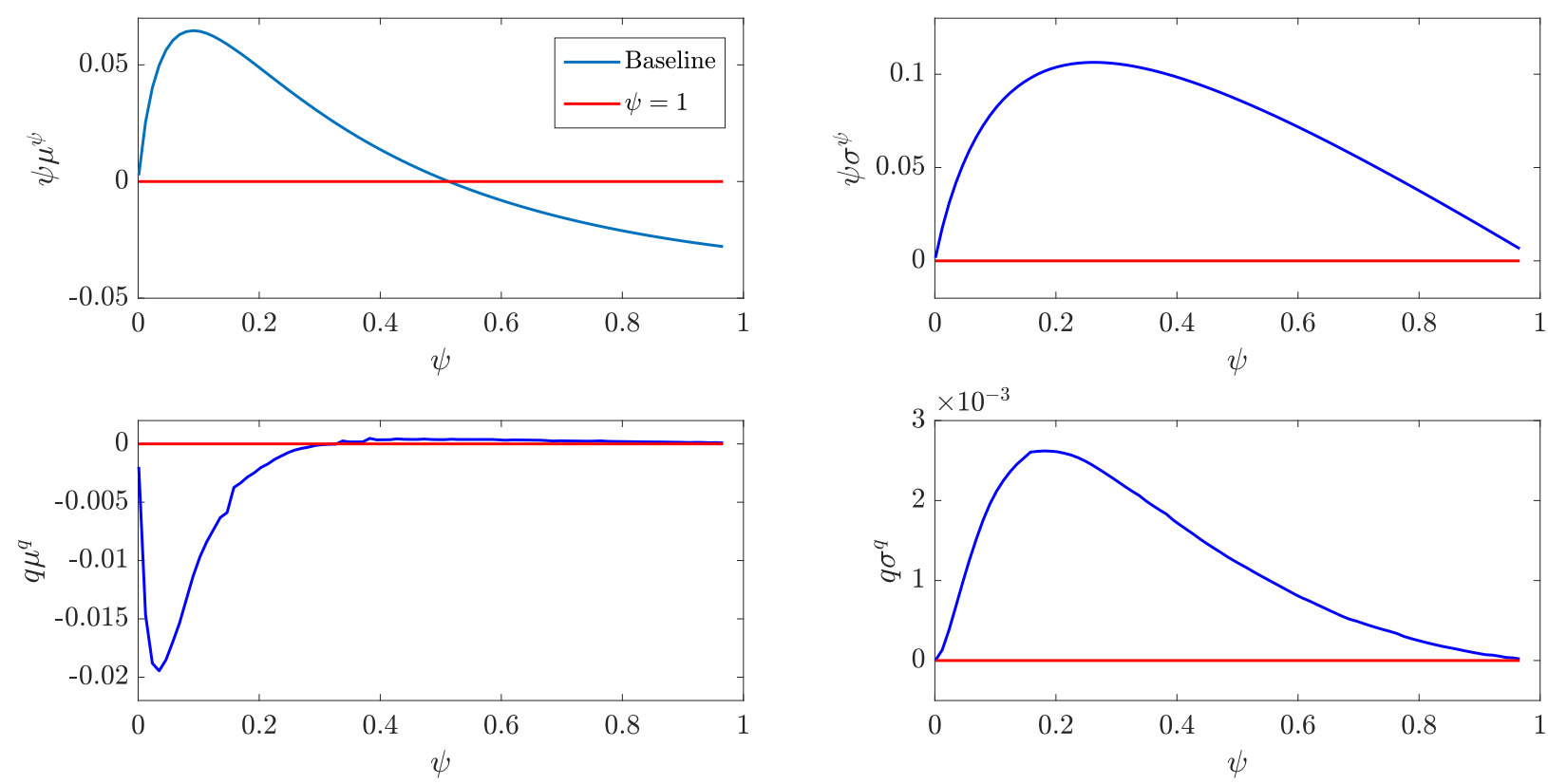

Figure 5: Top: drift (left) and diffusion (right) of the state dynamics $d \psi$ as a function of $\psi \in(0,1)$. Bottom: Drift (left) and diffusion (right) of the price dynamics $d q$ as a function of $\psi \in(0,1)$. In red, the benchmark cases of full-risk-pooling and no-risk-pooling.

is small, its drift is positive (negative for $q$ ). When the financial sector capitalization is big enough, instead, the drift of its relative capitalization is negative (positive for $q$ ). This is because the benefit of leverage is reduced while the costs associated to intermediation (proportional to $\eta / q$ ) are higher. Overall, the relative capitalization of the financial sector shrinks (while $q$ increase). The left panels of Figure 5 provide an illustration. ${ }^{17}$

\section{Risk-free Rates and Macro-dynamics}

In this section, we describe the equilibrium dynamics of leverage, risk-free interest rates, and macro-variables in an economy with partial risk-pooling. We shall characterise this case as a deviation from the benchmarks of full-risk-pooling and no-risk-pooling discussed in Appendix E.

\footnotetext{
${ }^{17}$ In the Online Appendix we show how drift and diffusion change with idiosyncratic risk $\tilde{\sigma}$ and systematic risk $\sigma$. When the financial sector is small (high leverage) they both increase with $\tilde{\sigma}$ (the higher the risk, the higher the demand for risk mitigation, the higher the leverage) and decrease with $\sigma$ (the higher the systematic risk, the lower the Sharpe ratio, the lower the leverage). The last result is consistent with the volatility paradox: due to leverage, a lower systematic risk increase endogenous fluctuations.
} 

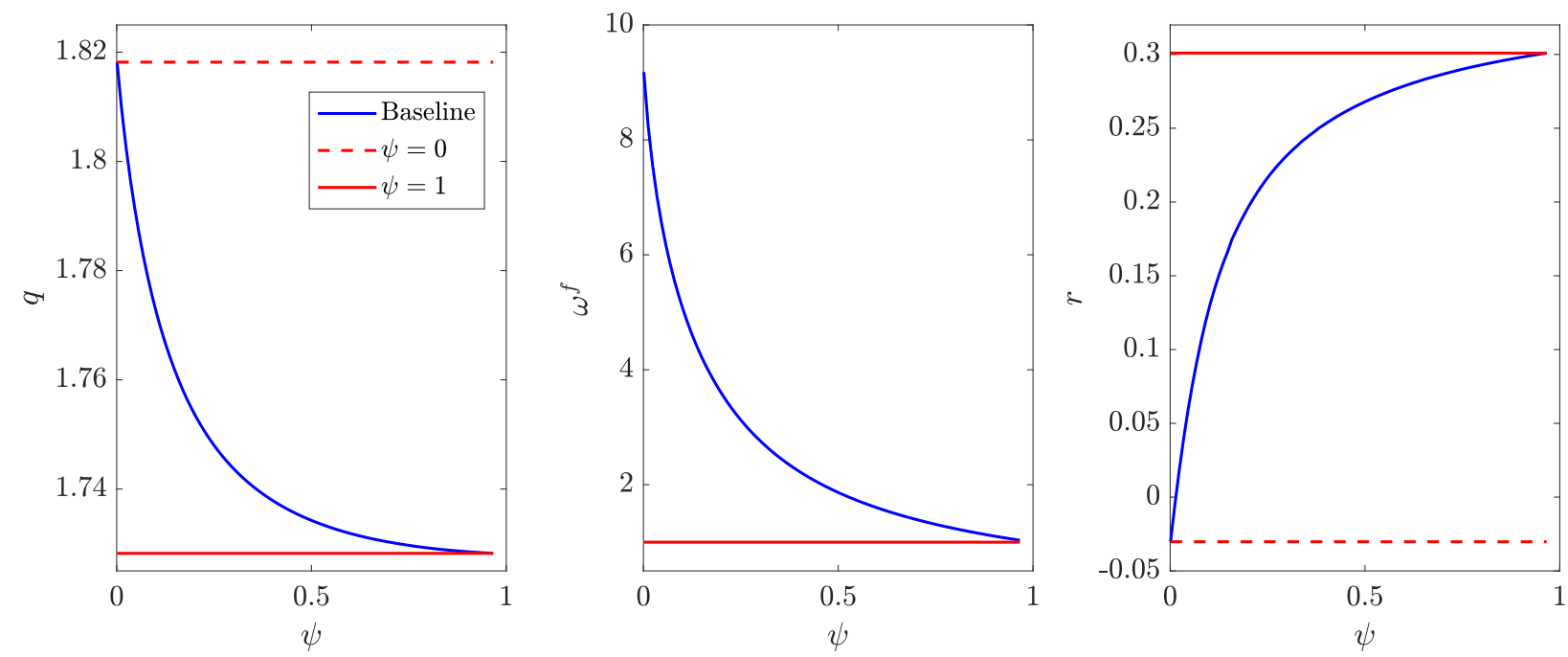

Figure 6: Price level $q$ (left), financial leverage $\omega^{b}$ (middle), and risk-free interest rate $r$ (right) as a function of the state $\psi \in(0,1)$. In red, the benchmark cases of full-risk-pooling (solid) and no-risk-pooling (dashed).

The discussion is structured as follows: first, Section 4.1 investigates the mechanism that links financial sector relative capitalization to equilibrium leverage and risk-free interest rates. Then, Section 4.2 studies how those fluctuations affect real macro-variables, such as aggregate consumption and disposable output.

\subsection{Leverage and Risk-free Rates}

Having solved for the competitive equilibrium, we are able to address several questions upon the theoretical implications of our model, namely: how does financial leverage react to positive and negative exogenous (systematic) shocks, respectively? What is the relationship connecting the financial sector relative capitalization, and thus its leverage, to risk-free interest rates?

Figure 6 displays price level (left), financial leverage $\omega^{f}$ (middle), and risk-free interest rate $r$ (right) as functions of $\psi$. In red, we show the benchmark cases of the full-risk-pooling (solid) and the no-risk-pooling (dashed) economy.

Financial leverage The financial sector leverage, $\omega^{f}$, is a decreasing function of $\psi$ because the smaller the financial sector, the higher the demand of risk mitigation, the larger the 
leverage (Figure 6, middle). As shown in the Online Appendix, in equilibrium it holds

$$
\omega_{t}^{f}=\frac{1}{\psi}\left[1-\frac{\mu_{t}-r_{t}}{\left(\sigma-\sigma_{t}^{q}\right)^{2}+\tilde{\sigma}^{2}}\left(1-\psi_{t}\right)\right] .
$$

Since in equilibrium leverage cannot be larger than $\frac{1}{\psi}$, which occurs when the financial sector holds all risky claims, the diminished financial sector leverage reflects its risk aversion. Note that, despite leverage is decreasing in $\psi$, the total capital holding of the financial sector $\left(\omega^{f} \psi\right)$ is increasing in $\psi$, consistently with the equilibrium nature of the model.

How does leverage change with exogenous shocks? As confirmed by Theorem 1, positive (negative) exogenous systematic shocks deteriorate the financial sector assets and move its size towards one (zero). Stated differently, the diffusion term $\sigma^{\psi}$ contributes positively to the size law of motion (Figure 5, top-right panel). The latter, together with the fact that $\omega^{f}$ is a decreasing function of $\psi$, implies that negative shocks increase equilibrium leverage. This is the result of a relatively higher demand for risk-mitigation instruments by the households. The opposite holds as a response to positive shocks: when the financial sector increases its relative capitalization, its leverage reduces, and so does its supply of risk-mitigation instruments.

Overall, the size of the financial sector is pro-cyclical and financial leverage is countercyclical as also suggested by the recent empirical findings in Yepez (2017) and He et al. (2017).

Risk-free interest rates As far as the equilibrium risk-free interest rate $r_{t}$ is concerned (see Figure 6, right), it is increasing in financial sector capitalization, due to a declining demand/increasing supply of mitigation instruments, making interest rates pro-cyclical (the stylized fact of pro-cyclical risk-free rates is documented in Fatih Guvenen, 2006, among the others).

For low value of financial sector capitalization, $r$ turns negative. Since both sides are equally risk-averse, with a high demand/low supply of bonds, households are willing to pay the financial sector to offload some of their risky claims to its balance sheet. This effect does not require any "crisis" contingency to take place, rather it is generated by restricted market 
participation jointly with the allocation of capital (and risk) among heterogeneous classes of agents.

As it is not the main concern of this paper, the asset pricing implications of our model (state dependent financial assets returns and Sharpe ratios) are discussed at length in Appendix B. Nonetheless, in the light of our results, it is relevant to highlight that our theoretical framework implies that: the link between financial leverage, Sharpe ratios, and risk-free interest rates strictly relates to the pooling capacity of the financial sector - this is an intermediary asset pricing model - and can be decomposed into two different components. First, higher financial leverage corresponds to lower (even negative, depending on the parameters) interest rates. Second, higher leverage corresponds to higher aggregate marginal productivity, and thus higher risky assets returns, since a smaller share of aggregate wealth is spent after pooling.

The size of idiosyncratic risks fundamentally contributes to financial sector risk premiums, despite the fact that they can be pooled, and therefore eliminated via diversification. Moreover, as long as residual (un-pooled) idiosyncratic risk exists, this is accounted for in the equilibrium risk-free rates.

Another relevant implication of the model is that there is no need of binding constraints to link financial leverage to Sharpe ratios: in this terms, it is an inherent effect of financial intermediation (unlike in He and Krishnamurthy, 2013). ${ }^{18}$

\subsection{Consumption and the Business Cycle}

The relationship between the size of the financial sector, its leverage, and the business cycle is a long-standing issue. In particular, the nature of such a connection is explored in several studies: In Denizer et al. (2002), for example, countries with more developed financial

\footnotetext{
${ }^{18}$ The argument that, as long as agents are able to adjust their leverage, Sharpe ratios are counter-cyclical, i.e. assets that covary with leverage are riskier and earn a proportionally larger risk premium, can be found in Brunnermeier and Pedersen (2008), Adrian et al. (2014), and Dell'Ariccia et al. (2014). The connection between higher risk premiums and restricted participation models is well known (see Fatih Guvenen, 2006), and dates back to Basak and Cuoco (1998). In the original model the limitation is extreme, since households have access to risk-free assets only. As a result, the equilibrium interest rate adjusts such that stockholders borrow the entire wealth owned by non-stockholders and make interest payments every period, which sustains the consumption of the latter group. Our contribution is to implement the aforementioned mechanism in a fully-fledged general equilibrium model of a production economy and, in particular, to draw the relationship between financial and real macro-dynamics.
} 
sectors are shown to experience less fluctuations in output, consumption, and investment growth. More recently, Beck et al. (2014) show that intermediation activities increase growth and reduce volatility in the long-run. Nevertheless, they argue that an over-sized financial sector could result in miss-allocation of resources. What follows is that the over-development of auxiliary financial services may lead the financial sector to grow too large relative to its social optimum. In the light of these empirical findings, we dispose of our theoretical framework to highlight the mechanism that relates the size of the financial sector to the equilibrium behaviour of real macro-variables such as aggregate consumption and disposable output.

In equilibrium, the aggregate output $Y_{t}$ can be decomposed as the sum of consumption $C_{t}$, investments $I_{t}$, and what is spent as intermediation costs due to pooling, $G_{t}$. We denote as disposable output $\tilde{Y}_{t}$ the fraction of total output that is either consumed or invested to generate new capital, $\tilde{Y}_{t}=C_{t}+I_{t}$, or, equivalently, $\tilde{Y}_{t}=Y_{t}-G_{t}$. $\tilde{Y}_{t}$ is the share of output that contributes at generating welfare. The dynamics of total output is

$$
d Y_{t}=A d K_{t}=\underbrace{d C_{t}+d I_{t}}_{d \tilde{Y}_{t}}+d G_{t}
$$

where $G_{t}=\eta K_{t}^{h}, I_{t}=\iota_{t} K_{t}$ and thus $C_{t}=\left(A-\iota_{t}\right) K_{t}-\eta K_{t}^{f}$ (note that $K_{t}^{f}$ represents the financial sector's physical capital holdings in equilibrium, i.e. $\left.K_{t}^{f}:=\omega_{t}^{f} E_{t}^{f}\right) .{ }^{19}$

Disposable output In Figure 7, we plot the drift (left) and the normalized diffusion (right) of the (aggregate) disposable output growth process $\frac{d \tilde{Y}}{\tilde{Y}}$. In red, we depict the benchmark cases of the full-risk-pooling (solid) and the no-risk-pooling (dashed) economy.

Both drift and diffusion depend on financial sector relative capitalization and they always remain within the bounds set by the two benchmarks. In particular, $\mu^{\tilde{Y}}$ is decreasing in $\psi$ (increasing in financial leverage), whereas the (normalized) diffusion term $\frac{\sigma^{\tilde{Y}}}{\sigma}$ is a convex function of $\psi$. Therefore, the size of the financial sector fundamentally affects the dynamics of the business cycle, and it does so in a highly non-linear fashion.

\footnotetext{
${ }^{19}$ For the purpose of our analysis, we focus on consumption and disposable output only. In the Online Appendix, we show that the dynamics of disposable output and consumption growth rates evolve as Itô's processes whose drifts and diffusions are function of both state $\psi$ and prices $q(\psi)$.
} 
In our model, the output drift is decreasing in $\psi$ due to a pecuniary externality: the larger the financial sector capitalization, the more risky assets it holds, the lower the productivity of capital (due to high absolute intermediation costs). In equilibrium, less productive capital associates to lower prices $q_{t}$ and, in turn, lower investments $\iota_{t} K_{t}$. This last result implies that, due to financial leverage, capital stock and prices react in the opposite way to exogenous systematic shocks.

In a nutshell, the mechanism reads as follows: when negative (positive) systematic shocks decrease (increase) the aggregate capital stock $K$, they also decrease (increase) - more than proportionally - the fraction of idiosyncratic risks that are pooled by the financial sector $\omega^{b} \psi$. Due to the intermediation costs $\eta$, lower (higher) capital under intermediaries' management increases (reduces) aggregate productivity, positively (negatively) affecting prices $q$ and, in turn, mitigating the effect of each shock over capital and thus output. All in all, the magnitude of the compensation between capital stock and price variation is state dependent and fundamentally relates the relative size of the financial sector. This result is summarised in the following:

Lemma 1. Mitigation The diffusion terms of disposable output growth can be written as mitigation with respect to the exogenous systematic shocks volatility $\sigma$. In particular

$$
\sigma_{t}^{\tilde{Y}}\left(\psi_{t}\right)=\sigma[1-\underbrace{\frac{\eta}{\sigma} \frac{\partial_{\psi}\left(\psi_{t} \omega_{t}^{f}\right)}{A-\eta \psi_{t} \omega_{t}^{f}} \psi_{t} \sigma_{t}^{\psi}}_{\text {Mitigation }}]
$$

Figure 7 (right panel) shows that the mitigation is a concave function of intermediaries' size. Indeed, the negative correlation between $\left(A-\eta \psi \omega^{f}\right)$ and $K$ implies mitigation to be maximal when the state volatility $\sigma^{\psi}$ is high, i.e. for relative small values of the financial sector size.

The mitigation of disposable output volatility is in line with the empirical findings in Beck et al. (2014) suggesting that, in the long-run, intermediation-based services negatively associate with growth volatility. ${ }^{20}$

\footnotetext{
${ }^{20}$ Conversely, non-intermediation services increase the output volatility of high income countries. Never-
} 

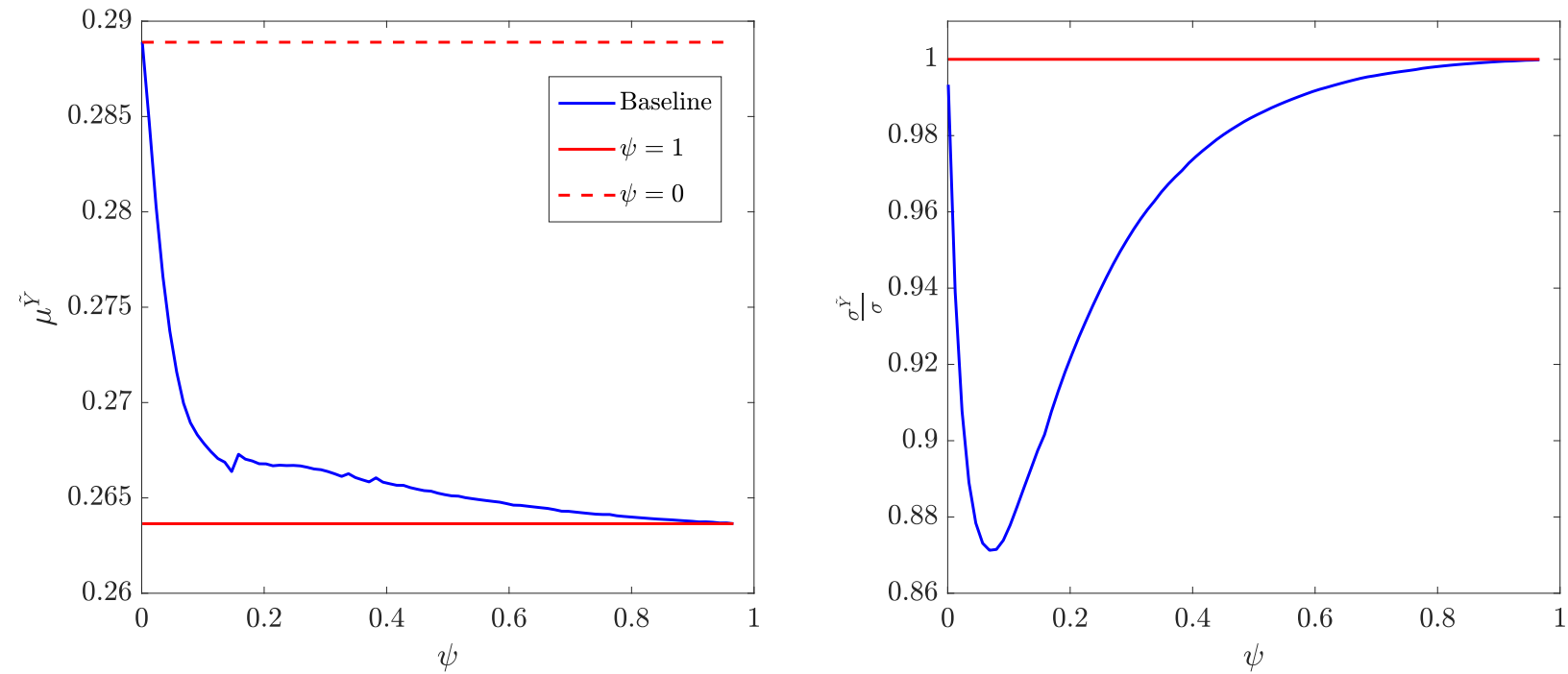

Figure 7: Diffusion (left) and normalized diffusion (right) of the (aggregate) disposable output growth rate $\frac{d \tilde{Y}}{\tilde{Y}}$. In red, the benchmark cases of the full-risk-pooling (solid) and the no-risk-pooling (dashed) economy.
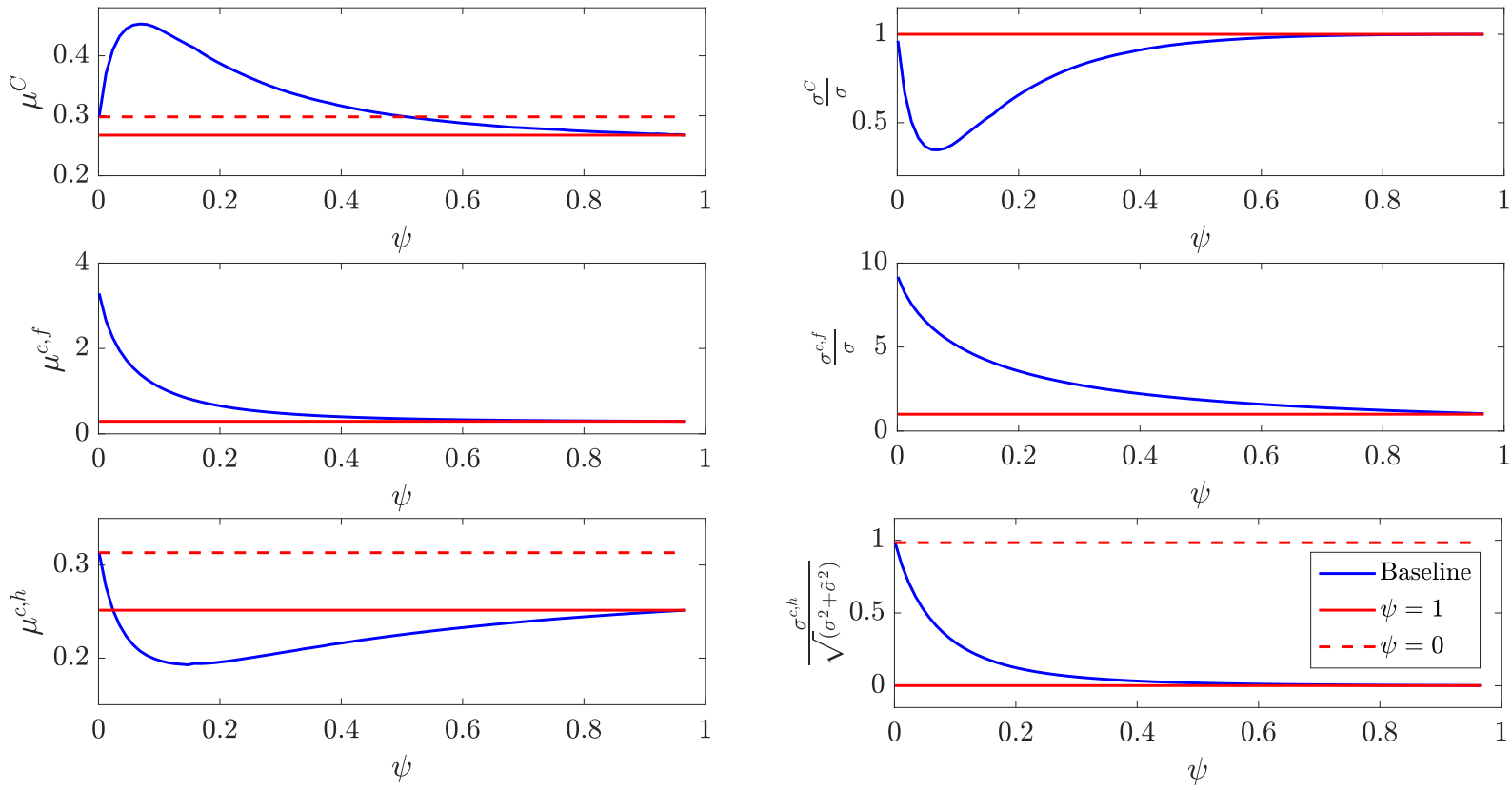

Figure 8: Top: Drift (left) and normalized diffusion (right) of the equilibrium aggregate consumption growth rate $\frac{d C}{C}$ as a function of $\psi$. Middle: Drift (left) and normalized volatility (right) of the financial sector consumption growth rate $\frac{d c^{f}}{c^{f}} \propto \frac{d e^{f}}{e^{f}}$ as a function of $\psi$. Bottom: Drift (left) and normalized volatility (right) of the households' consumption growth rate $\frac{d c^{h}}{c^{h}} \propto \frac{d e^{h}}{e^{h}}$ as a function of $\psi$. In red, the benchmark cases of the full-risk-pooling (solid) and the no-risk-pooling (dashed) economy. 
Consumption To understand the connection between financial relative capitalization and the consumption dynamics, the top panels of Figure 8 plot drift (left) and normalized diffusion (right) of the aggregate consumption growth rate $\frac{d C_{t}}{C}$ as functions of the state $\psi \in(0,1)$. In red, we depict the benchmark cases of the full-risk-pooling (solid) and the no-risk-pooling (dashed) economy.

In the aggregate, financial sector relative capitalization affects the drift of consumption growth $\mu^{C}$ in a highly non-linear fashion: it is increasing for relatively small sized financial sector, decreasing otherwise. Moreover, as long as $\psi$ is small enough, the consumption drift lays above the upper benchmark $(\psi=0$, Figure 8, top left panel). Once again, this result is due to the pecuniary externality of intermediaries' activity.

As far as consumption volatility is concerned, it features both an amplification and a mitigation term. However, the mitigation term always dominates in magnitude. Thus, similar to disposable output, consumption volatility exhibits a U-shape pattern, although its fluctuations are narrower than those of $\tilde{Y}$. This result is summarised in the following Lemma:

Lemma 2. Amplification and Mitigation The diffusion terms of aggregate consumption growth can be written with respect to the exogenous systematic shocks volatility $\sigma$ as sum of an amplification plus a mitigation term. In particular

$$
\sigma_{t}^{C}\left(\psi_{t}\right)=\sigma[1+\underbrace{\frac{\sigma_{t}^{q}}{\sigma} \frac{q_{t}}{\theta} \frac{1}{A-\iota_{t}-\eta \psi_{t} \omega_{t}^{f}}}_{\text {Amplification }}-\underbrace{\frac{\eta}{\sigma} \frac{\partial_{\psi}\left(\psi_{t} \omega_{t}^{f}\right) \psi_{t} \sigma_{t}^{\psi}}{A-\iota_{t}-\eta \psi_{t} \omega_{t}^{f}}}_{\text {Mitigation }}] .
$$

Within the framework of our model, the mitigation term always overtakes the amplification counterpart (Equation 8, top panel, right). This result is consistent with Denizer et al. (2002), whose empirical findings suggest that risk management services provided by financial intermediaries may be particularly important in reducing consumption volatility.

The remaining panels of Figure 8 consider separately the growth rates of financial sector (centre) and households' consumption (bottom). Both drift and volatility of financial sector

theless, the role that intermediation and non-intermediation financial activities play in the growth process of countries is not yet fully disentangled. 
consumption growth decline with its size. A somehow similar effect occurs for the households' consumption growth rate volatility. Here, however, idiosyncratic risks play a big role: the larger the financial sector, the higher the share of pooled idiosyncratic risk, the lower households' consumption growth rate volatility. The drift, instead, is first sharply declining in the financial sector size, reflecting the shape of households' wealth drift when the financial sector is small, and the slowly increasing when the financial sector is too large.

\section{Welfare, Leverage Constraints, and Redistributive Taxation}

This section studies the relationship between financial sector relative capitalization, leverage, and welfare. The aim is to investigate whether there exists a "welfare optimal" size of the financial sector for the households.

First, Section 5.1 characterise the welfare of both households and intermediaries as a function of financial sector relative capitalization. Second, Section 5.2 explores the effect of a static leverage constraint on the equilibrium dynamics and welfare. Finally, Section 5.3 investigates the role of a redistributive taxation policy.

\subsection{Welfare Analysis}

When analysing the impact of financial sector size and leverage on the economy, one should first characterise the agents' welfare as the expected value of the discounted utility of their future consumption, that is, their value function $V^{i}$ (see Equation 3). In this regard, it is possible to show that the welfare of agents $i \in\{h, f\}$ in our model, henceforth denoted $W^{i}(\psi)$, can be solely expressed as a function of relative financial sector capitalization $\psi$ (details are in Appendix D.3). ${ }^{21}$ This result is summarised in the following:

\section{Proposition 1. Welfare (Value) Function}

\footnotetext{
${ }^{21}$ Since the model is scale invariant in aggregate capital stock, we set $K=1$.
} 
The welfare function of sector $i$, for unitary capital, can be expressed as

$$
W^{i}(\psi)=V^{i}(\psi) \propto \ln \rho q(\psi) v^{i}(\psi)+H(\psi)^{i}, \quad i \in\{h, f\}
$$

where $v^{i}(\psi)$ is the class $i$ relative share of total wealth, that $i s, v^{f}(\psi)=\psi$ and $v^{h}(\psi)=1-\psi$, and $H^{i}$ solves agents' $i$ HJBE.

The welfare (value) function outlined in (14) is the sum of two components. The former is static, and accounts for the current benefit due to the ownership of a certain share of the aggregate capital $v(\psi)^{i}$ valued $q(\psi)$. The latter is dynamic, and summarizes the expected discounted benefit of future consumption conditional on an initial state $\psi$.

In the left panel of Figure 9, we show the welfare of households' as a function of the financial sector relative capitalization $\psi$ (blue). In red, we display the benchmark case $\psi=0 .{ }^{22}$ What stands out is that the households' conditional welfare $W^{h}$ is an inverted $U$ shaped function of the financial relative capitalization $\psi$. For low level of $\psi, W^{h}$ is increasing: the larger the financial relative capitalization, the higher the equilibrium risk-free interest rate (see Figure 6, bottom right), the more risk mitigation of aggregate output fluctuations is provided (see Figure 7, right), the higher households' welfare. Conversely, $W^{h}$ turns decreasing when the financial sector grows large, mainly because households are relatively poorer and capital is less valuable. Moreover, even if in those states the supply of risk mitigation is quite large, the small relative size of households affects the growth rate of consumption negatively (see also Figure 8, bottom panel), since a greater share of wealth is spent after the payment of intermediation costs. This result suggests that, from households' perspective, there exists a "welfare optimal" size of the financial sector.

In the right panel of Figure 9 we repeat the same exercise with respect to financial sector welfare $W^{f}$ : in blue, we plot $W^{f}$ contingent to the relative financial capitalization $\psi$, in red, we display the benchmark case when $\psi=1$. Overall, the financial sector conditional welfare is increasing in its own relative capitalization, and it is maximal when $\psi$ approaches one. This is mainly the result of intermediaries growing share of aggregate wealth stock that

\footnotetext{
${ }^{22}$ We compute the value of the function $H$ numerically by Monte Carlo simulations (see also Appendix D.3). In particular, we simulate $N=4,000$ paths of $\psi_{t}$ for $t=400$ periods over a equally spanned grid of initial values $\psi_{0}$. We then interpolate the results over the solution grid by means of a cubic function.
} 

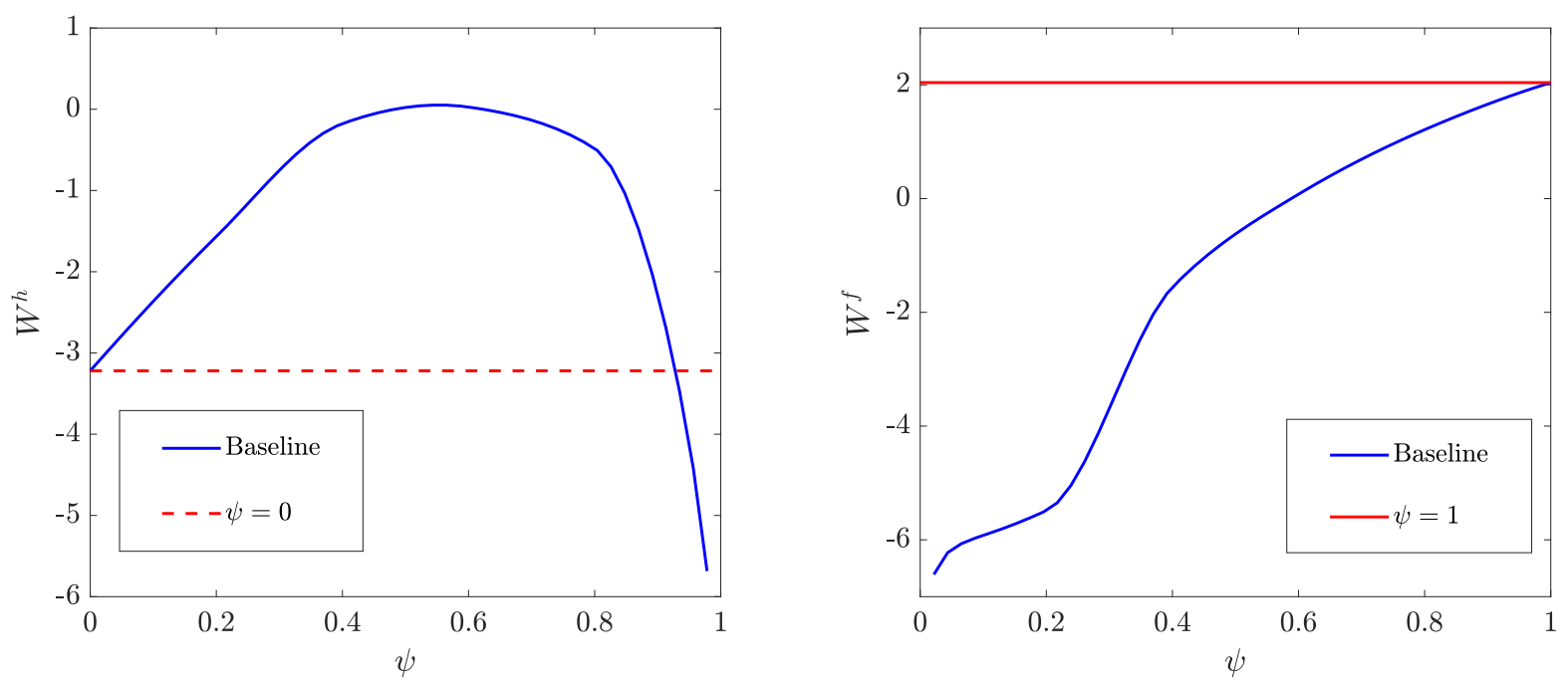

Figure 9: Welfare of households (left) and intermediaries (right) as a function of financial sector relative capitalization $\psi$. In red, the benchmark cases $\psi=0$ (dashed) and $\psi=1$ (solid).

fundamentally dominates the negative effect of intermediaries' size on capital price.

\subsection{The Equilibrium with Leverage Constraints}

The analysis of Section 5.1 suggests that controlling the size of the financial sector may improve households' welfare. When leverage is counter-cyclical, as captured by our model, this can be achieved by imposing a static leverage constraint. Our contribution is to provide theoretical evidence of the role that such constraints may have at determining the fluctuation of disposable output, consumption and, in turn, households' welfare.

Hereafter, we solve the model assuming a constraint to financial sector leverage. Then, we discuss the effect of such a constraint over the equilibrium dynamics. The financial sector optimization problem is now written to take into account the constraint $\omega_{t}^{f} \leq L C$. Finally, we compute the welfare in presence of a static Leverage Constraint (LC).

With a static LC, the HJBE of the financial sector becomes

$$
\rho V_{t}=\max _{\left\{\omega_{t}^{f}, c_{t}\right\}}\left\{\ln c_{t}^{f}+\frac{1}{d t} \mathbb{E}_{t}\left[d V_{t}\right]-\lambda_{t}\left(\omega_{t}^{f}-L C\right)\right\},
$$

with transversality condition $\lim _{s \rightarrow \infty} \mathbb{E}_{t} e^{-\rho s} V_{s}=0$, where $\lambda_{t}$ is the Lagrangian multiplier. The problem is solved in Appendix D.4. It is relevant to highlight that, since agents are 
risk averse, the $L C$ is not always binding. It follows that the motion through which the equilibrium shifts in and out the constrained area is state contingent: both its drift and volatility depend on how restrictive the $L C$ is.

Constrained dynamics In Figure 10 (top), we show the drift (left) and diffusion (right) of the (constrained) equilibrium relative wealth share process. We consider bounded $(L C=4$, green) and unbounded (blue) leverage constraints. In red (solid), we plot the benchmark case of the full risk pooling economy. What stands out is that, when $L C$ binds, it reduces both drift and diffusion of the state dynamics. This result is intuitive since, when the financial sector leverage is capped by the prudential policy (intermediaries capitalization is small), then their capacity to growth faster than households is hindered. Likewise, binding constraints also downsize the sensitivity of intermediaries balance sheet to exogenous shocks, and therefore the magnitude of $\sigma^{\psi}$.

Another relevant aspect of the constrained dynamics of $\psi$ that is important to stress is its relationship to the equilibrium allocation of risk (and capital). In this regard, Figure 10 (bottom) shows intermediaries' leverage $\omega^{f}$ (left) and households portfolio share in risky claims $\omega^{h}$ (right). Complementary to what we observe for the financial sector, binding constraints associate to a higher share of households' wealth allocated in risky assets. Therefore, their relative share of total wealth grows faster than how it would be with no constraints to intermediaries' leverage.

To better visualize these effects over the long-run equilibrium dynamics, Figure 11 depicts the stationary density of relative financial sector capitalization $\pi(\psi)$ for unbounded (blue) and bounded ( $L C=4$, green) constraints. As expected, limiting the maximal financial leverage makes the transition through "lower" states more persistent; accordingly, the stationary density of $\pi(\psi)$ shifts mass from the body to its left-hand tail.

Disposable output If we look at the effect of leverage constraints through the lenses of the business cycle (see Figure 12) we find that a mild $L C$ to the financial sector slightly increases the drift $\mu^{\tilde{Y}}$ (left) of disposable output growth. This is because, in our model, the productivity of households is higher than the financial sector's (due to intermediation costs). On the other hand, the constraint also impairs intermediaries' mitigation of aggregate output 

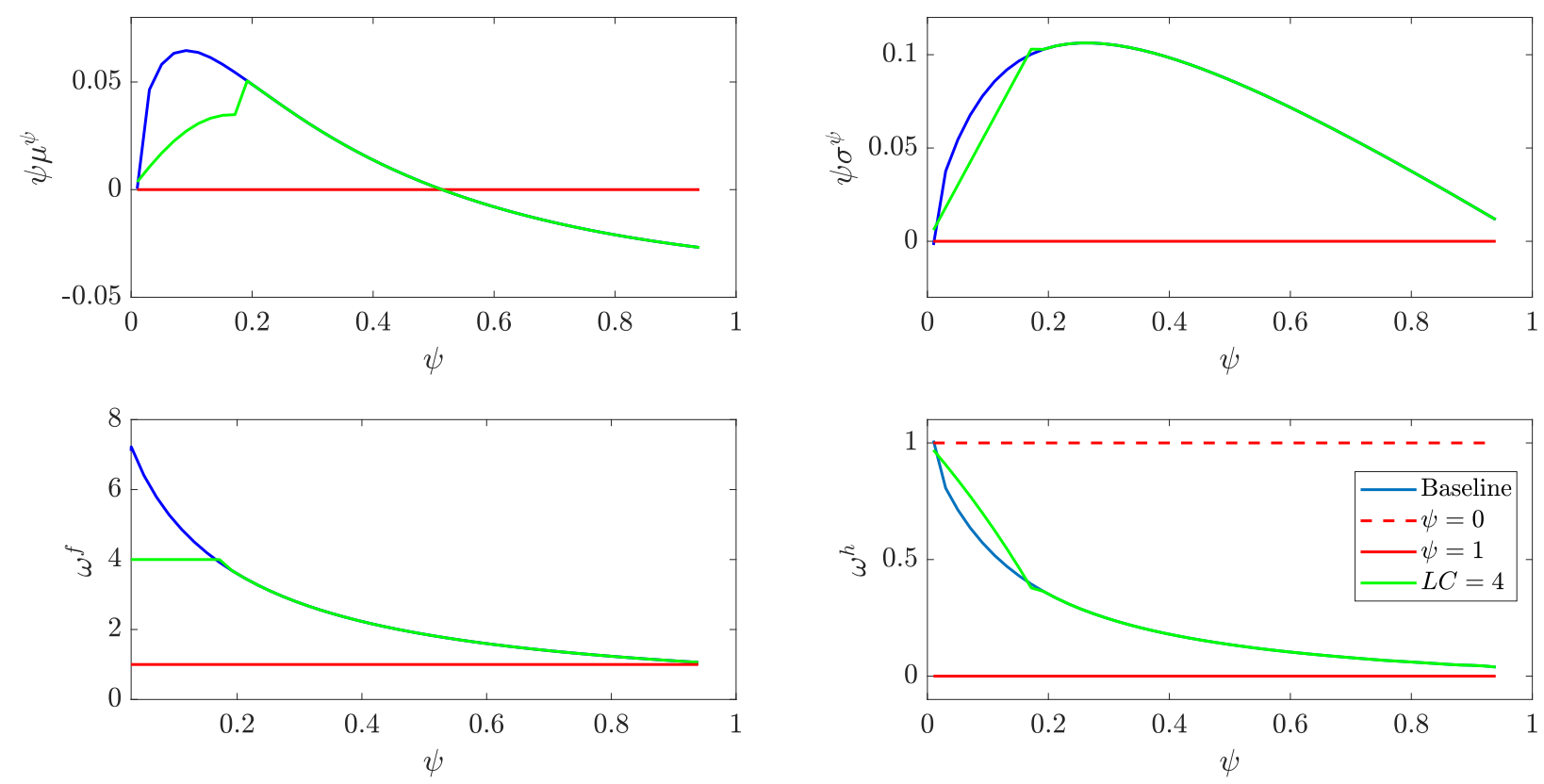

Figure 10: Top: Drift (left) and diffusion (right) of the process $d \psi_{t}$ for bounded $(L C=4$, green) and unbounded (blue) constraints. Bottom: Equilibrium financial sector's (right) and households' (left) portfolio shares for bounded $(L C=4$, green) and unbounded (blue) constraints. In red, the benchmark case of the full-risk-pooling economy.

volatility $\sigma^{\tilde{Y}}$ (Figure 12, right).

Consumption Similar to what we observed for the dynamics of aggregate (disposable) output, in Figure 13 (top panel) we plot the drift and diffusion of aggregate consumption for bounded ( $L C=4$, green) and unbounded (blue) constraints.

As for aggregate output, what stands out is that $L C$ s contribute at increasing consumption growth rate, while dampening the mitigation that comes after intermediaries' activity. In particular, the mitigation may be compromised to the point amplification dominates (see Lemma 2).

Instead, a rather different picture emerges if we look at the dynamics of intermediaries' and households' consumption apart from each other. From the perspective of the financial sector, biding constraints reduce the growth rate of its consumption as well as of its volatility, due to the limited leverage. Conversely, the growth rate of households' consumption is higher, due to the price effect of a greater share of risky capital in their portfolio (Figure 13, middle panel, left). At the same time, households suffer a scarce supply of risk-free bonds when 


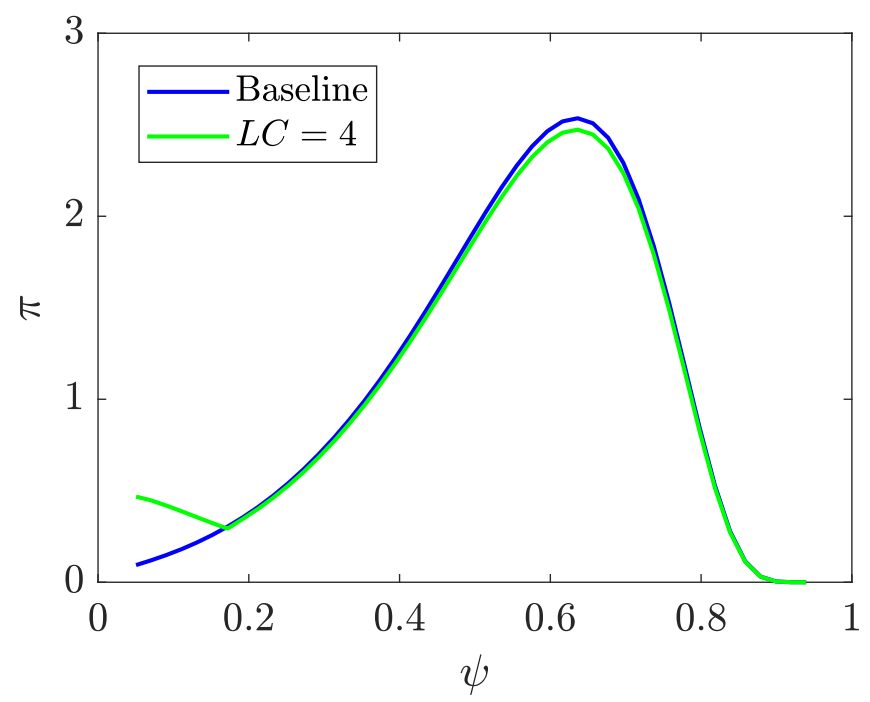

Figure 11: Stationary density of the financial sector relative capitalization $\pi$ as a function of the state for unbounded (blue) and bounded $(L C=4$, green) constraints.

they are needed the most; when financial capitalization is scarce (the constraint is binding) they sustain an extra exposure to idiosyncratic risks (bottom panel, right).

In summary, the most relevant pattern is that imposing limits to leverage hinders the mitigation of aggregate consumption fluctuations by the financial sector, as it reduces the volatility of relative wealth share. However, at the same time, it increases the aggregate consumption growth due to a higher share of capital allocated to - more productive - households.

In a similar fashion, the $L C$ s contribute at reducing the mitigation of disposable output fluctuations, since the constraint limits the externality due to the financial sector activity. Moreover, a restrictive policy hinders the optimal allocation of risk by setting an upper bound to the equilibrium supply of risk-mitigation instruments.

Leverage constraints and welfare When computing whether leverage constraints may be beneficial in a model with heterogeneous classes of agents and state dependent equilibrium aggregates, two issues arise. First, one should account, in principle, for the welfare of all agents jointly (here households and intermediaries). However, to do so, each class of agents must be weighted at the moment of aggregation. In this regard, the choice of proper weights may be critical, and undoubtedly complicates the analysis. 

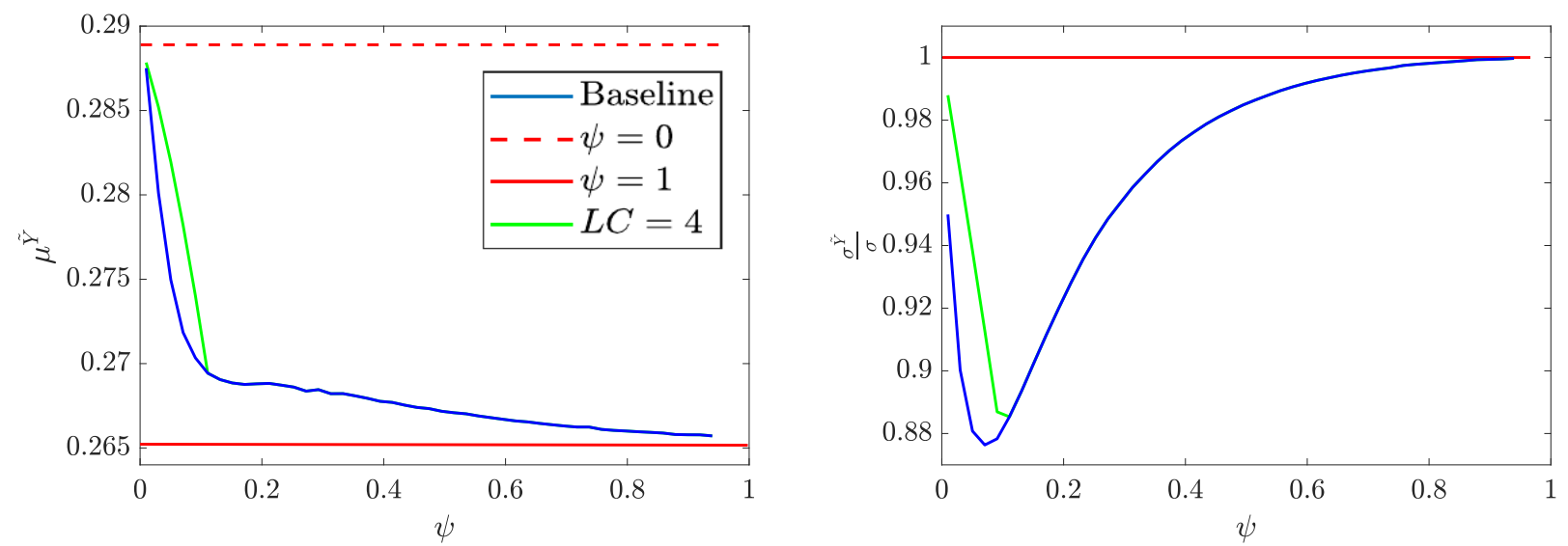

Figure 12: Diffusion (left) and normalized diffusion (right) of the (aggregate) disposable output growth rate $\frac{d \tilde{Y}}{\tilde{Y}}$ for unbounded (blue) and bounded $(L C=4$, green) constraints. In red, the benchmark cases of the full-risk-pooling (solid) and the no-risk-pooling (dashed) economy.
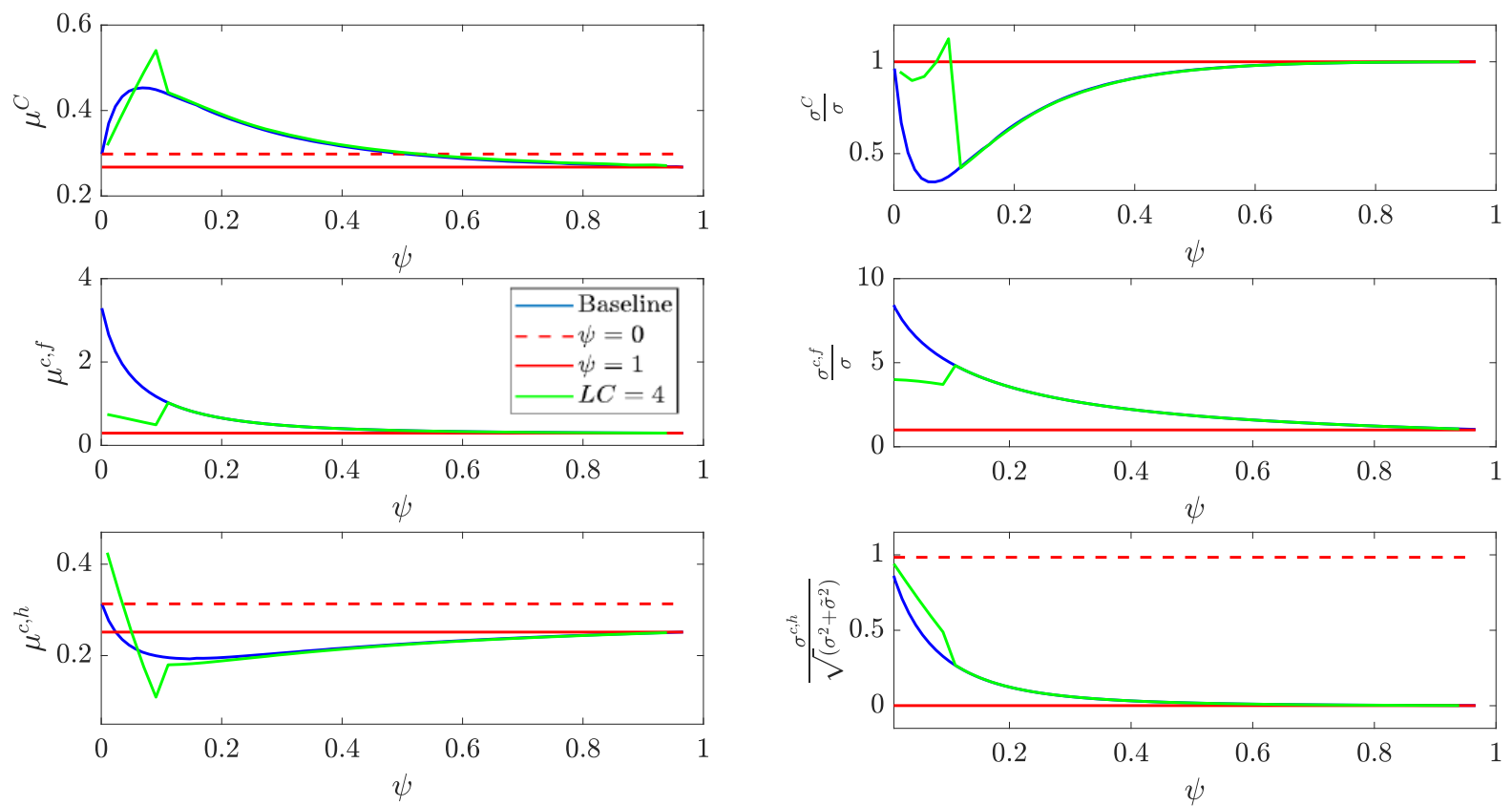

Figure 13: Consumption growth dynamics for bounded $(L C=4$, green) and unbounded (blue) constraints. Top: Drift (left) and normalized diffusion (right) of the equilibrium aggregate consumption growth rate $\frac{d C}{C}$ as a function of $\psi$. Middle: Drift (left) and normalized volatility (right) of the financial sector consumption growth rate $\frac{d c^{f}}{c^{f}}$ as a function of $\psi$. Bottom: Drift (left) and normalized volatility (right) of the households' consumption growth rate $\frac{d c^{h}}{c^{h}}$ as a function of $\psi$. In red, the benchmark cases of the full-risk-pooling (solid) and the no-risk-pooling (dashed) economy. 
To address this issue, we remind that, in our model, imposing exogenous limits to intermediaries' leverage confines them in states of low capitalization for longer periods (see Figure 11), and that in those states their leverage would be suboptimal, for intermediaries, due to the binding constraint. As a consequence, being the welfare (value) of intermediaries strictly increasing in their own aggregate capitalization $\psi$ (see Figure 9, right panel), imposing leverage constraints would mechanically decrease their welfare. On the contrary, the same constraints may improve households' welfare because, by slowing down intermediaries' growth, it prompts the complementary growth rate of households. Nevertheless, a too tight constraint may also harm households because it limits intermediaries' provision of risk mitigation in phases of low capitalization. In this paper, we concentrate on the exploration of this trade-off and evaluate the effect of leverage on households' welfare solely.

The second issue relates, instead, to the fact that households' welfare measure $W^{h}(\psi)$ depends on the initial state $\psi$. To neutrally evaluate the effect of leverage constraints, we should define a welfare measure that is "ex-ante", that is, it does not depend on the initial state $\psi$. We address this second issue by weighting households' value function $W^{h}(\psi)(14)$ for the associated stationary density $\pi(\psi)$ over the interval $\psi \in(0,1)$ :

$$
\mathbb{E} W^{i}=\int_{0}^{1} W^{i}(\psi) \pi(\psi) d \psi
$$

Now that we have defined a suitable measure of welfare, the next step is to use our framework to address the following question: since $L C$ s may be beneficial, how does households' welfare change for different levels of constraint? ${ }^{23}$

To answer this question, Figure 14 (left) shows households' welfare (value) as a function of $\psi$ before (blue) and after $L C$ s are introduced $(L C=4$, green). In red, we display the benchmark cases $\psi=0$ (dashed) and $\psi=1$ (solid). The same Figure (right) also depicts households' welfare "ex-ante", that is, integrated over the stationary distribution $\pi(\psi)$, as a function of the $L C .^{24}$

\footnotetext{
${ }^{23}$ For completeness, in the Online Appendix we study the aggregate welfare of the economy by jointly considering households and intermediaries ex-ante welfare and different weighting functions. We show that, when the weight of the intermediaries sector equals 1 , then $L C=4$ reduces their welfare. A similar result holds when we provide equal and constant weights to both intermediaries and households as well as when their welfare is weighted by their own relative share of wealth $\psi$ and $1-\psi$, respectively.

${ }^{24}$ The welfare is approximated numerically with $T=300$, and $N=4,000$ over a evenly 8 -spaced grid over
} 

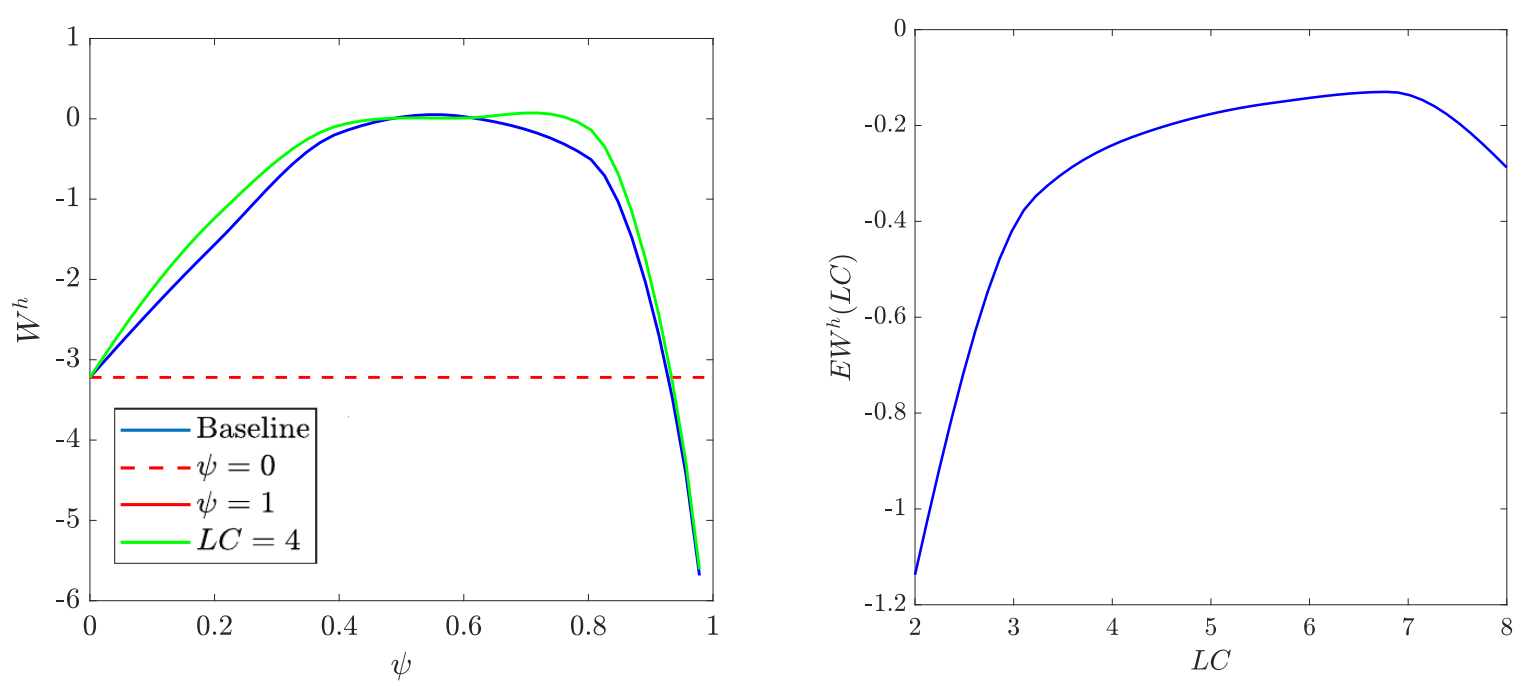

Figure 14: Left: Households' welfare function for bounded ( $L C=4$, green) and unbounded (blue) constraints. In red, the benchmark case of the no-risk-pooling (dashed) and the full-risk-pooling (solid) economy. Right: "ex-ante" households' welfare as a function of the leverage constraint.

When looking at households' welfare (value) as a function of $\psi$, what stands out is that $L C s$ may be beneficial when the financial sector is either under or over-capitalized. Quite the opposite, households' welfare reduces for intermediate values of $\psi$. If we instead consider the "ex-ante" measure of households' welfare (Figure 14, right panel), we see that, on the one hand, a mild constraint to financial leverage may improve welfare. Conversely, when too high, leverage constraints may hinder the equilibrium supply of risk mitigation instruments to the economy. Moreover, they weaken the positive effect of the pecuniary externality on output mitigation (Figure 12, right). This indicates that there exists an optimal level of leverage constraint that may improve the average household welfare.

The fact that leverage constraints could be useful has been already highlighted in the literature (see Blum and Hellwig, 1995; Blum, 2008; Myerson, 2014; DeAngelo and Stulz, 2015, among the others). However, the arguments considered for a lower leverage are mostly based on either partial equilibrium models or focusing on information asymmetries. To our knowledge, our paper, together with the contemporaneous paper by Pancost and Robatto (2019), is the first stressing the connection between leverage and the real as well as financial macro-dynamics, while explicitly highlighting the mechanism that links the agents' welfare to the size of the financial sector in a general, although extremely stylized, equilibrium model. $L C \in[2,8]$. We then interpolate the obtained points by a cubic function (blue, solid). 


\subsection{Redistributive Taxation and Welfare}

Having established the way leverage constraints may affect the households' welfare, we conclude by addressing the following complementary question: what is the role of a redistributive taxation that aims at reducing the relative capitalization of the financial sector?

This is relevant because, being the $L C$ related to the minimal size of the financial sector only, it does not prevent it from growing too large when the constraint is slack. In this term, the role of a redistributive taxation is to reduce the relative financial capitalization, and so the stock of resources intermediaries spend after the payment of intermediation costs.

Let $\tau$ be the constant (tax) rate over intermediaries' aggregate capital $E_{t}^{b}$. We assume that, over the time interval $[t, t+d t)$, the value $\tau E_{t}^{b} d t$ is instantaneously collected from the financial sector and evenly redistributed across households. In other words, the tax transfers net wealth from intermediaries to households. It is possible to show that, accounting for the taxation policy, the dynamics of $\psi$ evolves as follows:

$$
\frac{d \psi_{t}^{\tau}}{\psi_{t}^{\tau}}=\frac{d \psi_{t}}{\psi_{t}}-\tau \frac{\psi_{t}}{1-\psi_{t}} d t
$$

where the term $\frac{d \psi_{t}}{\psi_{t}}$ evolves as in (8) (details on the derivation are in the Online Appendix).

For our purposes, we investigate the effect of different tax rates $\tau$ on the stationary state density and households' ex-ante measure of welfare. To do so, Figure 15 (left) shows the stationary density $\pi(\psi)^{\tau}$ for no $(\tau=0$, blue $)$ and positive tax rate $(\tau=0.007$, green $)$. The right panel of the same Figure depicts instead households' ex-ante welfare $E W^{h}(\tau)$ as a function of the tax rate $\tau$.

According to our numerical results, the redistributive policy shifts the stationary density to the left, where the financial sector has a lower relative capitalization. In general, the higher $\psi$, the more effective the policy (the redistribution is hyperbolically increasing in the state). This is mainly because the absolute redistribution is directly proportional to the wealth stock of the financial sector. ${ }^{25}$

As far as the households' welfare is concerned, our numerical results suggest that the redistributive taxation may be welfare improving for a moderate rate $\tau$. This is because the

\footnotetext{
${ }^{25}$ Note that, at the boundaries: $\lim _{\psi \rightarrow 1} \frac{\partial}{\partial \psi}\left(\tau \frac{\psi_{t}}{1-\psi_{t}}\right)=\infty$, while $\lim _{\psi \rightarrow 0} \frac{\partial}{\partial \psi}\left(\tau \frac{\psi_{t}}{1-\psi_{t}}\right)=\tau$.
} 

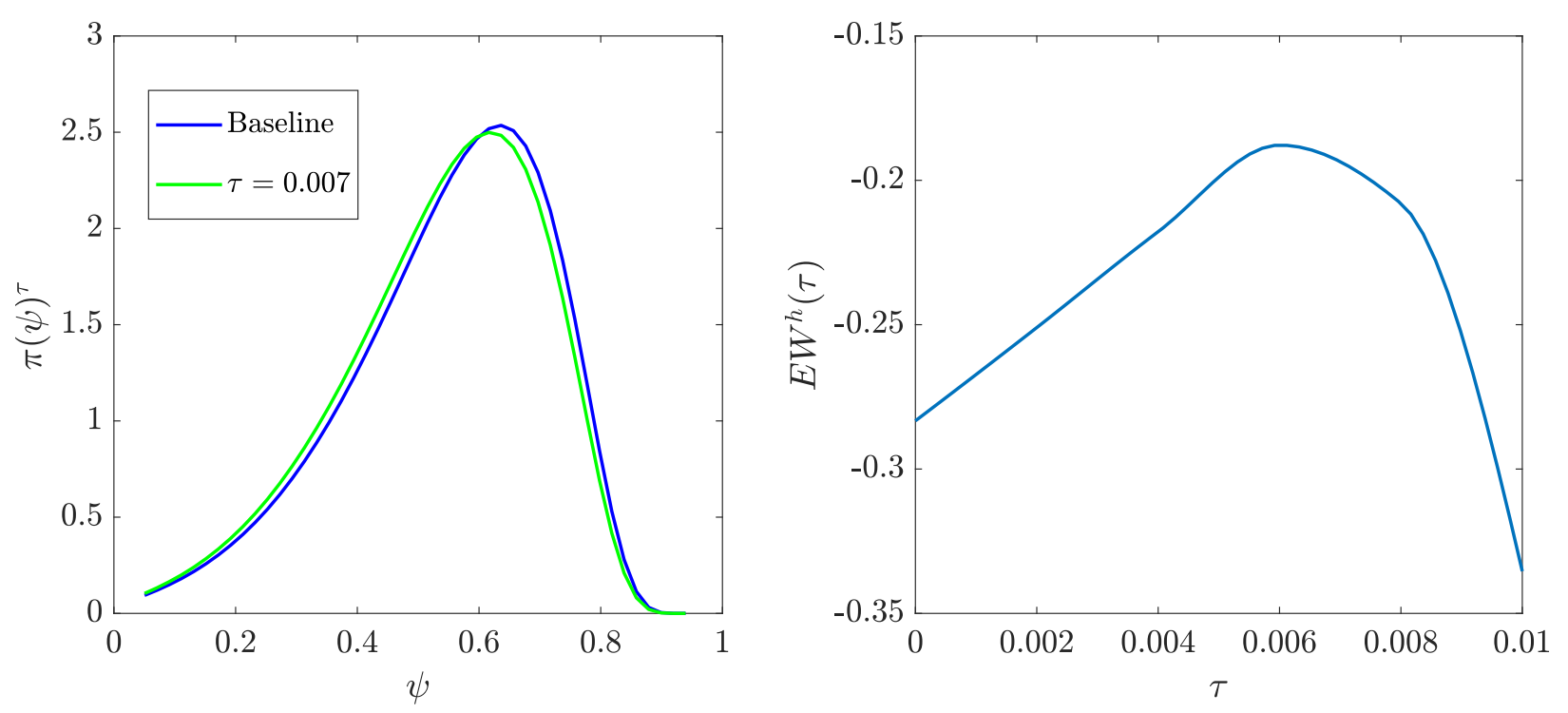

Figure 15: Left: Stationary state density $\pi(\psi)^{\tau}$ before (blue) and after (green) a redistributive taxation policy. Right: Ex households' welfare as a function of the tax rate $\tau$.

financial capitalization is more likely to float through states where the positive (mitigation) effect of the pecuniary externality is maximal, and fewer resources are spent after intermediation costs. Conversely, when $\tau$ is too high, the tax is welfare detrimental because the financial sector is hindered from growing big enough, and so from supplying - cheap - risk mitigation to the economy.

\section{Conclusions}

This paper develops a general equilibrium model with financial intermediaries in order to study the interlink between size (and leverage) of the financial sector, the business cycle, and the risk-free interest rate.

We show that, by pooling idiosyncratic risks, financial intermediaries not only amplify the variations of relative wealth between sectors but also dampen business cycle fluctuations (mitigation).

In our model this effect takes place as a pecuniary externality: when a negative (positive) systematic shock decreases (increases) the aggregate stock of capital, it also decreases (increases) intermediaries capitalization. Lower (higher) capital under intermediaries' manage- 
ment increases (decreases) aggregate productivity due to the intermediation costs, positively (negatively) affecting prices and, in turn, mitigating the effect of each shock over capital and thus output. The magnitude of the compensation between capital stock and price variations is state dependent and fundamentally relates to the size of the financial sector.

By providing the households with instruments of risk mitigation, intermediaries' size and leverage also associate to the cost of risk-pooling itself. Thus, higher intermediaries' capitalization (bigger size, lower leverage) originates lower, possibly negative, risk-free interest rates. As households and financial intermediaries do not internalize the effect of their choices over the equilibrium outcomes, regulating financial leverage and redistributive taxation policy may improve households' welfare.

Our theoretical results suggest that mild leverage constraints to the financial sector may be beneficial, as there exists a trade-off between the welfare gain from aggregate consumption growth and the cost of its fluctuations, as well as of risk mitigation instruments. On the other hand, a moderate redistributive taxation preventing the financial sector from growing too large, and so to destroy too many resources after intermediation costs, may also be welfare improving.

\section{Appendix}

\section{A Micro-foundation}

The micro-foundation structure proposed in this section is the continuous-time equivalent of the one proposed in Ljungqvist and Sargent (2012), Chapter 12.

Output producing firms There exists a continuum of unitary mass of output producing firms (henceforth, type II). Those firms produce output at a rate $A$. At each instant of time $t$, the $i^{t h}$ productive firm chooses the physical capital $k_{t}^{i}$ in order to solve a static problem

$$
\max _{k_{t}^{i} \geq 0}\left\{y_{t}^{i}-p_{t} k_{t}^{i}\right\}
$$


s.t.

$$
y_{t}^{i} \leq A k_{t}^{i}
$$

where $p_{t}$ is the rental rate of physical capital. Given linearity, the above has an interior solution only when the following zero-profit condition is satisfied:

$$
p_{t}=A
$$

If (17) holds, the size of the $i^{\text {th }}$ firm is indeterminate, and it is willing to supply any market demand.

Capital producing firms There exists a continuum of unitary mass of capital producing firms (henceforth, type I). Those firms transform output into capital, store capital, and earn revenues by renting capital to type II firms at the equilibrium rate $p_{t}=A$. At each instant of time $t$, the $i^{\text {th }}$ productive firm chooses how much value of capital $k_{t}^{i} q_{t}$ to store in order to earn stochastic returns $d R_{t}^{i}$ per unitary capital, and how much numéraire $\iota_{t}^{i} k_{t}^{i}$ to purchase to generate new capital $\Phi\left(\iota_{t}^{i}\right) k_{t}^{i}$. Firm $i$ finances itself by issuing state-contingent debt to the agent who supplies the capital stock. Thus, between $t$ and $s$, the $i^{\text {th }}$ firm solves the following problem

$$
\max _{\left\{k_{t}^{i}, \nu_{t}^{i}\right\}}\{\mathbb{E}_{t}^{\mathbb{Q}^{i}} \underbrace{\left[v_{s} e^{\left.-\int_{t}^{s} r_{s} d u\right]}\right.}_{\text {Discounted "Net" Revenues }}-\underbrace{k_{t}^{i} q_{t}}_{\text {Cost of Capital }}\},
$$

s.t.

$$
T^{i}: \quad \frac{d\left(k_{t}^{i} q_{t}\right)}{k_{t}^{i} q_{t}}=\left(\Phi\left(\iota_{t}^{i}\right)-\delta+\mu_{t}^{q}-\sigma_{t}^{q} \sigma\right) d t+\left(\sigma-\sigma_{t}^{q}\right) d W_{t}+\tilde{\sigma} d \tilde{W}_{t}^{i}
$$

where $\mathbb{Q}^{i}$ is the risk neutral measure. The revenues $v_{s}$ are "net" the cost of purchasing the "input", i.e. $e^{-\int_{t}^{s} \frac{\iota_{u}^{i}}{q_{u}} d u}$ for unit of capital. By Equation (18), we know that

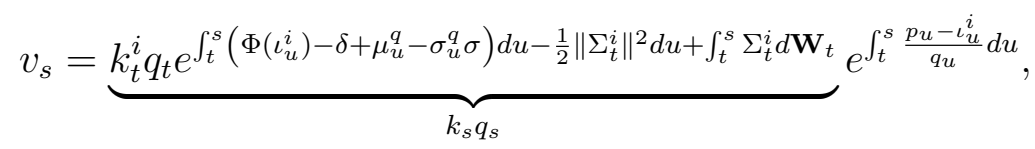


where $\Sigma_{t}^{i}=\left[\begin{array}{cc}\sigma_{t} & {\left[\mathbb{1}_{i=p}\right] \tilde{\sigma}}\end{array}\right]$ and $d \mathbf{W}_{t}=\left[\begin{array}{c}d W_{t} \\ d \tilde{W}_{t}\end{array}\right]$. The FOC on $\iota_{t}^{i}$ requires that

$$
\Phi^{\prime}\left(\iota_{u}^{i}\right)=\frac{1}{q_{u}}, \quad \forall u \in(t, s)
$$

By Type II firms optimality condition in (17), the FOC on $k_{t}^{i}$ implies the zero-profit condition

$$
\mathbb{E}_{t}^{\mathbb{Q}^{i}}\left[e^{\int_{t}^{s}\left(\mu_{u}-\frac{1}{2}\left\|\Sigma_{t}^{i}\right\|^{2}-r_{u}\right) d u+\int_{t}^{s} \Sigma_{u}^{i} d \mathbf{W}_{u}}\right]=1 . \quad \forall i
$$

Note that the zero profit condition is consistent with the equilibrium return on the $i^{\text {th }}$ risky claim $d R_{t}^{i}$ where

$$
\begin{gathered}
\mu_{t}:=\frac{\mathbb{E}_{t}\left[d R_{t}^{i}\right]}{d t}=\frac{A-\iota_{t}^{i}}{q_{t}}+\Phi\left(\iota_{t}^{i}\right)+\mu_{t}^{q}-\delta-\sigma_{t}^{q} \sigma, \\
\left\|\Sigma_{t}\right\|^{2}=\left(\sigma-\sigma_{t}^{q}\right)^{2}+\tilde{\sigma}^{2}=\frac{\mathbb{V a r}_{t}\left[d R_{t}^{i}\right]}{d t} \Longrightarrow \sigma_{t}:=\sigma-\sigma_{t}^{q} .
\end{gathered}
$$

Condition (19) is equivalent to a non-arbitrage condition so that the return on risky claims issued by type I firms (equity) is such that their present discounted value equals the current value of physical capital stock $k_{t}^{i} q_{t}$ supplied by the agents. If such condition holds, the firm breaks even for each $k_{t}^{i}$, its size is indeterminate, and it is willing to supply each market demand.

To grant the existence (and uniqueness) of the competitive equilibrium, condition (19) must be consistent with the no-arbitrage condition for the aggregate portfolio held by the financial sector. The result is summarised in the following proposition:

\section{Proposition 2. Risk Neutral Measure}

Given the zero-profit condition in (19) and the no arbitrage condition for the aggregate portfolio, the market price of systematic risk equals $\xi_{t}=\frac{\mu_{t}^{f}-r_{t}}{\sigma_{t}}$. The latter implies that there exists a unique $\mathbb{Q}^{i}$ such that the price kernel is well defined. ${ }^{26}$ Moreover, the price of idiosyncratic

\footnotetext{
${ }^{26}$ When the intermediation costs are null $\eta=0$, it follows that $\tilde{\xi}_{t}=0$ and, in turn, $\mathbb{Q}^{i}=\mathbb{Q}^{f}$. This case is consistent with the benchmark where markets are complete.
} 
risk $\tilde{\xi}_{t}$ equals

$$
\tilde{\xi}_{t}=\frac{\mu_{t}^{h}-\mu_{t}^{f}}{\tilde{\sigma}} \geq 0 \Longleftrightarrow \eta \geq 0 .
$$

Proof. Given the zero-profit condition in (19), by Girsanov Theorem III (see Øksendal, 2003), the correspondent Radon-Nykodym derivative equals

$$
\frac{d \mathbb{Q}^{i}}{d \mathbb{P}}=\exp \left\{-\int_{t}^{s} \xi_{u} d W_{u}-\int_{t}^{s} \tilde{\xi}_{u} d \tilde{W}_{u}-\frac{1}{2} \int_{t}^{s}\left(\xi_{u}^{2}+\tilde{\xi}_{u}^{2}\right) d u\right\}
$$

where $\mathbb{P}$ is the real probability measure, while $\xi_{t}$ and $\tilde{\xi}_{t}$ represent the market prices of systematic and idiosyncratic risk respectively. Given the no-arbitrage condition for the aggregate portfolio:

$$
\mathbb{E}_{t}^{\mathbb{Q}^{f}}\left[e^{\int_{t}^{s}\left(\mu_{u}^{f}-\frac{1}{2} \sigma_{u}^{2}-r_{u}\right) d u+\int_{t}^{s} \sigma_{u}^{2} d W_{u}}\right]=1
$$

it follows that

$$
\frac{d \mathbb{Q}^{f}}{d \mathbb{P}}=\exp \left\{-\int_{t}^{s} \xi_{t} d u-\frac{1}{2} \int_{t}^{s} \xi_{t}^{2} d W_{u}\right\} \Longleftrightarrow \xi_{t}=\frac{\mu_{t}^{f}-r_{t}}{\sigma_{t}} .
$$

The latter implies that the martingale measure for the $i^{\text {th }}$ firm $\mathbb{Q}^{i}$ satisfies

$$
d \mathbf{W}_{t}^{\mathbb{Q}^{i}}=\left[\begin{array}{c}
\xi_{t} \\
\tilde{\xi}_{t}
\end{array}\right] d t+d \mathbf{W}_{t}
$$

where $\tilde{\xi}_{t}=\frac{\mu_{t}^{h}-\mu_{t}^{f}}{\tilde{\sigma}}=\frac{1}{\tilde{\sigma}} \frac{\eta}{q_{t}}$ and, thus

$$
k_{s}^{i} q_{s} e^{-\int_{t}^{s}\left(r_{u}-\frac{A-\iota_{u}}{q_{u}}\right) d u}=k_{t}^{i} q_{t} e^{-\int_{t}^{t}\left(r_{u}-\frac{A-\iota_{u}}{q_{u}}\right) d u}+\int_{t}^{s} \Sigma_{t}^{\prime} d \mathbf{W}_{t}^{\mathbb{Q}^{i}}
$$

By taking the expected value under the probability measure $\mathbb{Q}^{i}$, it follows that

$$
\mathbb{E}_{t}^{\mathbb{Q}^{i}}\left[k_{s}^{i} q_{s} e^{-\int_{t}^{s}\left(r_{u}-\frac{A-\iota_{u}}{q_{u}}\right) d u}\right]=k_{t}^{i} q_{t}+\underbrace{\mathbb{E}_{t}^{\mathbb{Q}^{i}}\left[\int_{t}^{s} \Sigma_{t} d \mathbf{W}_{t}^{\mathbb{Q}^{i}}\right]}_{0},
$$

is a martingale under $\mathbb{Q}^{i}$. 


\section{B Asset Pricing}

To study how financial leverage relates to asset pricing in our theoretical framework,

Figure 16 plots the financial sector risky assets expected returns $\frac{1}{d t} \mathbb{E}\left[d R^{f}\right]=\mu^{f}$ (bottom, left) and volatility $\frac{1}{d t} \sqrt{\mathbb{V a r}\left[d R^{f}\right]}=\sigma^{f}$ (bottom, right) as a function of $\omega^{f}$. In the same Figure (top, right) we plot the Sharpe ratios of the financial sector $\xi^{f}$ (blue, solid) and of the households' $\xi^{h}$ (blue, dashed) as a function of $\omega^{f}$. What stands out is that Sharpe ratios are increasing with financial leverage. According to what we discussed in Section 4.1, there exists a negative relationship between the financial sector relative wealth share and its leverage, since financial leverage is counter-cyclical, so is the corresponding Sharpe ratio. This is because, as long as the financial sector is free to adjust its leverage, its assets covary with leverage, they are riskier, and thus earn a larger risk premium. The plot also clarifies that Sharpe ratios faced by the household (and including idiosyncratic risk) are lower than those faced by the financial sector, consistently with the opposite position that they have in the bond market. Accordingly, risk-free interest rates being decreasing in $\omega^{f}$ (Figure 16, top, right), are pro-cyclical. This is because, in our model, high leverage corresponds to scarce financial capitalization, and so a scarce supply of risk-free bonds. In this term, the link between financial leverage Sharpe ratios, and interest rates strictly relates to the pooling capacity of the financial sector, and can be decomposed into two different components. First, higher financial leverage corresponds to lower (even negative, depending on the parameters) interest rates. Second, higher leverage corresponds to higher aggregate marginal productivity, decreasing expected price level, and thus lower risky assets returns for the financial sector. Note that the size of idiosyncratic risks contribute also to the financial sector risk premiums despite the fact they can be pooled, and therefore eliminated via diversification. This is due to the assumption of restricted market participation as well as to agents' risk aversion. In fact, the households' exposure to idiosyncratic risk, jointly with their share of the aggregate wealth, determines the aggregate demand of risk-free bonds, and so the equilibrium financial leverage. As long as there exists residual (un-pooled) idiosyncratic risk, this is accounted for in the equilibrium risk-free rates. 

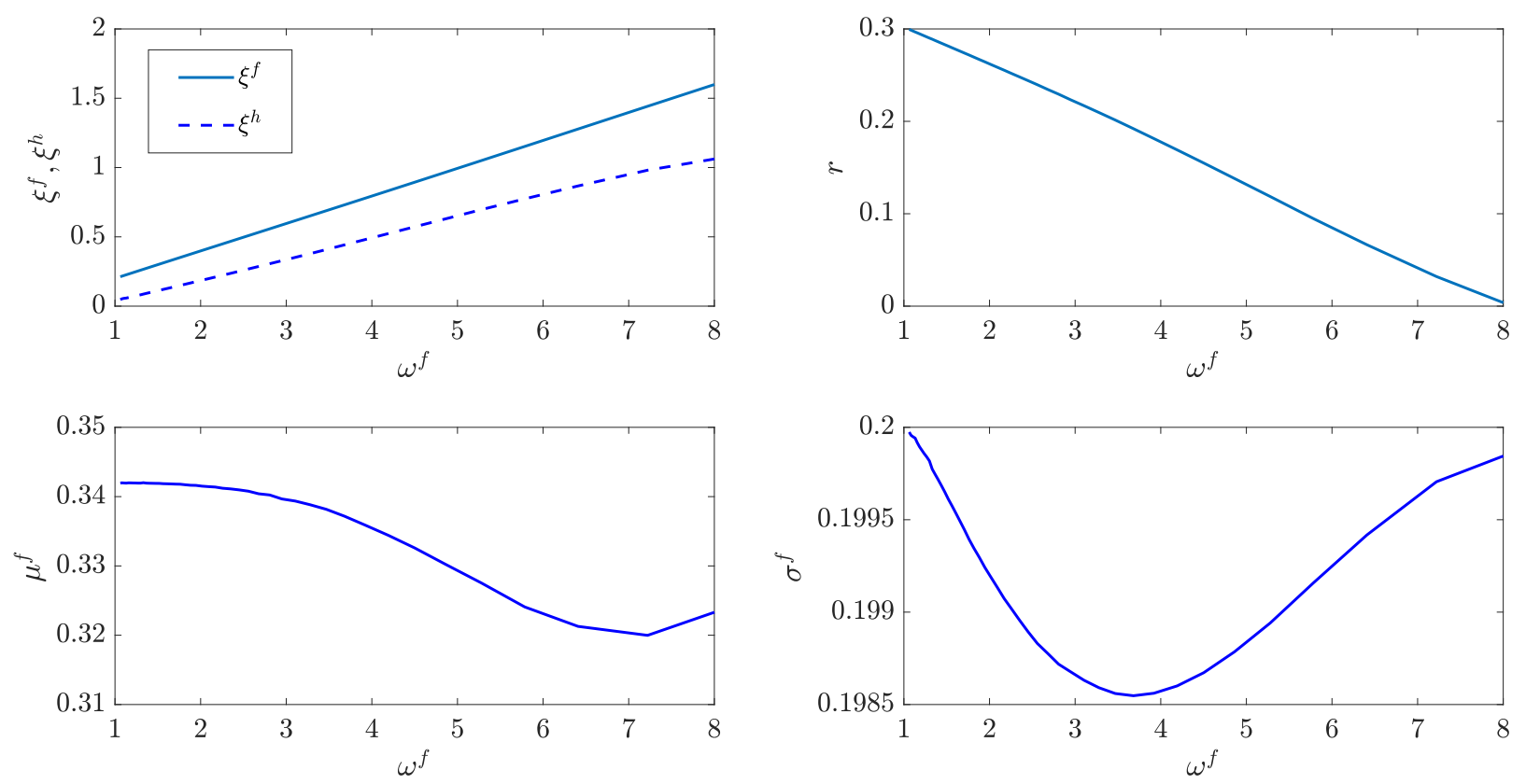

Figure 16: Top left: Sharpe ratios (left) financial sector $\xi^{f}$ (blue, solid) and of the households' $\xi^{h}$ (blue, dashed). Top right: Risk-free interest rate (right) as a function of financial leverage $\omega^{f}$. Bottom: Financial risky assets expected return $\mu^{f}$ (left) and diffusion $\sigma^{f}$ (right) as a function of financial leverage $\omega^{f}$. Baseline parameters: $A=0.5, \delta=0.05, \tilde{\sigma}=0.6, \sigma=0.2, \eta=0.05, \theta=2$, and $\rho=0.05$. 


\section{Competitive Equilibrium}

The formal definition of the competitive equilibrium reads as follows:

\section{Definition 2. Competitive Equilibrium: Definition}

Conditional on an initial allocation of capital among the agents, an equilibrium is an adapted stochastic process that maps histories of systematic shocks $\left\{d W_{t}\right\}$ to prices $\left\{q_{t}\right\}$, returns on

risky claims $\left\{d R_{t}^{h}, d R_{t}^{f} ; h \in \mathbb{H}\right\}$, risk-free rates $\left\{r_{t}\right\}$, production choices $\left\{k_{t}^{i}, \iota_{t}^{i} ; i \in[0,1]\right\}$, consumption choices $\left\{C_{t}^{h}, C_{t}^{f} ; h \in \mathbb{H}\right\}$, and asset allocations $\left\{\omega_{t}^{h}, \omega_{t}^{f} ; h \in \mathbb{H}\right\}$ such that:

1. Firms maximise their profits:

(a) Firms of type I

$$
\left\{k_{t}^{i}, \iota_{t}^{i}\right\} \in \arg \max _{\left\{k_{t}^{i}, \iota_{t}^{i}\right\} \in T^{i}}\left\{\mathbb{E}_{t}^{\mathbb{Q}^{i}}\left[k_{s}^{i} q_{s} e^{\int_{t}^{s} \frac{p_{u}-\iota_{u}^{i}}{q_{u}}-r_{u} d u}\right]-k_{t}^{i} q_{t}\right\}, \forall i \in[0,1]
$$

(b) Firms of type II

$$
k_{t}^{i} \in \arg \max _{k_{t}^{i} \geq 0}\left\{\left(A-p_{t}\right) k_{t}^{i}\right\}, \forall i \in[0,1] .
$$

2. Agents maximise their utility:

$$
\left\{c_{t}^{i}, \omega_{t}^{i}\right\} \in \arg \max _{\left\{c_{t}^{i}, \omega_{t}^{i}\right\} \in B^{i}} \mathbb{E}_{0}\left[\int_{0}^{\infty} e^{-\rho t} \ln c_{t}^{i} d t\right], \forall i \in \mathbb{H} \cup \mathbb{F} .
$$

3. All markets clear:

(a) Risky asset

$$
\int_{\mathbb{F}} \omega_{t}^{f} e_{t}^{f} d f+\int_{\mathbb{H}} \omega_{t}^{h} e_{t}^{h} d h=K_{t} q_{t}
$$

(b) Bond

$$
\int_{\mathbb{F}}\left(1-\omega_{t}^{f}\right) e_{t}^{f} d f+\int_{\mathbb{H}}\left(1-\omega_{t}^{h}\right) e_{t}^{h} d h=0 ;
$$

(c) Consumption

$$
\int_{\mathbb{F}}\left(A-\iota_{t}^{f}-\eta\right) k_{t}^{f} d f+\int_{\mathbb{H}}\left(A-\iota_{t}^{h}\right) k_{t}^{h} d h=C_{t}^{f}+C_{t}^{h}
$$


(d) Capital

$$
\int_{\mathbb{F}} k_{t}^{f} d f+\int_{\mathbb{H}} k_{t}^{h} d h=K_{t} .
$$

\section{Mathematical Appendix - Proofs}

\section{D.1 The Agents' Problem}

Given the agents' problem, the Hamiltonian reads as (we omit the up-scripts for sake of clear notation)

$$
\rho V_{t}=\max _{\{\omega, c\}}\left\{\log c_{t}+\frac{1}{d t} \mathbb{E}_{t}\left[d V_{t}\right]\right\}
$$

subjected to the terminal condition $\lim _{t \rightarrow \infty} e^{-\rho t} V\left(e_{t}^{i}\right)=0$. Given the generic motion of wealth stock of agent $i$,

$$
\frac{d e_{t}^{i}}{e_{t}^{i}}=\left[r_{t}+\omega_{t}\left(\mu_{t}^{i}-r_{t}\right)-\frac{c_{t}}{e_{t}}\right] d t+\omega_{t} \Sigma_{t}^{\prime} \mathbf{d} \mathbf{W}_{t}
$$

when dynamics of a generic state vector $\psi$ is described by a diffusion as

$$
\frac{d \psi_{t}}{\psi_{t}}=\mu_{t}^{\psi} d t+\Omega_{t}^{\psi} d \mathbf{W}_{t}
$$

we have that

$$
\rho V_{t}=\log \rho e_{t}+\partial_{\psi} V \psi_{t} \mu_{t}^{\psi}+\partial_{e} V e_{t} \mu_{t}^{e}+\partial_{\psi e} V e_{t} \psi \Sigma_{t}^{\prime} \Sigma_{t}^{\psi}+\frac{1}{2} \partial_{\psi \psi} V_{t} \psi_{t}\left\|\Sigma_{t}^{\psi}\right\|+\frac{1}{2} \partial_{e e} V e_{t}^{2}\left\|\Sigma_{t}\right\|
$$

By considering an ansatz of the value function in the form

$$
V_{t}:=H_{t}(\psi)+\frac{1}{\rho} \log e_{t}
$$

then, the FOCs on $\{\omega, c\}$ imply

$$
\begin{gathered}
\frac{c_{t}}{e_{t}}=\rho, \\
\omega_{t}=\frac{\mu_{t}-r_{t}}{\sqrt{\|\Sigma\|}} .
\end{gathered}
$$


and, under the optimal strategy $\{\omega, c\}$, the HJB holds as

$$
\rho H\left(\psi_{t}\right)=\log \rho+\frac{1}{\rho}\left(\mu_{t}^{e}-\frac{1}{2}\left\|\Sigma_{t}\right\|\right)+H_{\psi} \psi \mu^{\psi}+\frac{1}{2} H_{\psi \psi} \psi\left\|\Sigma_{t}^{\psi}\right\| .
$$

the By Feynman-Kač Theorem (see Huyên, 2009), the solution to (28) equals

$$
H\left(\psi_{0}\right)=\frac{1}{\rho} \mathbb{E}_{0} \int_{0}^{\infty} e^{-\rho t}\left(\mu_{t}^{e}-\frac{1}{2}\left\|\Sigma_{t}\right\|\right) d t-\frac{\log \rho}{\rho} .
$$

\section{D.2 Proof of Theorem 1}

Given the state

$$
\psi_{t}:=\frac{E_{t}^{f}}{K_{t} q_{t}}
$$

by Itô's lemma,

$$
\begin{aligned}
d \psi_{t}=\frac{\partial \psi_{t}}{\partial E_{t}^{f}} d E_{t}^{f}+\frac{\partial \psi_{t}}{\partial K_{t} q_{t}} d K_{t} q_{t} & +\frac{1}{2} \frac{\partial^{2} \psi_{t}}{\partial\left(E_{t}^{f}\right)^{2}}\left(d E_{t}^{f}\right)^{2}+ \\
& +\frac{1}{2} \frac{\partial^{2} \psi_{t}}{\partial\left(K_{t} q_{t}\right)^{2}} d\left(K_{t} q_{t}\right)^{2}+\frac{\partial^{2} \psi_{t}}{\partial\left(K_{t} q_{t}\right) \partial E_{t}^{f}} d K_{t} q_{t} d E_{t}^{f}
\end{aligned}
$$

By substituting the optimal portfolio in the budget constraint of the financial sector we have

$$
\frac{d E_{t}^{f}}{E_{t}^{f}}=\left(1-\omega_{t}^{f}\right) r_{t} d t-\rho d t+\mu_{t}^{f} \omega_{t}^{f} d t+\omega_{t}^{f} \sigma_{t} d W_{t}
$$

while the aggregate wealth evolves as

$$
\frac{d K_{t} q_{t}}{K_{t} q_{t}}=\mu_{t}^{f} d t+\omega_{t}^{f} \psi_{t} \frac{\eta}{q_{t}} d t+\sigma_{t} d W_{t}-\rho d t
$$

Given Equations (29) and (30) it follows that

$$
d \psi_{t}=\psi_{t} \frac{d E_{t}^{f}}{E_{t}^{f}}-\psi_{t} \frac{d K_{t} q_{t}}{K_{t} q_{t}}+\psi_{t} \sigma_{t}^{2} d t-\psi_{t} \sigma_{t}^{2} \omega_{t}^{f} d t
$$


By considering Proposition 3 and rearranging,

$$
\frac{d \psi_{t}}{\psi_{t}}=\underbrace{\sigma_{t}^{2}\left[1+\omega_{t}^{f}\left(\omega_{t}^{f}-2\right)-\omega_{t}^{f} \frac{\psi_{t}}{\sigma_{t}^{2}} \frac{\eta}{q_{t}}\right]}_{\mu_{t}^{\psi}} d t+\underbrace{\sigma_{t}\left(\omega_{t}^{f}-1\right)}_{\sigma_{t}^{\psi}} d W_{t} .
$$

The second part of point 1 can be proven by looking for a Markov equilibrium in the state variable $\psi_{t}$. Similarly to Haven et al. (2016), if such an equilibrium exists, one must be able to express both drifts and diffusion in Equation (6) as a function of $\psi_{t}$ only. By Itô's lemma,

$$
d q_{t}=\partial_{\psi} q\left(\psi_{t}\right) \psi_{t} \mu_{t}^{\psi} d t+\frac{1}{2} \partial_{\psi \psi}^{2} q\left(\psi_{t}\right) \psi_{t}^{2}\left(\sigma_{t}^{\psi}\right)^{2} d t-\partial_{\psi} q\left(\psi_{t}\right) \psi_{t} \sigma_{t}^{\psi} d W_{t}
$$

By matching drifts and diffusions of the dynamic Equations (31) and (6) we obtain the system in (9).

Persistent heterogeneity In the neighbourhood of the right-hand side boundary, $\lim _{\psi \rightarrow 1^{-}} \sigma_{t}^{q}=$ 0 implies, by continuity, that

$$
\lim _{\psi \rightarrow 1^{-}} \omega_{t}^{f}=1 \Rightarrow \lim _{\psi \rightarrow 1^{-}} \sigma_{t}^{\psi}=0
$$

By the latter,

$$
\lim _{\psi \rightarrow 1^{-}} \mu_{t}^{\psi}=-\left(\frac{\eta(1+\theta \rho)}{1+\theta(A-\eta)}\right)<0 \Longleftrightarrow \eta>0
$$

Similarly, in the neighbourhood of the left-hand side boundary, $\lim _{\psi_{t} \rightarrow 0^{+}} \sigma_{t}^{q}=0$. The latter implies that

$$
\lim _{\psi \rightarrow 0^{+}} \mu_{t}^{\psi}=\Delta^{2}, \quad \lim _{\psi \rightarrow 0^{+}} \sigma_{t}^{\psi}=\Delta
$$

where, by (51),

$$
\Delta=\tilde{\sigma}^{2}-\underbrace{\left(\frac{\eta(1+\theta \rho)}{1+\theta(A-\eta)}\right)}_{\frac{\eta}{\bar{q}}}
$$

is a positive constant. It follows that, in the surroundings of the left-hand side boundary, 
the dynamics of $\psi_{t}$ behaves as a geometric Brownian motion with positive drift:

$$
\psi_{t}^{\epsilon}=\epsilon \exp \left\{\left(\frac{1}{2} \Delta^{2}\right) t+\Delta W_{t}\right\}
$$

where $\epsilon$ is a positive number arbitrary close to 0 . Hence, the process never reaches the absorbing state $\psi=0$.

Given the Markov equilibrium in Theorem 1, and conditions (32) and (33), we know that state drift $\mu_{t}^{\psi}$ is positive at the left-hand side boundary whereas it is negative sign at the right-hand side one. It suffices to prove its derivative negative along the whole domain to grant a unique $\hat{\psi} \in(0,1)$ such that $\mu_{t}^{\psi}(\hat{\psi})=0$. In this fashion

$$
\frac{\partial}{\partial \psi_{t}} \mu_{t}^{\psi}<0, \forall \psi_{t} \in(0,1)
$$

which leads to,

$$
\begin{gathered}
\underbrace{2\left(\omega_{t}^{f}\right)^{\prime}\left(\sigma-\sigma_{t}^{q}\right)^{2}\left(\omega_{t}^{f}-1\right)}_{A}-2\left(\omega_{t}^{f}\right)^{2}\left(\sigma-\sigma_{t}^{q}\right)\left(\sigma_{t}^{q}\right)^{\prime}+ \\
\underbrace{-\frac{\eta\left(\rho+\frac{1}{\theta}\right)}{\frac{1}{\theta}+\eta \psi_{t}+A}-\psi_{t} \frac{\eta^{2}\left(\rho+\frac{1}{\theta}\right)}{\left[\frac{1}{\theta}+\eta \psi_{t}+A\right]^{2}}}_{B}+ \\
-2\left(\sigma-\sigma_{t}^{q}\right)\left(\sigma_{t}^{q}\right)^{\prime}+4\left(\sigma-\sigma_{t}^{q}\right)\left(\sigma_{t}^{q}\right)^{\prime} \omega_{t}^{f}<0 .
\end{gathered}
$$

and, after some algebra,

$$
\left(\sigma_{t}^{q}\right)^{\prime}\left(\sigma-\sigma_{t}^{q}\right)\left(\omega_{t}^{f}-1\right)^{2}>\frac{A+B}{2}
$$

Provided that we assume (and numerically check) $\left(\omega_{t}^{f}\right)^{\prime}<0, \sigma>\sigma_{t}^{q}>0$ and $\left(\sigma_{t}^{q}\right)^{\prime} \geq 0$, condition (35) is always satisfied, since $A, B<0$ and $\omega_{t}^{f}>1$. Moreover, by Theorem 1 $\sigma_{t}^{\psi} \propto \sigma_{t}^{q}$, it follows that $\sigma_{t}^{q}>0 \Rightarrow \sigma_{t}^{\psi}>0$.

By considering the dynamics of $d \psi_{t}$ in Theorem 1, a unique stationary distribution $\pi(\psi)$ exists as long as the first two moments of $\psi_{t}$ exist and are finite. A rigorous discussion of the sufficient conditions of existence of the stationary for Ito's Processes is in Zhenzhong and 
Chen (2013). Although we cannot derive a closed-form solution for $\psi_{t}$, its first moment can be determined as

$$
d\left(e^{-\int_{0}^{t} \mu_{s}^{\psi} d s} \psi_{t}\right)=-e^{-\int_{0}^{t} \mu_{s}^{\psi} d s} \mu_{s}^{\psi} \psi_{t} d t+e^{-\int_{0}^{t} \mu_{s}^{\psi} d s} d \psi_{t}=e^{-\int_{0}^{t} \mu_{s}^{\psi} d s} \psi_{t} \sigma_{t}^{\psi} d W_{t}
$$

If we integrate both sides and take expected value, we have

$$
\mathbb{E}_{0}\left[\psi_{t}\right]=\psi_{0} \mathbb{E}_{0}\left[e^{\int_{0}^{t} \mu_{s}^{\psi} d s}\right]+\mathbb{E}_{0}\left[e^{\int_{0}^{t} \mu_{s}^{\psi} d s} \int_{0}^{t} e^{-\int_{0}^{s} \mu_{u}^{\psi} d u} \psi_{s} \sigma_{s}^{\psi} d W_{s}\right]
$$

Since the term in $d W_{s}$ is an Itô integral, its expected value equals zero and thus

$$
\mathbb{E}_{0}\left[\psi_{t}\right]=\psi_{0} \mathbb{E}_{0}\left[e^{\int_{0}^{t} \mu_{s}^{\psi} d s}\right]
$$

where $\psi_{0}$ is an arbitrary starting point. Thus, the first moment of the distribution is defined as long as $\mathbb{E}_{0}\left[e^{\int_{0}^{t} \mu_{s}^{\psi} d s}\right]<\infty$. We prove it numerically by simulation. Similarly we can derive the variance as

$$
\operatorname{Var}_{0}\left[\psi_{t}\right]=\mathbb{E}_{0}\left[\psi_{t}^{2}\right]-\mathbb{E}_{0}\left[\psi_{t}\right]^{2}
$$

The first term of (37) can be found by solving

$$
d\left(x^{2}\right)=2 x d x+2 d x^{2}
$$

where $x=e^{-\int_{0}^{t} \mu_{s}^{\psi} d s} \psi_{t}$, which leads to

$$
d\left(e^{-2 \int_{0}^{t} \mu_{s}^{\psi} d s} \psi_{t}^{2}\right)=2 e^{-\int_{0}^{t} \mu_{s}^{\psi} d s} \psi_{t} e^{-\int_{0}^{t} \mu_{s}^{\psi} d s} \psi_{t} \sigma_{t}^{\psi} d W_{t}+e^{-2 \int_{0}^{t} \mu_{s}^{\psi} d s}\left(\psi_{t} \sigma_{t}^{\psi}\right)^{2} d t
$$

It follows that

$$
\mathbb{E}_{0}\left[\psi_{t}^{2}\right]=\psi_{0}^{2} \mathbb{E}_{0}\left[e^{2 \int_{0}^{t} \mu_{s}^{\psi} d s}\right]+\mathbb{E}_{0} E\left[e^{2 \int_{0}^{t} \mu_{s}^{\psi} d s} \int_{0}^{t} e^{-2 \int_{0}^{t} \mu_{s}^{\psi} d s}\left(\psi_{s} \sigma_{s}^{\psi}\right)^{2} d s\right]
$$

and thus

$$
\operatorname{Var}_{0}\left[\psi_{t}\right]=2 \mathbb{E}_{0}\left[e^{2 \int_{0}^{t} \mu_{s}^{\psi} d s} \int_{0}^{t} e^{-2 \int_{0}^{s} \mu_{u}^{\psi} d u}\left(\psi_{s} \sigma_{s}^{\psi}\right)^{2} d s\right]
$$


Therefore, the second (central) moment of the distribution is defined as long as ${\mathbb{V} a r_{0}}_{0}\left[\psi_{t}\right]<$ $\infty$. We prove it numerically by simulation.

Stationary density The details on how to obtain the stationary density $\pi(\psi)$ are in the Online Appendix.

\section{D.3 Proof of Proposition 1}

Given the results summarised in Appendix (D.1), it is straightforward that, for a unitary aggregate capital $K_{t}=1$, considering agents of the class $h$

$$
W^{h}\left(\psi_{t}\right)=\frac{\ln \rho q_{t}\left(1-\psi_{t}\right)}{\rho}+\frac{1}{\rho} H^{h}\left(\psi_{t}\right)
$$

where

$$
H\left(\psi_{t}\right)^{h}=\frac{1}{\rho} \mathbb{E}_{0}[\int_{0}^{\infty} e^{-\rho s} \underbrace{\mu_{s}^{e, h}-\frac{1}{2}\left(\omega_{s}^{h}\right)^{2}\left(\sigma_{s}^{2}+\tilde{\sigma}^{2}\right)}_{f\left(\psi_{s}\right)} d s]
$$

We compute the value of (38) conditional on the state $\psi_{0}$ by numerical simulation.

\section{D.4 Constrained Portfolios}

By considering the constrained version of the problem in Appendix D.1, by standard dynamic programming the HJBE satisfies

$$
\rho V_{t}=\max _{\left\{\omega_{t}, c_{t}\right\}}\left\{\ln c_{t}+\frac{1}{d t} \mathbb{E}_{t}\left[d V_{t}\right]-\lambda_{t}\left(\omega_{t}-L C\right)\right\}
$$

where $\lambda_{t}$ is the Lagrangian multiplier associated to the constraint

$$
\omega_{t} \leq L C
$$


By taking FOCs and considering complementary slackness, given the dynamics of $V_{t}$, the optimal portfolio share $\omega_{t}^{C}$ satisfies the following system:

$$
\left\{\begin{array}{l}
\omega_{t}^{U}-\omega_{t}^{C}=\frac{\lambda_{t}}{\rho \sigma_{t}^{2}} \\
\lambda_{t}\left(\omega_{t}^{C}-L C\right)=0 \\
\lambda_{t} \geq 0 \\
\omega_{t}^{C}-L C \leq 0
\end{array}\right.
$$

where $\omega_{t}^{U}$ is the unconstrained solution. The possible couples $\left\{\omega_{t}^{C}, \lambda_{t}\right\}$ that satisfy (39) are:

$$
\begin{cases}\omega_{t}^{C}=\omega_{t}^{U}, \lambda_{t}=0 & \omega_{t}^{U}<L C \\ \omega_{t}^{C}=L C, \lambda_{t}=\rho \sigma_{t}^{2}\left(\omega_{t}^{U}-L C\right) & \omega_{t}^{U} \geq L C\end{cases}
$$

\section{E The Benchmarks}

In this Appendix, we describe the two extreme cases that act as the benchmarks of our analysis. The former is the no-risk-pooling economy, where the households hold all the capital and restricted market participation plays a big role. The latter is the full-risk-pooling economy, where the financial sector holds the whole stock of physical capital and restricted market participation plays no role.

No-risk-pooling The equilibrium at the left-hand side boundary $(\psi=0)$ implies a constant price of physical capital $q(0)$ (in fact $\mu^{q}(0)=\sigma^{q}(0)=0$ ), investment $\iota(0)$, risk-free interest rates $r(0)$, risky claim return $\mu^{h}(0)$, and their Sharpe ratio $\xi^{h}(0)$. In particular,

$$
\begin{gathered}
q(0)=\frac{1+\theta A}{1+\theta \rho}, \quad \iota(0)=\frac{q(0)-1}{\theta}=\frac{A-\rho}{1+\theta \rho}, \quad r(0)=\rho+\Phi(\iota(0))-\delta-\sigma^{2}-\tilde{\sigma}^{2}, \\
\mu^{h}(0)=\frac{A-\iota(0)}{q(0)}+\Phi(\iota(0))-\delta, \quad \xi^{h}(0)=\frac{\frac{A-\iota(0)}{q(0)}+\sigma^{2}+\tilde{\sigma}^{2}-\rho}{\sqrt{\sigma^{2}+\tilde{\sigma}^{2}}} .
\end{gathered}
$$

In this economy markets are utterly restricted. Financial intermediaries do not supply any 
risk-mitigation instrument to the economy and each household has full exposure to its idiosyncratic shocks. The equilibrium interest rate is lower than how it would be with a financial sector, and it is such that, in absence of risk mitigation assets, agents are happy to invest their wealth in risky claims only. High value of $q$ decrease the dividend yield (but increases the capital gain due to higher investment) and decreases also the Sharpe ratio. The latter also depends on systematic and idiosyncratic risk. Although both increase risk, they also decrease the risk-free rate and thus, overall, increase the equilibrium Sharpe ratio. In this benchmark, the capital stock $K_{t}$ follows a Geometric Brownian Motion (GBM). The same holds for aggregate output (due to the linearity of type II technology) and for aggregate consumption:

$$
\left.\frac{d K_{t}}{K_{t}}\right|_{\psi=0}=\left.\frac{d C_{t}}{C_{t}}\right|_{\psi=0}=\left.\frac{d Y_{t}}{Y_{t}}\right|_{\psi=0}=[\Phi(\iota(0))-\delta] d t+\sigma d W_{t}
$$

Although aggregate output and consumption are moved only by the systematic shocks, each household's individual consumption bears its uninsured idiosyncratic risk leading to a low welfare.

Full-risk-pooling The full-risk-pooling economy is reachable when the cost of intermediation equals zero, unless the obvious case when the financial sector is endowed with the whole aggregate wealth at $t=0$ so that $\psi_{0}=1$. Also this equilibrium implies a constant price of physical capital $q(1)$, investment $\iota(1)$, risk-free interest rates $r(1)$, risky claim return $\mu^{h}(1)$, and their Sharpe ratio $\xi^{h}(1) .{ }^{27}$ In particular:

$$
\begin{gathered}
q(1)=\frac{1+\theta(A-\eta)}{1+\theta \rho}, \quad \iota(1)=\frac{A-\rho-\eta}{1+\theta \rho}, \quad r(1)=\rho+\Phi(\iota(1))-\delta-\sigma^{2}, \\
\mu^{f}(1)=\frac{A-\iota(1)-\eta}{q(1)}+\Phi(\iota(1))-\delta, \quad \xi^{f}(1)=\frac{\frac{A-\iota(1)-\eta}{q(1)}+\sigma^{2}-\rho}{\sigma} .
\end{gathered}
$$

Note that when $\eta>0$ capital prices and investment are lower: $q(1)<q(0)$ implies $\iota(1)<\iota(0)$. Interest rates are higher, $r(1)>r(0)$, due to the fact that the financial sector can diversify all

\footnotetext{
${ }^{27}$ Also this equilibrium is a special case of Cox et al. (1985).
} 
the idiosyncratic risk and thus has a zero demand/supply of risk mitigation for higher rates than when households are alone. Positive intermediation costs imply instead that capital is less productive (some resources are lost in the intermediation process) and its equilibrium price is lower. Lower prices imply also lower investment and thus lower drift, a pecuniary externality of the high intermediation costs. Risk premiums, and so Sharpe ratios, are also a function of capital prices. A low capital price implies a higher dividend yield and a lower capital gain (lower investment). The Sharpe ratio is also lower due to higher interest rates. Also in this benchmark the capital stock follows a GBM, the same process followed by total consumption and output:

$$
\left.\frac{d K_{t}}{K_{t}}\right|_{\psi=1}=\left.\frac{d C_{t}}{C_{t}}\right|_{\psi=1}=\left.\frac{d Y_{t}}{Y_{t}}\right|_{\psi=1}=[\Phi(\iota(1))-\delta] d t+\sigma d W_{t}
$$

With positive intermediation cost, $\eta>0$, the growth rate of output, capital, and consumption is lower in the full-risk-pooling economy than in the no-risk-pooling case. Nevertheless, in both cases the aggregate volatility is state independent and equals $\sigma$. The same process is followed also by the disposable output $\tilde{Y}$, defined as the output net of intermediation costs: $\tilde{Y}_{t}=Y_{t}-\eta K_{t}=(A-\eta) K_{t}$.

\section{References}

Adrian, T. and N. Boyarchenko (2012). Intermediary leverage cycles and financial stability. Federal Reserve Bank of New York Staff Reports no. 743.

Adrian, T., N. Boyarchenko, and D. Giannone (2019). Vulnerable growth. American Economic Review $109(4), 1263-1289$.

Adrian, T., N. Boyarchenko, and H. S. Shin (2016). On the scale of financial intermediaries. Federal Reserve Bank of New York Staff Reports no. 743.

Adrian, T. and M. Brunnermeier (2016). CoVaR. American Economic Review 106(7), $1705-41$.

Adrian, T., E. Erkko, and T. Muir (2014). Financial intermediaries and the cross-section of asset returns. The Journal of Finance 69(6), 2557-2596. 
Adrian, T. and H. S. Shin (2010). Liquidity and leverage. Journal of Financial Intermediation 19(3), 418-437.

Adrian, T. and H. S. Shin (2013). Procyclical leverage and Value-at-Risk. The Review of Financial Studies 27(2), 373-403.

Aiyagari and Rao (1994). Uninsured idiosyncratic risk and aggregate saving. The Quarterly Journal of Economics 109(3), 659-684.

Aiyagari, R. and M. Gertler (1991). Asset returns with transactions costs and uninsured individual risk. Journal of Monetary Economics 27(3), 311-331.

Ang, A., R. Hodrick, Y. Xing, and X. Zhang (2006). The cross-section of volatility and expected returns. The Journal of Finance 61(1), 259-299.

Basak, S. and D. Cuoco (1998). An equilibrium model with restricted stock market participation. The Review of Financial Studies 11(2), 309-341.

Beck, T., H. Degryse, and C. Kneer (2014). Is more finance better? Disentangling intermediation and size effects of financial systems. Journal of Financial Stability 10, 50-64.

Bernanke, B., M. Gertler, and S. Gilchrist (1999). The financial accelerator in a quantitative business cycle framework. Handbook of Macroeconomics 1, 1341-1393.

Blum, J. (2008). Why 'Basel II' may need a leverage ratio restriction. Journal of Banking and Finance 32(8), 1699-1707.

Blum, J. and M. Hellwig (1995). The macroeconomic implications of capital adequacy requirements for banks. European Economic Review 39(3-4), 739-749.

Borio, C. (2014). The financial cycle and macroeconomics: What have we learnt? Journal of Banking and Finance 45, 182-198.

Brunnermeier, M., T. Eisenbach, and Y. Sannikov (2012). Macroeconomics with financial frictions: A survey. National Bureau of Economic Research no. w18102.

Brunnermeier, M. and L. H. Pedersen (2008). Market liquidity and funding liquidity. The Review of Financial Studies 22(6), 2201-2238.

Brunnermeier, M. and Y. Sannikov (2014). A macroeconomic model with a financial sector. The American Economic Review 104(2), 379-421.

Brunnermeier, M. and Y. Sannikov (2016). The I theory of money. National Bureau of Economic Research (no w22533). 
Carlstrom, C. and T. S. Fuerst (1997). Agency costs, net worth, and business fluctuations: A computable general equilibrium analysis. The American Economic Review, 893-910.

Cox, J., J. Ingersoll, Jr., and S. Ross (1985). An intertemporal general equilibrium model of asset prices. Econometrica 53(2), 363-384.

Davydiuka, T., B. Glovera, and R. Szymanskia (2018). The decline in US public firms. Mimeo.

DeAngelo, H. and R. Stulz (2015). Liquid-claim production, risk management, and bank capital structure: Why high leverage is optimal for banks. Journal of Financial Economics 116(2), 219-236.

Dell'Ariccia, G., L. Laeven, and R. Marquez (2014). Real interest rates, leverage, and bank risk-taking. Journal of Economic Theory 149, 65-99.

Denizer, C., M. Iyigun, and A. Owen (2002). Finance and macroeconomic volatility. Contributions in Macroeconomics $2(1)$.

Diamond, D. W. (1984). Financial intermediation and delegated monitoring. The Review of Economic Studies 51(3), 393-414.

Duffie, D., J. Geanakoplos, A. Mas-Colell, and A. McLennan (1994). Stationary Markov equilibria. Econometrica 62(4), 745-781.

Fangjian, F. (2009). Idiosyncratic risk and the cross-section of expected stock returns. Journal of Financial Economics 91(1), 24-37.

Fatih Guvenen, a. B. K. (2006). Does market incompleteness matter for asset prices? Journal of the European Economic Association 4.2(3), 484-492.

Gao, X., J. Ritter, and Z. Zhu (2013). Where have all the IPOs gone? Journal of Financial and Quantitative Analysis 48(6), 1663-1692.

Gourinchas, P. and H. Rey (2017). Global real rates: A secular approach. BIS Working paper no. 793.

Haven, E., P. Molyneux, J. Wilson, S. Fedotov, and M. Duygun (2016). The Handbook of Post Crisis Financial Modeling. Palgrave Macmillan, London.

He, Z., B. Kelly, and A. Manela (2017). Intermediary asset pricing: New evidence from many asset classes. Journal of Financial Economics 126(1), 1-35.

He, Z., I. G. Khang, and A. Krishnamurthy (2010). Balance sheet adjustments during the 
2008 crisis. IMF Economic Review 58(1), 118-156.

He, Z. and A. Krishnamurthy (2011). A model of capital and crises. The Review of Economic Studies $79(2), 735-777$.

He, Z. and A. Krishnamurthy (2013). Intermediary asset pricing. The American Economic Review 103(2), 732-770.

He, Z. and A. Krishnamurthy (2019). A macroeconomic framework for quantifying systemic risk. American Economic Journal: Macroeconomics. 11(4), 1-37.

Heaton, J. and D. Lucas (2004). Capital structure, hurdle rates, and portfolio choice interactions in an entrepreneurial firm. Mimeo, Northwestern University.

Huggett, M. (1993). The risk-free rate in heterogeneous-agent incomplete-insurance economies. Journal of Economic Dynamics and Control 17(5), 953-969.

Huyên, P. (2009). Continuous-time stochastic control and optimization with financial applications, Volume 61. Springer.

Kiyotaki, N. and J. Moore (1997). Credit cycles. Journal of Political Economy 105(2), $211-248$.

Klimenko, N., S. Pfeil, and J.-C. Rochet (2017). A simple macroeconomic model with extreme financial frictions. Journal of Mathematical Economics 68, 92-102.

Korinek, A. and A. Simsek (2016). Liquidity trap and excessive leverage. American Economic Review $106(3), 699-738$.

Krishnamurthy, A. (2003). Collateral constraints and the amplification mechanism. Journal of Economic Theory 111(2), 277-292.

Ljungqvist, L. and T. J. Sargent (2012). Recursive Macroeconomic Theory. MIT press.

Moritz, S. and A. Taylor (2012). Credit booms gone bust: Monetary policy, leverage cycles, and financial crises, 1870-2008. American Economic Review 102(2), 1029-61.

Myerson, R. (2014). Rethinking the principles of bank regulation: A review of Admati and Hellwig's The Bankers' New Clothes. Journal of Economic Literature 52(1), 197-210.

Nuno, C. and H. Rey (2017). Financial cycles with heterogeneous intermediaries. National Bureau of Economic Research no. w23245.

Øksendal, B. (2003). Stochastic differential equations. Springer, Berlin.

Pancost, A. N. and R. Robatto (2019). The effects of capital requirements on good and bad 
risk taking. SSRN Working Paper no. 3084302.

Phelan, G. (2016). Financial intermediation, leverage, and macroeconomic instability. American Economic Journal: Macroeconomics 8(4), 199-224.

Philippon, T. (2010). Financiers versus engineers: Should the financial sector be taxed or subsidized? American Economic Journal: Macroeconomics 2(3), 158-82.

Philippon, T. and A. Reshef (2012). Wages and human capital in the us finance industry: 1909-2006. The Quarterly Journal of Economics 127(4), 1551-1609.

van Oordt, M. (2014). Securitization and the dark side of diversification. Journal of Financial Intermediation 23(2), 214-231.

Wolf, W. (2010). Diversification at financial institutions and systemic crises. Journal of Financial Intermediation 19(3), 373-386.

Yepez, C. (2017). Financial intermediation, consumption dynamics, and business cycles. Economic Modelling 60, 231-243.

Zhenzhong, Z. and D. Chen (2013). A new criterion on existence and uniqueness of stationary distribution for diffusion processes. Advances in Difference Equations 13(2013). 


\section{- Online Appendix -}

\section{Restricted Participation and Transaction Costs}

In this appendix we consider the generalisation of the competitive equilibrium in Section 3 where both classes of agents, households and financial intermediaries respectively, have full access to risk-free bonds and pooled $(p)$ as well as un-pooled $(n)$ risky claims. In particular we assume that, in order to pool risky claims from different firms, households have to pay a transaction cost $\varepsilon$. We show that restricted market participation arises naturally when the transaction cost is big enough with respect to the financial intermediation cost $\eta$.

Given problem (3), the optimal pooled and un-pooled portfolio choices of both classes of agents satisfy the following:

$$
\begin{gathered}
\omega_{t}^{i, n}=\frac{\mu_{t}-r_{t}}{\sigma_{t}^{2}+\tilde{\sigma}^{2}}, \quad i:=\{h, f\} ; \\
\omega_{t}^{f, p}=\frac{\mu_{t}-\frac{\eta}{q_{t}}-r_{t}}{\sigma_{t}^{2}}, \quad \omega_{t}^{h, p}=\frac{\mu_{t}-\frac{\varepsilon}{q_{t}}-r_{t}}{\sigma_{t}^{2}} .
\end{gathered}
$$

In equilibrium, the whole amount of wealth invested in risky claims, whether it is pooled or not, must equal the aggregate amount of physical capital, whereas the risk-free bonds must be in zero net supply. By market clearing conditions

$$
\begin{gathered}
\left(\omega_{t}^{h, n}+\omega_{t}^{h, p}\right)\left(1-\psi_{t}\right)+\left(\omega_{t}^{f, p}+\omega_{t}^{f, n}\right) \psi_{t}=1, \\
\left(1-\omega_{t}^{h, n}-\omega_{t}^{h, p}\right)\left(1-\psi_{t}\right)+\left(1-\omega_{t}^{f, p}-\omega_{t}^{f, n}\right) \psi_{t}=0 .
\end{gathered}
$$

By matching equations (40) and (41), the market clearing conditions (42) and (43), it follows that

$$
\omega_{t}^{f}=\omega_{t}^{f, n}+\omega_{t}^{f, p}=1+\frac{\varepsilon-\eta}{q_{t}} \frac{1+\psi_{t} \frac{\tilde{\sigma}^{2}}{\sigma_{t}^{2}}}{2 \sigma_{t}^{2}+\tilde{\sigma}^{2}},
$$

and

$$
\omega_{t}^{h}=\omega_{t}^{h, p}+\omega_{t}^{h, n}=1-\frac{\frac{\varepsilon-\eta}{q_{t}}}{\sigma_{t}^{2}} \psi_{t} .
$$


We now look for those parametric conditions such that there exists restricted market participation, i.e. the financial sector always leverages its balance sheet by issuing risk-free bonds in every state. On the contrary, households smooth consumption by allocating their wealth into both risky and risk-free claims in positive amounts whatever share of total wealth. The aforementioned conditions are satisfied if the following holds:

$$
\left\{\begin{array}{l}
\omega_{t}^{f}=\omega_{t}^{f, p}+\omega_{t}^{f, n}>1 \\
\omega_{t}^{h}=\omega_{t}^{h, p}+\omega_{t}^{h, n}>0 \\
\omega_{t}^{h}=\omega_{t}^{h, p}+\omega_{t}^{h, n}<1 .
\end{array}\right.
$$

By matching equations (44) and (45) with system (46), we find that the following conditions must hold

$$
\varepsilon>\eta \Rightarrow \omega_{t}^{h}<1, \omega_{t}^{f}>1
$$

while

$$
\varepsilon<\eta+\sigma_{t}^{2} \frac{q_{t}}{\psi_{t}} \Rightarrow \omega_{t}^{h}>0
$$

Is summary, the transition cost for households $\varepsilon$ is required to be bounded:

$$
\eta<\varepsilon<\eta+\min _{\psi_{t}}\left\{\sigma_{t}^{2}\left(\psi_{t}\right) \frac{q_{t}\left(\psi_{t}\right)}{\psi_{t}}\right\}
$$

The lower bound grants a comparative advantage to the financial sector at pooling risk, whereas the upper bound prevents the households to short the un-pooled security in equilibrium.

\section{Equilibrium Portfolios, Leverage, and Prices}

According to Definition 1, the market clearing conditions for physical capital and risk-free bonds in Equations (22) and (23) can be written in terms of relative wealth share as:

$$
\omega_{t}^{f} E_{t}^{f}+\omega_{t}^{h} E_{t}^{h}=K_{t} q_{t} \Longleftrightarrow \omega_{t}^{h}\left(1-\psi_{t}\right)+\omega_{t}^{f} \psi_{t}=1
$$




$$
\frac{E_{t}^{f}\left(1-\omega_{t}^{f}\right)+E_{t}^{h}\left(1-\omega_{t}^{h}\right)}{K_{t} q_{t}}=0 \Longleftrightarrow\left(1-\omega_{t}^{h}\right)\left(1-\psi_{t}\right)=\left(\omega_{t}^{f}-1\right) \psi_{t}
$$

Accordingly, the market clearing for consumption good (24) equals:

$$
\left(A-\iota_{t}\right)\left(K_{t}^{h}+K_{t}^{f}\right)-\eta K_{t}^{f}=\rho\left(E_{t}^{h}+E_{t}^{f}\right)
$$

By matching the market clearing condition on capital (47) and the optimal portfolios policy, we obtain

$$
\omega_{t}^{f}=\frac{1}{\psi_{t}}-\frac{\mu_{t}-r_{t}}{\sigma_{t}^{2}} \frac{\left(1-\psi_{t}\right)}{\psi_{t}}
$$

Moreover, by (5) we know that the relationship between intermediaries and households returns on risky claims holds as:

$$
\mathbb{E}_{t} d R_{t}^{h}=\mathbb{E}_{t} d R_{t}^{f}+\frac{\eta}{q_{t}} d t
$$

Thus, (49) can be written as

$$
\omega_{t}^{f}=\frac{1}{\psi_{t}}-\frac{\frac{\eta}{q_{t}}}{\sigma_{t}^{2}+\tilde{\sigma}^{2}} \frac{\left(1-\psi_{t}\right)}{\psi_{t}}-\frac{\left(1-\psi_{t}\right)}{\psi_{t}} \underbrace{\frac{\left(\mu_{t}^{f}-r_{t}\right)}{\sigma_{t}^{2}}}_{\omega_{t}^{f}} \frac{\sigma_{t}^{2}}{\sigma_{t}^{2}+\tilde{\sigma}^{2}} .
$$

Rearranging we find that

$$
\omega_{t}^{f}=\frac{\sigma_{t}^{2}+\tilde{\sigma}^{2}-\frac{\eta}{q_{t}}\left(1-\psi_{t}\right)}{\psi_{t} \tilde{\sigma}^{2}+\sigma_{t}^{2}} .
$$

By substituting (50) into the market clearing for the risk-free bond (47), it is straightforward to find $\omega_{t}^{h}$. Similarly, the equilibrium interest rate $r_{t}$ can be obtained from the optimal portfolio policy. The results are summarized in the following Proposition:

\section{Proposition 3. Equilibrium Portfolios and Interest Rate}

Equilibrium portfolio shares $\omega_{t}^{f}, \omega_{t}^{h}$ and the interest rate $r_{t}$ depend on relative wealth share $\psi_{t}$ only:

$$
\omega_{t}^{f}=\frac{\tilde{\sigma}^{2}+\sigma_{t}^{2}-\frac{\eta}{q_{t}}\left(1-\psi_{t}\right)}{\psi_{t} \tilde{\sigma}^{2}+\sigma_{t}^{2}}, \quad \omega_{t}^{h}=1-\left(\omega_{t}^{f}-1\right) \frac{\psi_{t}}{1-\psi_{t}} .
$$




$$
r_{t}=\rho+\left(\psi_{t} \omega_{t}^{f}-1\right) \frac{\eta}{q_{t}}+\Phi\left(\iota_{t}\right)+\mu_{t}^{q}-\sigma \sigma_{t}^{q}-\delta-\sigma_{t}^{2} \omega_{t}^{f}
$$

We assumed both classes of agents have the same preferences. It follows that the portfolio share of the financial sector must be greater than or equal to 1 . This is because, since the risk-free bond is in zero net supply, a positive portfolio share in bonds by the financial sector must be supplied by households. In equilibrium, this is not possible due to households assets exposure to idiosyncratic risk. Under the assumption that the idiosyncratic volatility $\tilde{\sigma}^{2}$ is greater than the intermediation cost rate $\frac{\eta}{q_{t}}$, the financial sector portfolio share $\omega_{t}^{f}$ is strictly greater than 1. The result is summarised in the following Corollary of Proposition 3 :

\section{Corollary 1. Financial Leverage}

When the idiosyncratic volatility is greater than the intermediation cost rate, the financial sector holds a leveraged position, while the households hold positive portfolio shares in both risky and risk-free claims:

$$
\tilde{\sigma}^{2}>\frac{\eta}{q_{t}}, \quad \Rightarrow \omega_{t}^{f}>1, \quad \omega_{t}^{h} \in(0,1)
$$

Proof. The result comes after solving $\omega_{t}^{f}>1$.

Under the assumption of $\log$ investment function $\Phi\left(\iota_{t}\right)=\frac{\ln \left(\theta \iota_{t}+1\right)}{\theta}$, where the parameter $\theta$ represents the cost of technical illiquidity between physical capital and consumption good, rate of re-investment $\iota_{t}$ is an affine transform of the state $\psi_{t}$, whereas $q\left(\psi_{t}\right)$ is affine in the equilibrium physical capital holdings of the financial sector $\omega_{t}^{f} \psi_{t}$. In fact, by matching the consumption market clearing condition in (48), it follows that:

$$
q\left(\psi_{t}\right)=\frac{1+\theta\left(A-\eta \psi_{t} \omega_{t}^{f}\right)}{1+\theta \rho}, \quad \iota\left(\psi_{t}\right)=\frac{q\left(\psi_{t}\right)-1}{\theta} .
$$

\section{Macro-dynamics}

The aggregate consumption equals $C_{t}=\left(A-\iota_{t}\right) K_{t}-\eta K_{t}^{f}$. To characterize the dynamics of aggregate consumption, it may be useful to define an auxiliary variable that summarises 
the fraction of total capital allocated to the financial sector $K_{t}^{f}$. Let $\kappa$ be

$$
\kappa\left(\psi_{t}\right):=\frac{K_{t}^{f}}{K_{t}}
$$

with dynamics

$$
\frac{d \kappa_{t}}{\kappa_{t}}=\mu_{t}^{\kappa} d t+\sigma_{t}^{\kappa} d W_{t}
$$

whose drift and diffusion might be pinned down as

$$
\mu_{t}^{\kappa} \kappa_{t}=\partial_{\psi} \kappa_{t} \psi_{t} \mu_{t}^{\psi}+\frac{1}{2} \partial_{\psi \psi} \kappa_{t}\left(\psi_{t} \sigma_{t}^{\psi}\right)^{2}
$$

and

$$
\sigma_{t}^{\kappa} \kappa_{t}=\partial_{\psi} \kappa_{t} \psi_{t} \sigma_{t}^{\psi}
$$

Therefore, it follows that

$$
C_{t}=\left(A-\iota_{t}-\eta \kappa_{t}\right) K
$$

and, by Itô's lemma,

$$
d C_{t}=\left(A-\iota_{t}-\eta \kappa_{t}\right) d K-K d \iota_{t}-K \eta d \kappa_{t}-\operatorname{Cov}_{t}\left[d K_{t}, d \iota_{t}\right]-\operatorname{Cov}_{t}\left[d K_{t}, d \kappa_{t}\right]
$$

By considering the stochastic processes $d K_{t}$ and $d \psi_{t}$ and

$$
d \iota_{t}=\frac{1}{\theta}\left(q_{t} \mu_{t}^{q}-q_{t} \sigma_{t}^{q} d W_{t}\right)
$$

we obtain, by substitution and rearranging

$$
\begin{aligned}
& \frac{d C_{t}}{C_{t}}=\left[\Phi\left(\iota_{t}\right)-\delta\right] d t-\frac{\frac{q_{t}}{\theta} \mu_{t}^{q}+\eta \kappa_{t}-\frac{\sigma}{\theta} \sigma_{t}^{q}+\kappa_{t} \sigma_{t}^{\kappa} \sigma}{A-\iota_{t}-\eta \kappa_{t}} d t+ \\
& \quad+\sigma\left[1+\frac{\sigma_{t}^{q}}{\sigma} \frac{q_{t}}{\theta} \frac{1}{A-\iota_{t}-\eta \kappa_{t}}-\frac{1}{\sigma} \frac{\eta \kappa_{t} \sigma_{t}^{\kappa}}{A-\iota_{t}-\eta \kappa_{t}}\right] d W_{t} .
\end{aligned}
$$

By Itô's lemma, the dynamics of aggregate investment $I_{t}=\iota_{t} K_{t}$ is given by

$$
d I_{t}=d\left(\iota_{t} K_{t}\right)=K_{t} d \iota_{t}+\iota_{t} d K_{t}+\operatorname{Cov}\left[d \iota_{t} d K_{t}\right]
$$


and, after substituting and rearranging,

$$
\frac{d I_{t}}{I_{t}}=\left[\Phi\left(\iota_{t}\right)-\delta+\frac{q_{t}}{\theta \iota_{t}}\left(\mu_{t}^{q}-\sigma_{t}^{q} \sigma\right)\right]+\sigma\left(1-\frac{1}{\theta} \frac{\sigma_{t}^{q}}{\sigma} \frac{q_{t}}{\iota_{t}}\right) d W_{t} .
$$

Similarly, the dynamics of aggregate intermediation costs $G_{t}=\eta \kappa_{t} K_{t}$ is given by

$$
\frac{d G_{t}}{G_{t}}=\left[\Phi\left(\iota_{t}\right)-\delta+\mu_{t}^{\kappa} d t+\sigma_{t}^{\kappa} \sigma\right] d t+\left(\sigma+\sigma_{t}^{\kappa}\right) d W_{t}
$$

Accordingly,

$$
\frac{d \tilde{Y}_{t}}{\tilde{Y}_{t}}=\left[\Phi\left(\iota_{t}\right)-\delta-\eta \kappa_{t} \frac{\mu_{t}^{\kappa}+\sigma \sigma_{t}^{\kappa}}{A-\eta \kappa_{t}}\right] d t+\sigma\left(1-\frac{\eta}{\sigma} \frac{\kappa_{t} \sigma_{t}^{\kappa}}{A-\eta \kappa_{t}}\right) d W_{t}
$$

\section{Stationary Density}

The Fokker-Plank equation for the stationary density satisfies

$$
\frac{\partial}{\partial t} \pi(\psi, t)=-\frac{\partial}{\partial \psi}\left\{\psi \mu^{\psi} \pi(\psi, t)-\frac{1}{2} \frac{\partial}{\partial \psi}\left[\psi^{2}\left(\sigma_{t}^{\psi}\right)^{2} \pi(\psi, t)\right]\right\}=0
$$

By integrating over $(0, \psi)$ and rearranging, we can write $(52)$ as the following ODE

$$
d \ln h(\psi)=2 \frac{\mu^{\psi}}{\psi\left(\sigma^{\psi}\right)^{2}},
$$

where

$$
h(\psi)=\pi(\psi) \psi^{2}\left(\sigma^{\psi}\right)^{2}
$$

By integrating one more time, given a boundary condition $h(0)=h_{0}$, we obtain the density function of $\psi_{t}$ as

$$
\pi(\psi)=\frac{h_{0} e^{\left.\int_{0}^{\psi} \frac{2 \mu^{\psi}(s)}{s\left(\sigma^{\psi}(s)\right.}\right)^{2}} d s}{\psi^{2}\left(\sigma^{\psi}\right)^{2}}
$$

where $h_{0}$ is such that $\int_{0}^{1} \pi(\psi) d \psi=1$. 


\section{Numerical Solution}

Consider the equilibrium outcomes summarised in Theorem 1:

$$
\begin{gathered}
q_{t} \sigma_{t}^{q}=\partial_{\psi} q_{t} \psi_{t} \sigma_{t}^{\psi}, \\
\sigma_{t}^{\psi}=\omega_{t}^{f}\left(\sigma-\sigma_{t}^{q}\right),
\end{gathered}
$$

jointly with the equilibrium price of physical capital as given in Equation (51)

$$
q\left(\psi_{t}\right)=\frac{1+\theta\left(A-\eta \psi_{t} \omega_{t}^{f}\right)}{1+\theta \rho}
$$

Let the auxiliary function $\kappa\left(\psi_{t}\right)$ denote the capital holdings of the financial sector $\omega_{t}^{f} \psi_{t}$. As we shall see, the auxiliary function $\kappa$ is useful to solve the model for its competitive equilibrium as it has a compact support and a well defined boundary condition when $\psi=0$.

By matching (53) and (54), it is straightforward to pin down the volatility of physical capital price (see also Brunnermeier and Sannikov, 2014) as

$$
\sigma^{q}\left(\psi_{t}\right)=-\sigma \frac{\partial_{\psi} q_{t} \frac{\psi_{t}}{q_{t}}\left(\kappa_{t}-\psi_{t}\right)}{1-\partial_{\psi} q \frac{\psi_{t}}{q_{t}}\left(\kappa_{t}-\psi_{t}\right)}
$$

Considering (56) jointly with (50) one can obtain the following bi-variate ODE:

$$
\frac{\kappa_{t}}{\psi_{t}} \sigma^{2}\left(1-\frac{\partial_{\psi} q \frac{\kappa_{t}-\psi_{t}}{q_{t}}}{1+\partial_{\psi} q \frac{\kappa_{t}-\psi_{t}}{q_{t}}}\right)+\frac{\eta}{q_{t}}=\left[\sigma^{2}\left(1-\frac{\partial_{\psi} q \frac{\kappa_{t}-\psi_{t}}{q_{t}}}{1+\partial_{\psi} q \frac{\kappa_{t}-\psi_{t}}{q_{t}}}\right)^{2}+\tilde{\sigma}^{2}\right] \frac{1-\kappa_{t}}{1-\psi_{t}}
$$

By taking the first derivative of (55), matching it to (57) and rearranging, we obtain the following - fully implicit - system of ODEs

$$
\left\{\begin{array}{l}
\left(\frac{\kappa_{t}}{\psi_{t}}-\frac{1-\kappa_{t}}{1-\psi_{t}}\right)\left[\sigma^{2}\left(1+\partial_{\psi} q_{t} \frac{\kappa_{t}-\psi_{t}}{q_{t}}\right)^{-2}\right]+\frac{\eta}{q_{t}}-\tilde{\sigma}^{2} \frac{1-\kappa_{t}}{1-\psi_{t}}=0 \\
\partial q_{\psi}+\frac{\theta \eta}{1+\theta \rho} \partial \kappa_{\psi}=0
\end{array}\right.
$$

that can be solved numerically given suitable boundary conditions. We solve it by Matlab 
ode15i by setting $q(0)=\frac{1+\theta A}{1+\theta \rho}$ and $\kappa(0)=0$.

Once we have the solution vector $\{q, \kappa\}_{\psi \in(0,1)}$, we compute all the equilibrium quantities so that $\omega_{t}^{f}=\frac{\kappa_{t}}{\psi_{t}}$, where we approximate the first and second derivatives of physical capital prices as $\partial_{\psi} q(\psi) \approx \frac{q(\psi+\Delta)-q(\psi)}{\Delta}$ and $\partial_{\psi \psi} q(\psi) \approx \frac{q(\psi+\Delta)+q(\psi-\Delta)-2 q(\psi)}{2 \Delta^{2}}$, respectively, over the solution grid. Similarly, $\partial_{\psi} \kappa(\psi) \approx \frac{\kappa(\psi+\Delta)-\kappa(\psi)}{\Delta}$ and $\partial_{\psi \psi} \kappa(\psi) \approx \frac{\kappa(\psi+\Delta)+\kappa(\psi-\Delta)-2 \kappa(\psi)}{2 \Delta^{2}}$.

\section{Comparative Statics}

In this Appendix, we discuss the changes of equilibrium dynamics with respect to the key parameters in the model, namely the size of systematic and idiosyncratic risk as well as intermediation costs.

Figure 17 shows the drift (left) and diffusion (right) of the process $d \psi_{t}$ as a function of the state $\psi \in(0,1)$ for different values of systematic diffusion $\sigma$. In Figure 18, we perform the same comparative statics for equilibrium portfolio shares $\omega^{f}$ and $\omega^{h}$.

With reference to Figure 17, when the financial sector is arbitrary well capitalised ( $\psi$ is high), decreasing systematic risk $\sigma$ has the effect of reducing $\sigma^{\psi}$ : the lower the risk, the lower both state drift and diffusion. When instead $\psi$ approaches the left side boundary $\psi=0$, a lower $\sigma$ is associated to higher leverage and less risky households' portfolio (Figure 18). Indeed, higher leverage is associated to a sharper drift $\mu^{\psi}$. This phenomenon is associated to the so-called volatility paradox (Adrian and Boyarchenko, 2012; Brunnermeier and Sannikov, 2014; Phelan, 2016).

Figure 19 displays a similar exercise by plotting equilibrium portfolio choices over $\psi \in$ $(0,1)$ with respect to different values of idiosyncratic diffusion $\tilde{\sigma}$. What stands out is that the lower the idiosyncratic risk the lower the equilibrium leverage of the financial sector. This pattern is the consequence of a reduced advantage of the financial sector due to pooling: when idiosyncratic risk is relatively lower, the demand for mitigation is also reduced, households keep a wider fraction of their wealth allocated in risky claims, and equilibrium risk-free rate is higher.

Finally, in Figure 20 (top) we repeat the same analysis for different values of intermediation costs $\eta$. In the bottom graphs, we consider two sections of the upper ones for null (blue) 

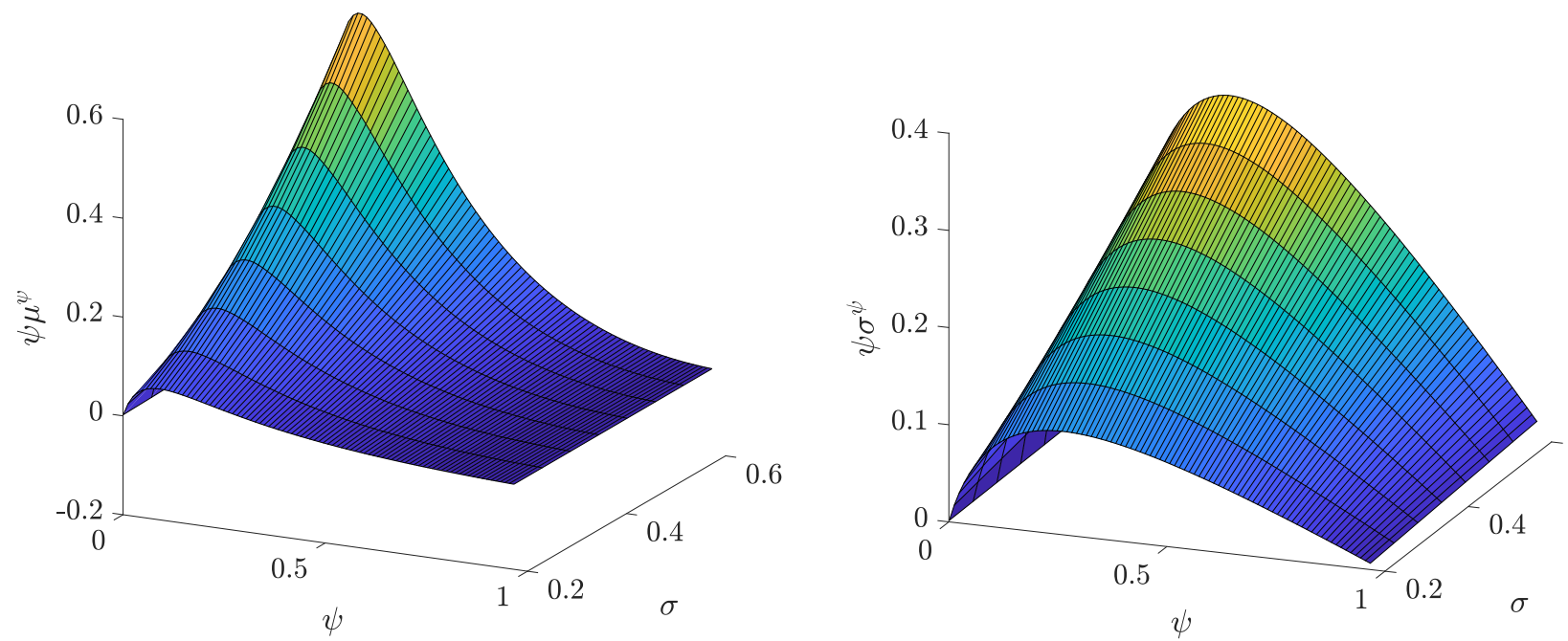

Figure 17: Drift (left) and diffusion (right) of the process $d \psi_{t}$ for different values of systematic volatility $\sigma$. Baseline parameters: $A=0.5, \delta=0.05, \tilde{\sigma}=0.6, \eta=0.05, \theta=2$, and $\rho=0.05$.
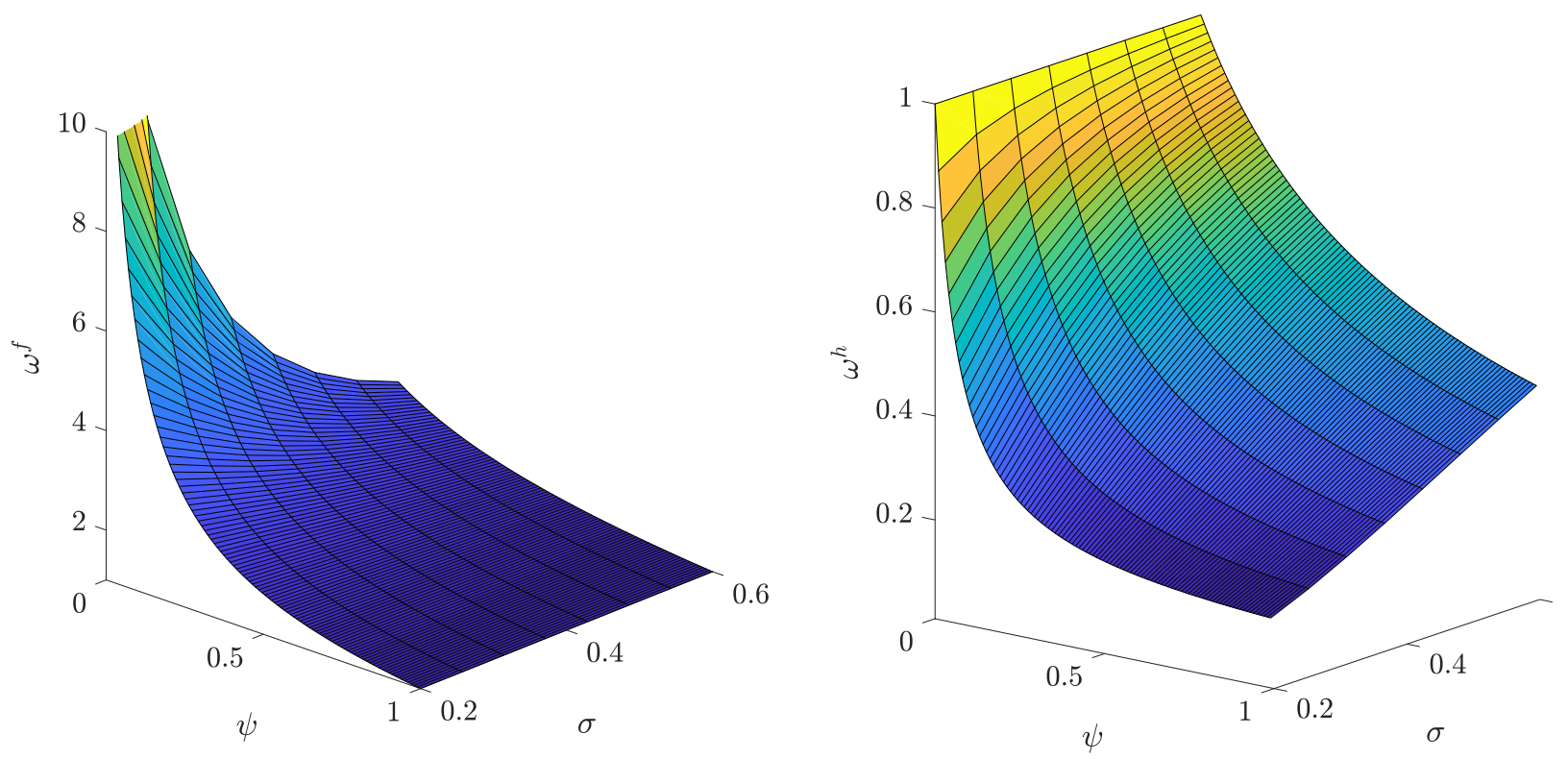

Figure 18: Equilibrium portfolio shares $\omega^{f}$ (left) and $\omega^{h}$ (right) for different values of systematic diffusion $\sigma . A=0.5, \delta=0.05, \tilde{\sigma}=0.6, \eta=0.05, \theta=2$, and $\rho=0.05$. 

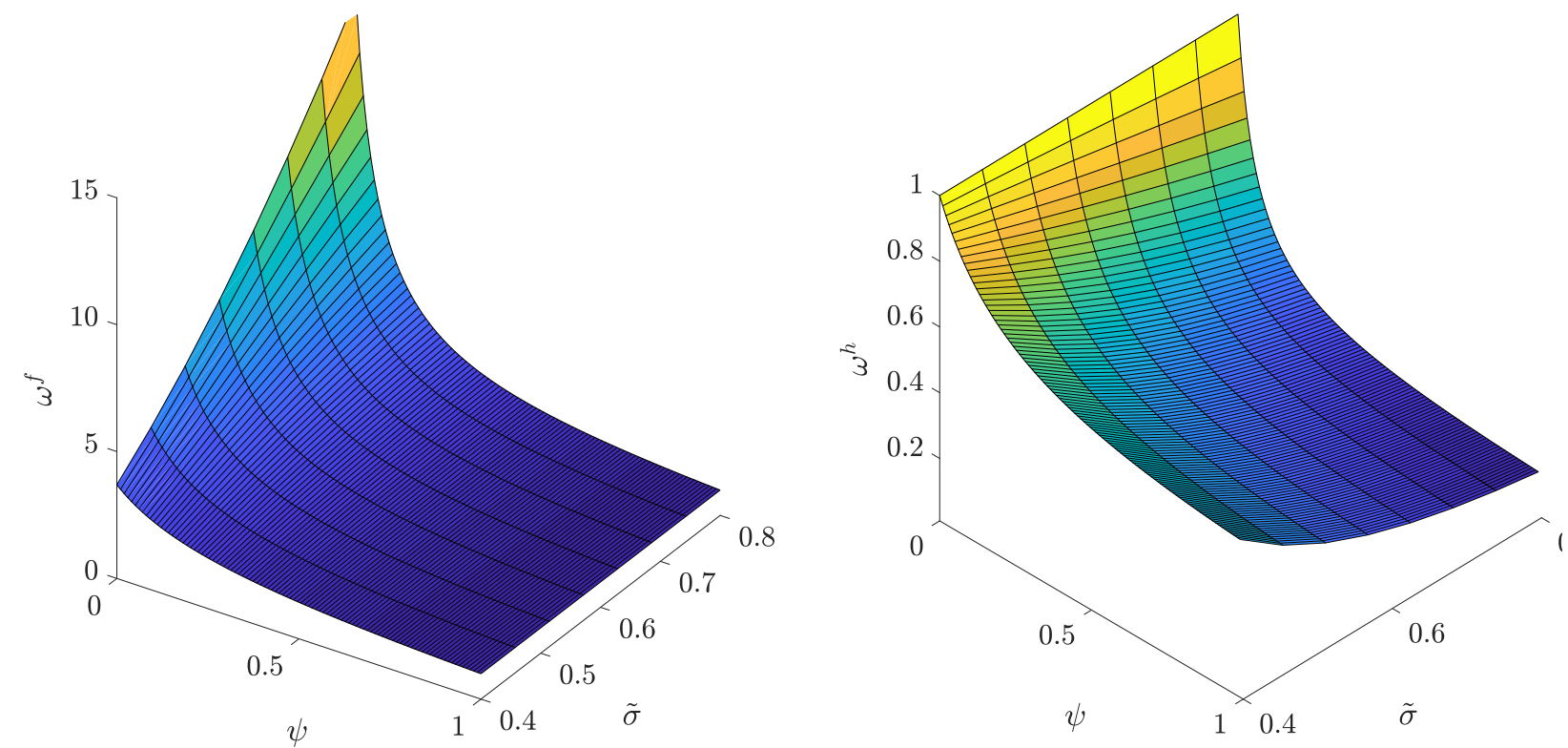

Figure 19: Equilibrium portfolio shares $\omega^{f}$ (left) and $\omega^{h}$ (right) for different values of idiosyncratic diffusion $\tilde{\sigma}$. Baseline parameters: $A=0.5, \delta=0.05, \sigma=0.4, \eta=0.1, \theta=2$, and $\rho=0.05$.
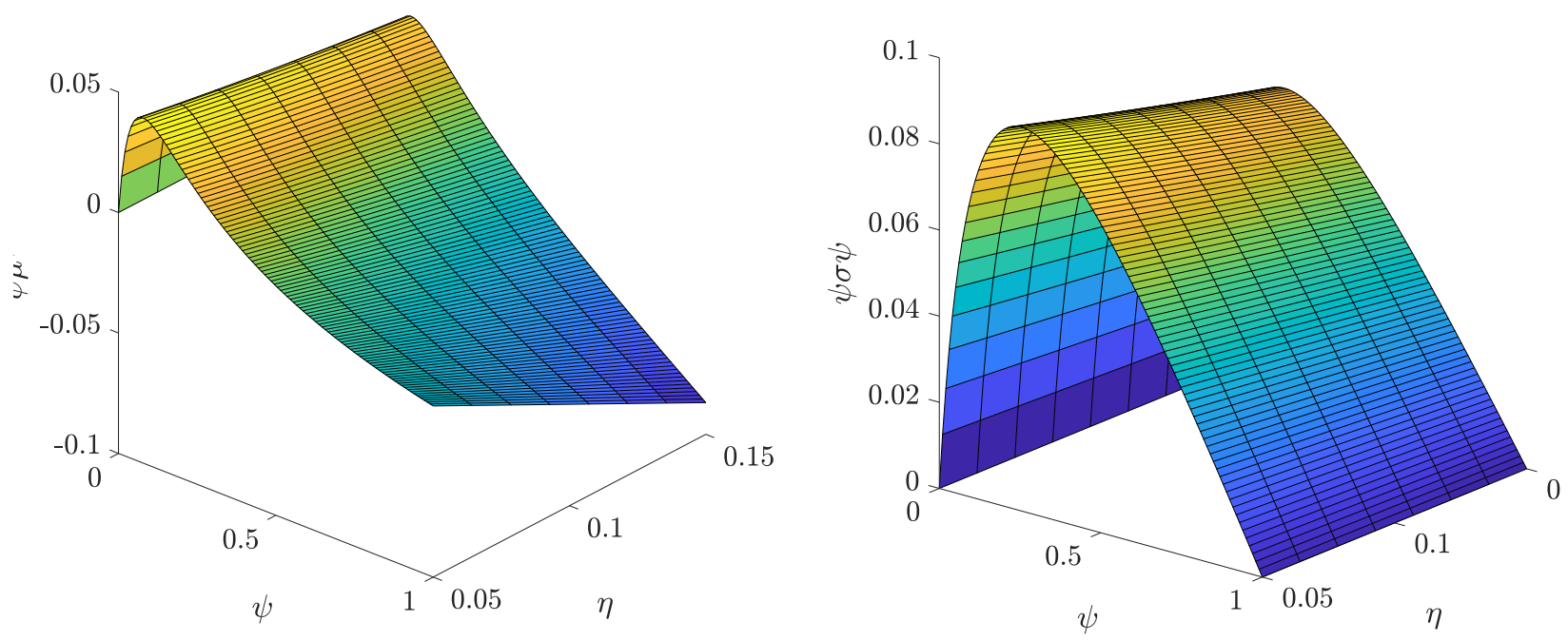

Figure 20: Drift (left) and diffusion (right) of the process $d \psi_{t}$ for different intermediation costs $\eta$. Baseline parameters: $A=0.5, \delta=0.05, \tilde{\sigma}=0.6, \sigma=0.2, \theta=2$, and $\rho=0.05$. 
and positive (green) intermediation costs $\eta$. From Figure 20 we notice that, when there are

no intermediation costs, the drift $\mu_{t}^{\psi}$ is positive for each $\psi$. In the long-run the financial sector dominates and thus it drains the whole wealth in the economy. Moreover, positive intermediation costs (green) mainly affect the right-hand side of the state space, when $\psi$ approaches 1 . Higher costs progressively sharpen the negative drift, when the financial sector is relatively well capitalised, making the recovery of households' wealth faster.

\section{Redistributive Taxation}

In this appendix, we describe the equilibrium dynamics of the relative financial capitalization $\psi$ when an exogenous taxation evenly redistributes resources at a rate $\tau$ from the financial sector to the households. In this setting, we consider the case where the taxation is constant and equals $\tau$ for every value of the state $\psi \in(0,1)$.

Since all the agents have log preferences and the tax transfer is proportional to their whole stock of wealth, it does not directly affect their portfolio and consumption choices. It does instead affect their conditional and unconditional welfare.

Let the dynamic budget constraint of the households' and of the financial sector evolve as

$$
\begin{gathered}
d E_{t}^{h}=E_{t}^{h}\left(\mu_{t}^{e, h} d t+\sigma_{t}^{e, h} d W_{t}\right)+\underbrace{\tau E_{t}^{f} d t}_{(\text {Positive) Tax }}, \\
d E_{t}^{f}=E_{t}^{f}\left(\mu_{t}^{e, f} d t+\sigma_{t}^{e, f} d W_{t}\right)-\underbrace{\tau E_{t}^{f} d t}_{\text {(Negative) } \operatorname{Tax}},
\end{gathered}
$$

respectively, where the drift and diffusion terms $\mu_{t}^{e, i}, \sigma_{t}^{e, i} i \in\{h, f\}$ are defined in Equation (4). The tax terms in Equations (58) and (59) represent the redistribution effect of wealth between sectors by mean of the taxation policy. Note that the absolute value of the tax, $\tau E_{t}^{f}$, is directly proportional to the financial sector stock of wealth $E_{t}^{f}$; as such it proportionally enters the households' dynamic budget constraint. 
By Itô's Lemma, the level of relative financial capitalization evolves as

$$
\begin{aligned}
d\left(\frac{E_{t}^{b}}{E_{t}^{b}+E_{t}^{h}}\right)=\frac{E_{t}^{h}}{\left(E_{t}^{b}+E_{t}^{h}\right)^{2}} d E_{t}^{b} & -\frac{E_{t}^{b}}{\left(E_{t}^{b}+E_{t}^{h}\right)^{2}} d E_{t}^{h}+ \\
& +\frac{\partial \psi}{\partial E^{h} \partial E^{b}} d E_{t}^{h} d E_{t}^{b}+\frac{1}{2} \frac{\partial^{2} \psi}{\partial^{2} E^{h}}\left(d E_{t}^{h}\right)^{2}+\frac{1}{2} \frac{\partial^{2} \psi}{\partial^{2} E^{b}}\left(d E_{t}^{b}\right)^{2},
\end{aligned}
$$

where the dynamics of wealth follow the processes in (58) and (59). By substituting, rearranging, and considering: $\frac{E_{t}^{h}}{E_{t}^{f}}:=\frac{1}{\psi_{t}}-1$ :

$$
\frac{d \psi_{t}^{\tau}}{\psi_{t}^{\tau}}=\frac{d \psi_{t}}{\psi_{t}}-\tau \frac{\psi_{t}}{1-\psi_{t}} d t
$$

where the process $\frac{d \psi_{t}}{\psi_{t}}$ is defined as in (8).

\section{F Aggregate Welfare Analysis}

To the purpose of analysing the economy total welfare while account for both households and intermediaries, we shall build an aggregate measure that weights both classes of agents by a proper function. Accordingly, we defined aggregate welfare as follows:

$$
W_{L C}^{\Gamma}=\sum_{i} \mathbb{E}_{0}\left[W^{i} \mid \omega^{f} \leq L C\right] \Gamma(\psi)^{i},
$$

where $\Gamma(\psi)^{i}$ represents the weight attribute to class $i$ in the state $\psi$.

Table 1 reports the constrained $(L C=4)$ and unconstrained $(L C=\infty)$ aggregate welfare (60) for different weighting functions $\Gamma^{i} .{ }^{28}$ We start by focusing on the households' and intermediaries' welfare apart from each other, that is, by considering the extreme weights $\Gamma^{h}=1, \Gamma^{f}=0$ and $\Gamma^{f}=1, \Gamma^{h}=0$, respectively.

When looking solely at the welfare of households, we find that constraints may be welfare improving ( $\Gamma^{h}=1$ and $\Gamma^{f}=0$, Table 1 , first row). Quite the opposite, when only the financial sector is taken into consideration, we find $L C$ s to be welfare detrimental $\left(\Gamma^{f}=1\right.$

\footnotetext{
${ }^{28}$ We compute (60) numerically. In particular, we approximate the welfare conditional on state $\psi$ over an evenly spaced grid $[0,0.2,0.4,0.6,0.8,1]$ and interpolate it by using a cubic polinomial. Then, we integrate by trapezoid method $W^{i}$ over the an evenly matched stationary density $\pi(\psi)$ weighted by $\Gamma(\psi)^{i}$.
} 


\begin{tabular}{lccc} 
& & & $W_{L C}^{\Gamma}$ \\
Weights, $\Gamma(\psi)^{i}$ & LC Unbounded & LC Bounded (4) & \% Gain \\
\hline$\Gamma(\psi)^{h}=1 ; \Gamma(\psi)^{f}=0$ & -0.2847 & -0.2188 & +0.3 \\
$\Gamma(\psi)^{f}=1 ; \Gamma(\psi)^{h}=0$ & -0.4143 & -0.5838 & -0.29 \\
$\Gamma(\psi)^{h}=\Gamma(\psi)^{f}=0.5$ & -0.3495 & -0.4012 & -0.13 \\
$\Gamma(\psi)^{h}=1-\psi ; \Gamma(\psi)^{f}=\psi$ & -0.0252 & -0.0400 & -0.25
\end{tabular}

Table 1: Aggregate welfare for different weighting functions $\Gamma$.

and $\Gamma^{h}=0$, Table 1 , second row).

Finally, the last two rows of Table 1 report aggregate welfare when the weighting function $\Gamma$ is either constant and even (third row), or proportional to each class relative wealth share (fourth row). In either cases, $L C$ s are welfare detrimental. In the former case this means that, at this level of leverage constraint, the welfare gain of the households less than compensate intermediaries' losses. Not surprisingly, the same result holds when the weighting function is proportional to agents' relative share of wealth.

Of course, the result of leverage constraints being detrimental when jointly considering households and intermediaries is fundamentally tied up to the arbitrary choice of the weighting function $\Gamma$. 


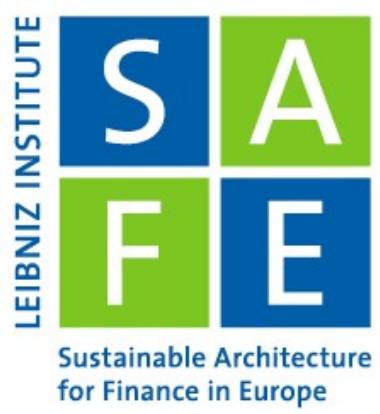

\section{Recent Issues}

No. 270 Mario Bellia, Kim Christensen, Aleksey Kolokolov, Loriana Pelizzon, Roberto Renó

No. 269 Ester Faia, Maximilian Mayer, Vincenzo Pezone

No. 268 Lorenzo Maria Levati, Marie Lalanne

No. 267 Wataru Kureishi, Hannah PaulePaludkiewicz, Hitoshi Tsujiyama, Midori Wakabayashi

No. 266 Benjamin Bluhm, Jannic Cutura

No. 265 Christian Schlag, Julian Thimme, Rüdiger Weber

No. 264 Hengjie Ai, Jun E. Li, Kai Li, Christian Schlag

No. 263 Vanya Horneff, Daniel Liebler, Raimond Maurer, Olivia S. Mitchell

No. 262 Andrea Bedin, Monica Billio, Michele Costola, Loriana Pelizzon

No. 261 Monica Billio, Michele Costola, Loriana Pelizzon, Max Riedel

No. 260 Matthias Thiemann, Tobias H. Tröger

No. 259 Inaki Aldasoro, Florian Balke, Andreas Barth, Egemen Eren

No. 258 Anderson Grajales-Olarte, Burak R. Uras, Nathanael Vellekoop
High-Frequency Trading During Flash Crashes: Walk of Fame or Hall of Shame?

The Value of Firm Networks: A Natural Experiment on Board Connections

The Impact of Job Referrals on Employment Outcomes in Top Corporate Positions

Time Preferences over the Life Cycle

Econometrics at Scale: Spark Up Big Data in Economics

Implied Volatility Duration: A Measure for the Timing of Uncertainty Resolution

The Collateralizability Premium

Implications of Money-Back Guarantees for Individual Retirement Accounts: Protection Then and Now

Credit Scoring in SME Asset-Backed Securities: An Italian Case Study

Buildings' Energy Efficiency and the Probability of Mortgage Default: The Dutch Case

The Case for a Normatively Charged Approach to Regulating Shadow Banking Multipolar Regulatory Dialogues as a Means to Detect Tail Risks and Preclude Regulatory Arbitrage

Spillovers of Funding Dry-ups

Rigid Wages and Contracts: Time- versus State-Dependent Wages in the Netherlands 